\title{
Risks for dysregulated appetite : Texture, stress, food reward and inhibition -.
}

Citation for published version (APA):

Martens, M. (2012). Risks for dysregulated appetite : Texture, stress, food reward and inhibition -.

[Doctoral Thesis, Maastricht University]. Uitgeverij BOXPress. https://doi.org/10.26481/dis.20121221mm

Document status and date:

Published: 01/01/2012

DOI:

10.26481/dis.20121221mm

Document Version:

Publisher's PDF, also known as Version of record

\section{Please check the document version of this publication:}

- A submitted manuscript is the version of the article upon submission and before peer-review. There can be important differences between the submitted version and the official published version of record.

People interested in the research are advised to contact the author for the final version of the publication, or visit the DOI to the publisher's website.

- The final author version and the galley proof are versions of the publication after peer review.

- The final published version features the final layout of the paper including the volume, issue and page numbers.

Link to publication

\footnotetext{
General rights rights.

- You may freely distribute the URL identifying the publication in the public portal. please follow below link for the End User Agreement:

www.umlib.nl/taverne-license

Take down policy

If you believe that this document breaches copyright please contact us at:

repository@maastrichtuniversity.nl

providing details and we will investigate your claim.
}

Copyright and moral rights for the publications made accessible in the public portal are retained by the authors and/or other copyright owners and it is a condition of accessing publications that users recognise and abide by the legal requirements associated with these

- Users may download and print one copy of any publication from the public portal for the purpose of private study or research.

- You may not further distribute the material or use it for any profit-making activity or commercial gain

If the publication is distributed under the terms of Article $25 \mathrm{fa}$ of the Dutch Copyright Act, indicated by the "Taverne" license above, 


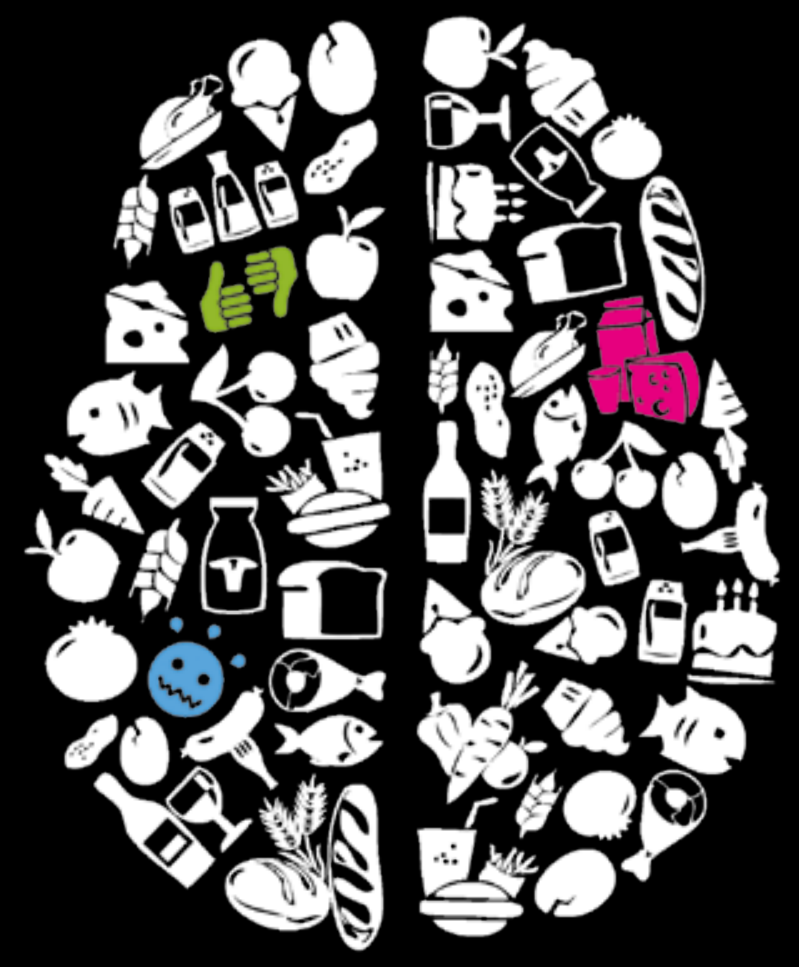

RISKS FOR DYSREGULATED APPETITE

TEXTURE I STRESS I FOOD REWARD \& INHBITION 


\section{高苗}

\section{RISKS FOR DYSREGULATED APPETITE}

TEXTURE । STRESS । FOOD REWARD \& INHIBITION 
The study presented in this thesis was performed within NUTRIM School for Nutrition, Toxicology and Metabolism which participates in the Graduate School VLAG (Food Technology, Agrobiotechnology, Nutrition and Health Sciences), accredited by the Royal Netherlands Academy of Arts and Sciences.
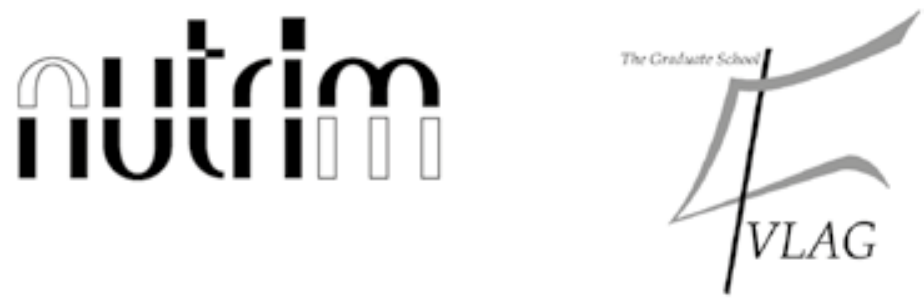

Cover design and layout: Maarten elens

Printed by: Proefschriftenmaken.nl II uitgeverij boxPress

(C) Copyright Mieke J.I. Martens, Maastricht 2012

ISBN 9789088915277 


\section{RISKS FOR DYSREGULATED APPETITE}

TEXTURE I STRESS । FOOD REWARD \& INHIBITION

\section{PROEFSCHRIFT}

ter verkrijging van de graad van doctor aan de Universiteit Maastricht, op gezag van de Rector Magnificus, Prof. L. L. G. Soete volgens het besluit van het College van Decanen, in het openbaar te verdedigen

op vrijdag 21 december 2012 om 12 uur

door

\section{MIEKE JENNY IVONNE MARTENS}

Geboren te Herk-de-Stad, 18 februari 1985 


\section{PROMOTOREN}

Prof. dr. M.S. Westerterp-Plantenga

Prof. dr. R. Goebel

Dr. T.C. Adam

\section{BEOORDELINGSCOMMISSIE}

Prof. dr. ir. R.P. Mensink (voorzitter)

Dr. N. Bouvy

Prof. dr. E. Formisano

Prof. dr. A.A.M Masclee

Prof. dr. T. Moran (Johns Hopkins Univ. School of Medicine, USA) 

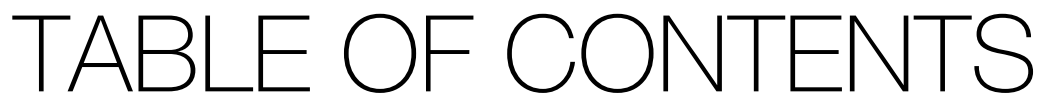

CHAPTER 1

General introduction

CHAPTER 2

A solid high-protein meal evokes stronger hunger

CHAPTER 3 suppression than a liquefied high-protein meal between appetite parameters and blood values with solid and liquefied carbohydrate meals

CHAPTER 4 Mode of consumption plays a role in alleviating hunger and thirst

CHAPTER 5

Effects of single macronutrients on serum cortisol concentrations in normal weight men

CHAPTER 6 Liking and the orosensory perception of food in a stress versus rest condition in overweight and normal weight participants

CHAPTER 7 Flexibility of food-reward related brain signaling in overweight and normal weight subjects

CHAPTER 8 General discussion

Summary

Samenvatting

Dankwoord

List of publications

About the author 


$$
\text { 湢它㖄 }
$$




\section{CHAPTER 1}

GENERAL INTRODUCTION 
The increasing prevalence of obesity forms a severe health threat to present and future generations, not least due to associated chronic diseases, including diabetes and cardiovascular disease (1). Obesity is a global epidemic that results from disturbance of the energy balance, i.e. energy intake exceeding energy expenditure $(2,3)$. The cause of this disturbance is diverse and complex and can be attributed to physiological, environmental, behavioral, neuro-endocrine, genetic and other factors. A recent study observed that physical activity has not declined over the same period that obesity rates have increased dramatically; hence, it is unlikely that decreased expenditure has fuelled the obesity epidemic (4). Therefore, the cause most likely lies on the energy intake side of the energy balance. Appetite serves to regulate adequate energy intake to maintain energy balance. It is regulated by an interaction between peripheral hormones of the digestive tract and the adipose tissue acting on neural circuits in the brain. A chronic deregulation of energy balance, with energy intake exceeding energy expenditure, leads to storage of the excessive energy as fat. Disruption of appetite regulation therefore may affect the decision to finish a meal, promote overeating, and contribute to obesity. This thesis aims to identify risks for this disruption of appetite regulation.

\section{HUNGER AND THIRST MECHANISMS}

Appetite is the desire to eat food, felt as hunger. Hunger is often defined as a sensation that promotes food seeking and ingestive behaviors, with the primary function to ensure that energy needs are met $(5,6)$. The regulation of food intake and energy homeostasis is based on hunger and satiety signals produced in the hypothalamus and in peripheral organs (7). Satiety signals, such as insulin, cholecystokinin (CCK), glucagon-like peptide 1 (GLP-1) and peptide YY (PYY) are of capital importance in appetite control for the termination of food intake by inhibiting the effect of hunger signals, such as neuropeptide $\mathrm{Y}$, ghrelin, the orexins, agouti-related peptide, and melanin-concentrating hormone (7). The identification of peptides that function as appetite regulatory signals has stimulated interest in their use as biomarkers and potential pharmacological targets for the treatment of dysregulated energy intake $(8,9)$. Ghrelin, glucose and insulin may be particularly relevant for that purpose (8). Ghrelin is an orexigenic hormone produced primarily by the stomach and proximal small intestine (10) was shown to increase food intake in diverse species (11), including humans (12). Contrary to satiety peptides, circulating levels of ghrelin peak shortly before meals and are suppressed by ingested nutrients; carbohydrates are most effective in suppressing ghrelin compared to proteins, and lipids (13). Glucose may be involved in meal initiation, as feeding is usually preceded by a decrease in blood glucose concentrations (14-17). Moreover, glucose triggers insulin secretion from the pancreatic islets and similar to blood glucose, insulin has been hypothesized to play a role in appetite regulation $(12,14,18,19)$. In addition to the use of biomarkers to assess appetite, a common approach is to use self-reports of various 
somatic sensations on open ended questionnaires or rating scales (9). Measured feelings of appetite expressed as ratings on visual analogue scales (VAS) have shown to be highly reproducible and therefore reliable (20).

Thirst is a subjective perception that provides the urge for humans and animals to consume fluids to meet hydration needs (21). It is a physiological state that is often difficult to diagnose but a system that is very finely controlled (22). James Fitzsimons was the first to describe two major thirst stats: primary drinking and secondary drinking (23). In primary drinking there is an actual need for water, it is an emergency response to a deficit of body fluid (24). In secondary drinking, however, there does not appear to be any present internal need for water despite the fact of drinking, it may be induced by a variety of cues such as for example a dry mouth and the circadian rhythm of drinking (24). Primary thirst is subsequently divided into that of intracellular origin and that of extracellular origin. From a purely physiological point of view the regulation of thirst is absolutely necessary for the correct functioning of our milieu intérieur (25). Yet despite this fact humans appear to respond inappropriately to thirst signals (22). This inappropriate reaction may have undesirable consequences related to overweight and obesity.

Although hunger and thirst mechanisms show a multitude of similarities $(9,26)$ the health implications of deficits or surfeits of eating and drinking are distinct. While for eating there are no short-term life-threatening consequences of a deficit, drinking deficits lead to life-threatening consequences in a time frame of days, making thirst a particular salient signal, less likely to be ignored (26). Contrarily however, eating to excess may pose a great health risk in the long term by leading to overweight and obesity with the resulting co-morbidities, while drinking in excess, save extreme condition, poses little health risk (26). Furthermore, there are contradictory findings regarding the cause and effect of eating and drinking. Some studies state that feeding is a determinant of drinking, and fluid intake is regulated secondarily to food intake (26-31). This statement is based on several observations; $75 \%$ of fluid intake is peri-prandial (28-30), there is a direct relationship between eating and drinking under ad lib conditions (28-30) and significant positive correlations between meal size and quantity of water consumed have been observed $(27,28,31)$. Other studies postulate that fluid intake is independent of energy needs $(26,32)$. This view is physiologically more plausible as greater consequences are associated with fluid deficits relative to the effects of deviations from energy balance, as described above.

These asymmetries in the mechanisms related to hunger and thirst, together with a possible drive to maintain fluid balance hold important implications in the current environment with an abundance of soft drinks, fruit or sport beverages, gourmet coffees, etc; all supplying energy while drinking.

Approaching hunger, or desire to eat, which is related to eating, and thirst, or desire to drink, which is related to drinking, at the same time is complicated. Eaten foods contain 
water and generate water endogenously during their metabolism, while on the other hand; drinking certain beverages provides energy and essential nutrients. This shows that the principles of eating foods or drinking beverages may exert effects contributing vice versa, namely to water- and nutrient-ingestion respectively. Here the mode of consumption (eating or drinking) is not straightforwardly in line with the expected functions (9). The question remains whether biological consequences may differ according to the mode of consumption. For instance, will gastro-intestinal and post-intestinal responses to the ingested items differ?

The confusion of energy ingestion by drinking and fluid ingestion by eating may imply a risk for a positive energy balance if for instance drinking energy-dense liquids leads to over-consumption, or, vice versa, a risk for under-nutrition or unbalanced macronutrient intake from eating mainly foods with a high water content.

\section{FOOD TEXTURE}

A general definition of food texture states that texture is a sensory property perceived as a multi-parameter attribute derived from the structure of food that is detected by several senses, the most important ones being the senses of touch and pressure (33). Differences in the mechanisms by which the body senses ingested energy contained in different food textures are previously reported. Food texture can influence appetite through effects on satiety and satiation. Satiation is the process that determines meal size. It is mainly driven by early processes ( $<20 \mathrm{~min}$ ), such as sensory, cognitive, and early pre-absorptive factors, which can all be influenced by food texture (34). Satiety is the process that suppresses the internal drive to eat (appetite), which can be quantified by measuring the intermeal-interval (34). The processes responsible for the differences in satiation and satiety responses between liquid and solid foods have not been fully clarified. Studies regarding the comparison of satiety evoked by solid and liquid meals are controversial.

Some studies suggest that energy-yielding liquids seem to elicit less satiation and cause less satiety compared to solid counterparts (35-39). Furthermore, they evoke a weak compensatory response in balancing energy intake throughout the day compared to solids (39-43) as evidenced by several longitudinal intervention studies $(38,44)$. Other studies assign this weaker satiating response of liquids compared to solids to oral sensory exposure and the need to chew $(36,45,46)$. Oral sensory exposure is increased with longer oral transit time, which is observed in solid foods because of the need for oral processing (chewing) before swallowing. It is hypothesized that due to the high rate of consumption and consequently the lower oral sensory exposure time in liquids the cephalic phase response is bypassed (47), leading to a delayed meal termination and thus over consumption of energy.

Other studies did not find differences in the satiating response between liquid and solid 
foods $(37,48)$. For example, in the study of Almiron-Roig et al. thirty-two volunteers consumed equal-energy preloads of regular cola or fat-free raspberry cookies after which they measured hunger ratings, satiety and subsequent energy intake (37). They observed that the different physical food-forms suppressed hunger ratings equally and did not observe any difference in satiety or subsequent energy intake (37). However, the interpretation of these studies is often unclear because of the use of dissimilar foods. Foods that differ along other dimensions than texture (energy density, palatability, macronutrient composition, etc.) evoke responses that cannot solely be ascribed to differences in food texture.

Still other studies showed that liquids are more satiating than solids, but they almost all concentrate on soup in comparison to a solid meal (49-52). These studies confirm that soups have a higher satiety value than beverages despite their fluid form and that soup has to be differentiated from beverages. Several hypotheses exist regarding the high satiating value of soup. Firstly, the principle source of energy in most consumed beverages is carbohydrate whereas this can be more variable in soups. Secondly, several researchers have proposed that cognitive factors likely contribute to the high satiety value of soups $(41,50)$. Furthermore, soup implies a mode of consumption, which is different from a drink; soup may be viewed as a meal component ingested to address sensations of hunger as compared to a beverage, which is used to satisfy thirst. This could lead to a conscious decision to stop eating, which decreases overall calorie intake. This again attests the problem of mode of consumption; foods may be differentiated from beverages based on physical form; however, a classification on this basis may be modified by mode of consumption (eating or drinking). The same consumption can be classified as a drink or as a soup depending on the delivery to the oral cavity by a particular vessel (e.g., glass, mug, or bowl) or utensil (e.g., spoon or straw) (9). Therefore, in previous studies, it is difficult to disentangle the effects of food texture and those of mode of consumption of foods on differences in satiating value between liquids and solids.

Liquid energy containing foods and drinks (protein shakes, soft-drinks, sport-beverages, dessert coffee, etc.) are abundantly eaten and drunk in our current society and are adding to the obesity epidemic. For example; there has been an undeniable temporal association between the growing consumption of sweetened beverages and the rise in obesity rates, particularly among adolescents and young adults (53). Previous research finds contradicting effects of texture on appetite and does not always take mode of consumption into account; therefore, further research on the impact of liquid calories on appetite regulation is necessary. 


\section{STRESS}

One of the environmental factors contributing to overeating may be stress-induced eating (54-57). Previous studies show that acute psychological stress causes eating in the absence of hunger and cause especially visceral overweight individuals to consume more food compared to lean individuals $(58,59)$. Chronic stress has been associated with greater weight gain among participants who are already overweight or obese (57, $60,61)$. Moreover, literature shows that the incidence of both visceral obesity and the metabolic syndrome correlates with indices of stress in the affected populations (62, 63). However, the effect of stress on food intake has been discussed controversially. Increased food intake as well as decreased food intake has been reported depending on parameters such as dietary restraint, gender and body weight $(57,58,64,65)$. Stress possibly influences food intake through effects on the HPA-axis and the reward system. Stress is associated with increased HPA-axis activity and is mirrored by increased cortisol concentrations in the blood (66). The cascade of the HPA response beholds that the hypothalamus produces corticotropin-releasing hormone $(\mathrm{CRH})$, which subsequently stimulates the production of adrenocorticotropin (ATCH) from the anterior pituitary, which in turn will stimulate the synthesis and release of cortisol by the adrenal cortex (67). Evidence of the involvement of the HPA axis in body-weight regulation is found in two extremes of plasma cortisol levels in humans; Addison's disease (hypocortisolism) that has been related to weight loss, and Cushing's syndrome (hypercortisolism) that has been related to rapid weight gain $(68,69)$. Furthermore, visceral fat accumulation in obese subjects is related to altered HPA-axis functioning, such as decreased salivary and serum cortisol levels $(70-72)$, increased urinary secretion of cortisol $(73,74)$, decreased cortisol variability $(70,75,76)$ and enhanced cortisol awakening response $(77)$.

Rodent as well as human studies implicate the involvement of the brain reward system in stress-induced eating (78-80). Both the opioid system, which is involved in the process of liking, as the dopamine system, which is involved in the process of wanting seem to be altered in reaction to stress or increased HPA-axis activity (81-83). Overall, it seems that stress causes a decreased sensitivity of the reward system to food cues. A study by Born et al. confirms this by showing a decreased activation of food reward related brain areas (amygdala, hippocampus and cingulated cortex) after acute stress in a satiated state, which was associated with an increased energy intake (84). This implies that stress influences meal termination, thereby promoting eating in the absence of hunger and thus overeating. Furthermore, research showed mesolimbic dopamine release in response to a stressful task (83) and a negative correlation between the tendency to eat when emotionally stressed and dopamine D2 receptor availability in normal weight subjects (80).

It has been shown that food choice shifts towards so-called 'comfort-foods', which are high in sugar and fat, in stressful conditions, possibly because they are perceived as 
highly rewarding and in this way form a coping mechanism to deal with stress (58, 8591). For example, from animal studies we know that pleasurable behaviors such as palatable food intake contribute to stress reduction through the recruitment of brain reward pathways (92). Moreover, there is some evidence that sweetness, and sensory cues to high energy density, can mitigate effects of stress via the brain's reward system (93). This suggests that the orosensory attributes of liking may change during stress. However, results are controversial and there is also evidence for increased HPA-axis activity in response to these preferred foods $(94,95)$. A study by Vicennati et al. showed that a high carbohydrate meal, in contrast to a high protein/fat meal significantly increased cortisol levels in female visceral obese subjects (94). In contrast, however, other studies did not find a cortisol response to meal consumption nor did they find macronutrientrelated differences in cortisol levels or mood (96-99). Furthermore, research even indicated increased cortisol levels in reaction to a protein-rich meal $(100,101)$. Taken together, this shows a need for studies clarifying the effect of single macronutrients on cortisol release.

The above-described findings may be indicative of a vicious circle in which stress leads to a delayed meal termination, which leads to eating in the absence of hunger, possibly through a preference for foods high in fat and sugar, which in turn increase HPA-axis activity. Therefore, functional foods, with a specific macronutrient composition that lead to a decreased cortisol response have to be discovered.

Taken together, research shows that stress is a risk factor for delayed meal terminating and thus eating in the absence of hunger, leading to weight gain through effects on HPA axis functioning and the brain reward system. Further research on the effect of stress on food reward (liking and wanting) may open an avenue to understanding the impact of food reward on eating behavior $(78,102-104)$. In this context it is important that also the orosensory attributes of liking are investigated, as they may be changed during stress (93). Furthermore, in light of the relationship between HPA axis functioning and body-weight regulation, there is a need for information related to the regulation of meal induced cortisol secretion due to its possible clinical implications and potential as a clinical marker of health. Further research on the role of single macronutrients in meal-induced cortisol secretion may result in the finding of a macronutrient composition that relatively decreases cortisol concentrations, which may lead to the development of functional foods to prevent overeating.

\section{FOOD REWARD}

Food intake is regulated homeostatically as well as non-homeostatically (102). The homeostatic regulation of food intake depends on the nutritional status and aims for energy intake to be in balance with energy expenditure through hunger and satiety signals produced in the hypothalamus and in peripheral organs. Non-homeostatic food 
intake entails that energy intake does not match energy expenditure, which occurs via the involvement of factors such as food reward, environmental cues and cognitive factors. Non-homeostatic regulation of food intake is largely independent of nutritional status and is closely related to the rewarding value of food, often leading to eating in the absence of hunger to reach reward homeostasis (105-107). Ideally, energy and reward regulation act in concert to promote eating behaviors under conditions of deprivation and to inhibit food intake under conditions of satiety. Disruption of the interaction between energy and reward regulation might promote overeating and contribute to obesity (80). According to the incentive salience concept by Berridge et al. the rewarding value of food is divided into two components: 'liking' and 'wanting' (78, 102, 106, 108-110). Liking is the hedonic or affective process of palatability/pleasure/displeasure, often associated with the orosensory stimulation by food, and wanting is the motivational incentive component consisting of the non-affective, purely motivational process of appetite or craving $(78,102,106,108-110)$. Wanting translates affect into the action of obtaining food $(78,102,106,108-110)$. Liking and wanting go hand in hand and are both needed to gain full reward $(78,106)$. However, under certain circumstances liking and wanting may diverge, for example due to cognitive restraint or addiction. Less liked foods may be selected due to their health benefits $(110,111)$ and drugs may be taken without always actually being liked (112).

The effects of weight status as well as nutritional status on liking and wanting diverge. Several studies reported liking as a relatively stable trait-like feature, not influenced by weight status $(113,114)$. Those studies found no significant differences between lean and obese consumers for overall pleasantness scores, or separately for foods classified for sweet, salty, sour or bitter (113). Mela et al. suggested that obesity may be associated with greater motivation to obtain food (wanting), possibly directed to energy-dense foods, without deriving any greater pleasure from the oro-sensory experience of eating (liking) (110). Epstein et al. showed that deprivation in humans causes an increase in wanting, but they observed no influences in the deprived group for the subjective or objective hedonic measures (liking) (115). Finally, Born et al. found that the liking of food remained stable postprandially, whilst the wanting decreased (84).

In contrast with those studies, others found a flexibility in liking: Finlayson et al. found a significant general decline in acute hedonic ratings for most food categories following a meal intervention, except for sweet and low fat sweet foods (109), and Lemmens et al. found a decreased relative liking for desserts after eating a dessert-specific food item (116). Taken together, most studies seem to suggest that liking is rated at a constant level $(84,104,110,113,117)$, yet specific variability was reported for certain food items after eating a meal $(109,116)$, while wanting seems to be variable across nutritional as well as weight status $(84,104,110,117)$.

Evidence in humans suggests that taste contributes to the selection of foods to be eaten and to palatability, defined by Yeomans as 'the hedonic evaluation of orosensory 
food cues under standardized conditions' $(118,119)$. Previous studies regarding differences between the orosensory or taste perception of food between normal weight and overweight individuals are contradictory. Earlier studies did not find differences in tasting threshold for various tastes comparing overweight and normal weight participants $(119,120)$ For example, Cox et al. suggest that overall, lean and obese humans do not differ in the selection of foods with perceived tastes and hedonic attributes $(113,114)$. However, studies investigating the effects of gastric bypass surgery found increases in bitter and sour sensitivity and decreases in sweet and salt sensitivity in the morbidly obese after gastric bypass surgery (119-121). Furthermore, Bartoshuk et al. suggest that the obese live in different oro-sensory and oro-hedonic worlds than do the non-obese; they found that the obese experience reduced sweetness, which they think intensifies fat sensations, and that the obese like both sweet and fat more than the non-obese do (122). Overall, previous research has not reached a consensus regarding differences in the orosensory perception of food between overweight and normal weight individuals and how this contributes to differences in liking or the rewarding value of food. Therefore, it is necessary that in the context of studying the liking of food, orosensory perception of food has to be taken into account.

In behavioral measurements of food reward the two components, liking and wanting are often measured separately. Recent human behavioral studies quantified liking by either subjective ratings on VAS, objective measures of facial affective expressions or measuring liking by means of indicating relative preference of paired food items, resulting in a relative ranking of liking $(104,109,116,123,124)$. Wanting has been measured by a forced choice methodology in which individuals were presented with pairs of food items and had to choose which item was most wanted at that time $(103,109)$. Another method to measure wanting is by measuring the motivation to obtain food as a proxy for wanting by assessing the reinforcing value of food using progressive reinforcement schedules $(104,116,125)$. Hereby, motivation to obtain food is expressed as the willingness to work for a chosen food item, sometimes compared to alternate reinforces such as money $(104,116,125)$.

More recently, neuroimaging studies have measured food reward, by measuring signaling in brain areas involved in dopamine release or the regulation thereof (i.e: amygdala, hippocampus, ventral pallidum, nucleus accumbens and striatum, the ventral tegmental area and substantia nigra, as well as the anterior cingulate, orbitofrontal, insular, dorsolateral prefrontal and medial prefrontal cortices $(126,127))$. Several methods of brain imaging and neuronal recording are available, but one of the most commonly used techniques is functional magnetic resonance imaging (fMRI). FMRI is a MRI procedure that measures neuronal activity by detecting associated changes in regional blood supply (128-131). FMRI uses a blood oxygen level dependent (BOLD) measurement, which is based upon the magnetic properties of de-oxygenated hemoglobin in oxygen-poor blood vs. the non-magnetic properties of oxygenated hemoglobin in oxygen-rich blood (128). 
When a brain area becomes active, oxygen demand increases, this demand is met with a higher than proportional increase in blood flow, thereby causing a temporal regionally greater proportion of oxygen-rich blood and thus oxygenated hemoglobin. This causes a local increase in the homogeneity of the magnetic field, which can be measured by the MRI scanner when using the correct settings. In this way the scanner can make whole brain images of localized variations in blood supply, and via the relation of blood supply with neuronal activity, signaling in different brain areas can be measured.

The fMRI technique allows us to get a better view on the integrative role of the central nervous system (CNS) in energy and reward homeostasis. Previous observations point towards an overlap between the neurocircuitries that regulate food-reward perception and energy homeostasis $(132,133)$ and as previously stated, disruption of the interaction between energy and food-reward regulation might promote overeating and contribute to obesity. Especially important in food-reward related brain signaling is the dopamine related reward circuitry. Dopamine projections originate in the ventral tegmental area (VTA) and project to the nucleus accumbens (NAc), striatum (caudate, putamen and globus pallidus) and the thalamus (134-136). These food-reward related brain areas are in turn connected to several control related brain areas such as the prefrontal cortex (PFC) and the orbitofrontal cortex (OFC), which are involved in inhibitory control that is possibly necessary to terminate a meal (134-136). Recently, fMRI studies were able to identify separate areas of liking and wanting brain signaling (137-139).

Previous literature concerning food-reward signaling in the brain points towards two different models: the reward-surfeit hypothesis and the reward deficiency hypothesis (134-136). According to the reward-surfeit model hyper-responsivity of brain reward circuitry leads to overeating $(140,141)$. Evidence for this model can be found in studies showing that overweight/ obese participants show greater brain signaling in response to food cues and anticipated reward compared to normal weight participants (140, 142-146). This increased reward-related brain signaling in the overweight or obese has been observed pre- as well as post-prandially (140, 143, 146-148). Furthermore, even after diet-induced weight loss, formerly obese humans still exhibit an increased responsiveness to food cues relative to the normal weight or obese in reward related brain regions, such as insula, dorsal striatum and frontal cortex (149-152). The reward deficiency model posits that individuals showing hypo-responsivity of the brain reward circuitry overeat to compensate for reward defiency $(140,153)$. Evidence for this model is found in the fact that obese vs. normal-weight humans show less striatal D2 dopamine receptor availability (153) and less striatal response to actual food intake, which predicts future weight gain for individuals at genetic risk for comprised dopamine signaling (140, 144).

As previously stated, food-reward related brain areas are linked with several control related brain areas such as the PFC and the OFC (105, 154); previous research using positron emission tomography (PET) in lean and obese persons indicates that the PFC 
may play an important role in the central regulation of eating behavior by sending inhibitory inputs (155-161). Furthermore, self-report and behavioral data suggest that impulsivity or decreased inhibition may contribute to the development and maintenance of obesity (162). Support for this is found in PET studies showing that satiation is associated with an increased activity in the PFC. However, when comparing obese with lean people PET studies show conflicting results (156-160). Some report a larger increase in PFC activity from the fasted to the satiated state in the obese vs. lean $(159,160)$, while others show the exact opposite $(156,157)$. Using fMRI, the group of Stice et al. among others showed that in a hungry state $\mathrm{BMI}$ is negatively correlated with activation in the PFC when subjects are required to inhibit responses to appetizing foods $(147,162)$. The latter studies particularly underline how altered activity in the PFC and thus altered inhibitory control may play an important role in the development of obesity by influencing the decision-making.

Taking all studies together, these are examples of possible dysregulation of appetite, confusing the decision for meal termination.

\section{OUTLINE OF THE THESIS}

The research presented in this thesis deals with 'risks for dysregulated appetite', especially focusing on the risks that texture, stress, food reward and inhibition represent. The risk that texture represents for dysregulated appetite is present in the form of abundantly available liquid energy containing foods and drinks in our current society. Previous research shows contradicting effects of texture on appetite; therefore, further research on the impact of liquid calories on appetite regulation is necessary. Here we present texture-related research with different macronutrients. Assessment of differences in appetite profile and in physiological parameters after consumption of a subject-specific meal in liquefied vs. solid form, controlled for energy density, weight, and volume is described for a meal only containing protein in chapter $\mathbf{2}$ and for a meal only containing carbohydrates in chapter 3 . Herewith the risk for dysregulated appetite on confused decision making for meal termination is assessed from a texture and macronutrient specific point of view.

The risk that texture represents leads straightforwardly to the risk that different modes of consumption may cause for dysregulated appetite. These effects are disentangled by focusing on the behavioral and physiological consequences of mode of consumption, structure, and thirst separately (chapter 4).

In our everyday life, stress is abundantly present; therefore, it is desirable to develop functional foods that are able to influence the physiological and psychological stress response in a favorable way. However, there are still discrepancies regarding the role of single macronutrients in meal-induced cortisol secretion. Therefore, we identified effects of protein and fat in comparison to carbohydrate on cortisol concentrations and 
tried to find a macronutrient composition that may decrease cortisol concentrations and subsequently prevent overeating (chapter 5).

As described above, stress as well as appetitive food and food cues in our current environment may imply risks for dysregulated appetite through reward homeostasis overwriting energy homeostasis via altered mechanisms of food reward signaling in the brain, decreased inhibitory control and changed liking, wanting or orosensory perception of food. We aimed to characterize how these orosensory attributes of food are correlated with liking, in overweight compared to normal weight participants during rest or stress and we assessed the effect of stress on orosensory perception and on liking in overweight vs. normal weight participants (chapter 6).

The risks for dysregulated appetite that are represented by food reward and disinhibition are explored using fMRI. Here we assessed differences between overweight and normal weight subjects in the flexibility of food-reward related brain signaling between food and non-food-stimuli, while controlling for subject specific energy requirement and visual complexity (chapter 7). Special attention was paid to the sensitivity of food reward in the hungry state as well as in the satiated state. The latter was related to decision making for meal termination.

Finally, in the general discussion the results and interpretations of the above-described studies are discussed and presented in an overview (chapter 8). 


\section{REFERENCES}

1. Guh D, Zhang W, Bansback N, Amarsi Z, Birmingham C, Anis A. The incidence of co-morbidities related to obesity and overweight: a systematic review and meta-analysis. BMC Public Health. 2009;9:88.

2. Joosen A, Westerterp K. Energy expenditure during overfeeding. Nutrition \& Metabolism 2006;3:25.

3. World. Health Organisation Obesity: preventing and managing the global epidemic. Technical report series 894, World Health Organisation, Geneva, Switzerland 2000.

4. Westerterp KR, Speakman JR. Physical activity energy expenditure has not declined since the 1980s and matches energy expenditures of wild mammals. Int J Obes 2008;32:1256-1263.

5. Nicolaidis S, Even P. Physiological determinant of hunger, satiation, and satiety. Am J Clin Nutr. 1985;42:1083-1092.

6. Castonguay T, Applegate E, Upton D, JS S. Hunger and appetite: old concepts/new distinctions. Nutr Rev. 1983;41:101-110.

7. Erlanson-Albertsson C. How Palatable Food Disrupts Appetite Regulation. Basic \& Clinical Pharmacology \& Toxicology 2005;97:61-73.

8. Lemmens S, Martens E, Kester A, MS W-P. Changes in gut hormone and glucose concentrations in relation to hunger and fullness. Am J Clin Nutr. 2011;94:717-725.

9. Mattes RD. Hunger and thirst: issues in measurement and prediction of eating and drinking. Physiol Behav. 2010;100:22-32.

10. Cummings DE, Foster-Schubert KE, Overduin J. Ghrelin and energy balance: focus on current controversies. Curr. Drug Targets 2005;6:153-169.

11. Tschop M, Smiley D, ML H. Ghrelin induces adiposity in rodents. Nature 2000;407:908-913.

12. Wren AM, Seal LJ, Cohen MA, et al. Ghrelin enhances appetite and increases food intake in humans. J Clin Endocrinol Metab 2001;86:5992.

13. Cummings DE, Overduin J. Gastrointestinal regulation of food intake. J Clin Invest 2007;117:13-23.

14. Campfield LA, Smith FJ, Rosenbaum M, Hirsch J. Human eating: Evidence for a physiological basis using a modified paradigm. Neuroscience \& Biobehavioral Reviews 1996;20:133-137.

15. De Graaf C, Blom WAM, Smeets PAM, Stafleu A, Hendriks HFJ. Biomarkers of satiation and satiety. The American Journal of Clinical Nutrition 2004;79:946-961.

16. Mayer J. Regulation of energy intake and the body weight: the glucostatic theory and the lipostatic hypothesis. Annals of the New York Academy of Sciences 1955;63:15-43.

17. Thorens B. Glucose sensing and the pathogenesis of obesity and type 2 diabetes. Int $\mathrm{J}$ Obes 2008;32:S62-S71.

18. Lavin J, Wittert G, Sun W, Horowitz M, Morley J, Read N. Appetite regulation by carbohydrate: role of blood glucose and gastrointestinal hormones. Am J Physiol. 1996;271:E209-14.

19. Verdich C, Toubro S, Buemann B, Lysgård Madsen J, Juul Holst J, A A. The role of postprandial releases of insulin and incretin hormones in meal-induced satiety--effect of obesity and weight reduction. Int J Obes Relat Metab Disord. 2001;25:1206-1214.

20. Flint A, Raben A, Blundell JE, Astrup A. Reproducibility, power and validity of visual analogue scales in assessment of appetite sensations in single test meal studies. Int $\mathrm{J}$ Obes Relat Metab Disord. 2000;24:38-48.

21. McKinley MJ, Johnson AK. The Physiological Regulation of Thirst and Fluid Intake. News Physiol Sci 2004;19:1-6.

22. Thornton S. Thirst and hydration: Physiology and consequences of dysfunction. Physiol Behav. 2010;100:15-21.

23. Fitzsimons JT. The hypothalamus and drinking. Br Med Bull 1966;22:232-237. 
24. Fitzsimons JT. Thirst. Physiol. Rev. 1972;52:468-561.

25. Bernard C. Leçons sur les phénomènes de la vie communs aux animaux et aux végétaux. 2 ed. Paris: Baillière, 1878-1879:112-113.

26. McKiernan F, Houchins JA, Mattes RD. Relationships between human thirst, hunger, drinking, and feeding. Physiol Behav. 2008;94:700-708.

27. Fitzsimons T, Le Magnen J. Eating as a regulatory control of drinking in the rat. J Comp Physiol Psychol. 1969;67:273-283.

28. Engell D. Interdependency of food and water intake in humans. Appetite 1988;10:133-141.

29. Phillips P, Rolls B, Ledingham J, JJ M. Body fluid changes, thirst and drinking in man during free access to water. Physiol Behav. 1984;33:357-363.

30. de Castro J. A microregulatory analysis of spontaneous fluid intake by humans: evidence that the amount of liquid ingested and its timing is mainly governed by feeding. Physiol Behav. 1988;43:705714.

31. Bellisle F, Le Magnen J. The structure of meals in humans: eating and drinking patterns in lean and obese subjects. Physiol Behav. 1981;27:649-658.

32. Blundell J, Stubbs R, Hughes D, Whybrow S, NA K. Cross talk between physical activity and appetite control: does physical activity stimulate appetite? Proc Nutr Soc. 2003;62:651-661.

33. Szczesniak A. Texture as a sensory property. Food Quality and Preference 2002;13:215-225.

34. Blundell JE. The control of appetite: basic concepts and practical implications. Schweizerische medizinische Wochenschrift 1999;129:182-188.

35. Haber GB, Heaton KW, Murphy D, Burroughs LF. Depletion and disruption of dietary fibre: effects on satiety, plasma-glucose, and serum-insulin The Lancet 1977;310:679-682.

36. Zijlstra N, Mars M, de Wijk RA, Westerterp-Plantenga MS, de Graaf C. The effect of viscosity on ad libitum food intake. Int J Obes 2007;32:676-683.

37. Almiron-Roig E, Flores SY, Drewnowski A. No difference in satiety or in subsequent energy intakes between a beverage and a solid food. Physiol Behav. 2004;82:671-677.

38. DiMeglio DP, Mattes RD. Liquid versus solid carbohydrate: effects on food intake and body weight. Int J Obes Relat Metab Disord 2000;24:794-800.

39. Cassady B, Considine R, RD M. Beverage consumption, appetite, and energy intake: what did you expect? Am J Clin Nutr. 2012;95:587-593.

40. Mattes RD. Dietary Compensation by Humans for Supplemental Energy Provided as Ethanol or Carbohydrate in Fluids. Physiol Behav. 1996;59:179-187.

41. Tournier A, Louis-Sylvestre J. Effect of the physical state of a food on subsequent intake in human subjects. Appetite 1991;16:17-24.

42. Soenen S, Westerterp-Plantenga MS. No differences in satiety or energy intake after high-fructose corn syrup, sucrose, or milk preloads. Am J Clin Nutr 2007;86:1586-1594.

43. Mourao DM, Bressan J, Campbell WW, Mattes RD. Effects of food form on appetite and energy intake in lean and obese young adults. Int J Obes 2007;31:1688-1695.

44. Raben A, Vasilaras T, Møller A, Astrup A. Sucrose compared with artificial sweeteners: different effects on ad libitum food intake and body weight after $10 \mathrm{wk}$ of supplementation in overweight subjects. Am J Clin Nutr. 2002;76:721-729.

45. Almiron-Roig E, Chen Y, Drewnowski A. Liquid calories and the failure of satiety: how good is the evidence? Obesity Reviews 2003;4:201-212.

46. Zijlstra N, de Wijk R, Mars M, Stafleu A, de Graaf C. Effect of bite size and oral processing time of a semisolid food on satiation. Am J Clin Nutr 2009;90:269-275.

47. De Graaf $\mathrm{C}$. Why liquid energy results in overconsumption. Proceedings of the Nutrition Society 2011;70:162-170.

48. Kissileff HR. Effects of physical state (liquid-solid) of foods on food intake: procedural and substantive 
contributions. Am J Clin Nutr 1985;42:956-965.

49. Kissileff HR, Gruss LP, Thornton J, Jordan HA. The satiating efficiency of foods. Physiol Behav. 1984;32:319-332.

50. Rolls BJ, Bell EA, Thorwart ML. Water incorporated into a food but not served with a food decreases energy intake in lean women. Am J Clin Nutr 1999;70:448-455.

51. Himaya A, Louis-Sylvestre J. The Effect of Soup on Satiation. Appetite 1998;30:199-210.

52. Mattes R. Soup and satiety. Physiol Behav. 2005;83:739-747.

53. Flegal KM, Carroll MD, Ogden CL, Curtin LR. Prevalence and Trends in Obesity Among US Adults, 1999-2008. JAMA 2010;303:235-241.

54. Torres SJ, Nowson CA. Relationship between stress, eating behavior, and obesity. Nutrition 2007;23:887-894.

55. Ozier AD, Kendrick OW, Leeper JD, Knol LL, Perko M, Burnham J. Overweight and Obesity Are Associated with Emotion- and Stress-Related Eating as Measured by the Eating and Appraisal Due to Emotions and Stress Questionnaire. Journal of the American Dietetic Association 2008;108:49-56.

56. De Vriendt T, Moreno LA, De Henauw S. Chronic stress and obesity in adolescents: Scientific evidence and methodological issues for epidemiological research. Nutrition, Metabolism and Cardiovascular Diseases 2009;19:511-519.

57. Dallman MF. Stress-induced obesity and the emotional nervous system. Trends in Endocrinology \& Metabolism 2010;21:159-165.

58. Rutters F, Nieuwenhuizen AG, Lemmens SGT, Born JM, Westerterp-Plantenga MS. Acute Stressrelated Changes in Eating in the Absence of Hunger. Obesity 2008;17:72-77.

59. Slochower J, Kaplan S, Mann L. The effects of life stress and weight on mood and eating. Appetite 1981;2:115-125.

60. Block JP, He Y, Zaslavsky AM, Ding L, Ayanian JZ. Psychosocial stress and change in weight among US adults. American Journal of Epidemiology 2009;170:181-192.

61. Kivimaki M, Head J, Ferrie JE, et al. Work stress, weight gain and weight loss: evidence for bidirectional effects of job strain on body mass index in the Whitehall II study. International Journal of Obesity 2006;30:982-987.

62. Epel ES, McEwen B, Seeman T, et al. Stress and Body Shape: Stress-Induced Cortisol Secretion Is Consistently Greater Among Women With Central Fat. Psychosom Med 2000;62:623-632.

63. Kyrou I, Chrousos GP, Tsigos C. Stress, visceral obesity, and metabolic complications. Ann N Y Acad Sci 2006;1083:77-110.

64. Adam TC, Epel ES. Stress, eating and the reward system. Physiol Behav. 2007;91:449-458.

65. Heatherton TF, Herman CP, Polivy J. Effects of physical threat and ego threat on eating behavior. Journal of Personality and Social Psychology 1991;60:138-143.

66. Axelrod J, Reisine TD. Stress hormones: their interaction and regulation. Science 1984;224:452-459.

67. Nieuwenhuizen AG, Rutters F. The hypothalamic-pituitary-adrenal-axis in the regulation of energy balance. Physiol Behav. 2008;94:169-177.

68. Lépez M, Caamaño E, Romero C, Fiedler J, Araya V. Salivary cortisol among subjects with and without Cushing syndrome. Rev Med Chil. 2010;138:168-174.

69. Neary N, Nieman L. Adrenal insufficiency: etiology, diagnosis and treatment. Curr Opin Endocrinol Diabetes Obes. 2010;17:217-223.

70. Ljung T, Holm G, Friberg $P$, et al. The activity of the hypothalamic-pituitary-adrenal axis and the sympathetic nervous system in relation to waist/hip circumference ratio in men. Obes Res 2000;8:487495.

71. Travison T, O'Donnell A, Araujo A, Matsumoto A, McKinlay J. Cortisol levels and measures of body composition in middle-aged and older men. Clin Endocrinol 2007;67:71-77.

72. Misra M, Bredella M, Tsai P, Mendes N, Miller K, Klibanski A. Lower growth hormone and higher 
cortisol are associated with greater visceral adiposity, intramyocellular lipids, and insulin resistance in overweight girls. Am J Physiol Endocrinol Metab. 2008;295:E385-92.

73. Marin P, Darin N, Amemiya T, Andersson B, Jern S, Bjorntorp P. Cortisol secretion in relation to body fat distribution in obese premenopausal women. Metabolism 1992;41:882-886.

74. Pasquali R, Cantobelli S, Casimirri F, et al. The hypothalamic-pituitary-adrenal axis in obese women with different patterns of body fat distribution. J Clin Endocrinol Metab 1993;77:341-346.

75. Garcia-Prieto MD, Tebar FJ, Nicolas F, Larque E, Zamora S, Garaulet M. Cortisol secretary pattern and glucocorticoid feedback sensitivity in women from a Mediterranean area: relationship with anthropometric characteristics, dietary intake and plasma fatty acid profile. Clinical Endocrinology 2007;66:185-191.

76. Putignano $\mathrm{P}$, Dubini A, Toja $\mathrm{P}$, et al. Salivary cortisol measurement in normal-weight, obese and anorexic women: comparison with plasma cortisol. Eur J Endocrinol 2001;145:165-171.

77. Therrien F, Drapeau V, Lupien SJ, et al. Awakening cortisol response in relation to psychosocial profiles and eating behaviors. Physiol Behav. 2008;93:282-288.

78. Berridge KC. 'Liking' and 'wanting' food rewards: Brain substrates and roles in eating disorders. Physiol Behav. 2009;97:537-550.

79. Dallman MF, Pecoraro NC, La Fleur SE, et al. Glucocorticoids, chronic stress, and obesity. Progress in Brain Research: Elsevier, 2006:75-105.

80. Volkow N, Wang G-J, RD B. Reward, dopamine and the control of food intake: implications for obesity. Trends in Cognitive Sciences 2011 2011;15:37-46.

81. O'Hare E, Shaw D, Tierney K, E-M K, Levine A, RA S. Behavioral and neurochemical mechanisms of the action of mild stress in the enhancement of feeding. Behav Neurosci. 2004;118:173-177.

82. Yoshida M, Koyanagi S, Matsuo A, et al. Glucocorticoid hormone regulates the circadian coordination of micro-opioid receptor expression in mouse brainstem. J Pharmacol Exp Ther. 2005;315:1119-1124.

83. Pruessner J, Champagne F, Meaney M, Dagher A. Dopamine release in response to a psychological stress in humans and its relationship to early life maternal care: a positron emission tomography study using [11C]raclopride. J Neurosci. 2004;24:2825-2831.

84. Born JM, Lemmens SGT, Rutters F, et al. Acute stress and food-related reward activation in the brain during food choice during eating in the absence of hunger. International Journal of Obesity 2010;34:172-181.

85. Garg N, Wansink B, Inman J. The Influence of Incidental Affect on Consumers' Food Intake. Journal of Marketing 2007;71:194-206.

86. Oliver G, Wardle J, Gibson E. Stress and food choice: a laboratory study. Psychosom Med. 2000;62:853-865.

87. Zellner DA, Loaiza S, Gonzalez Z, et al. Food selection changes under stress. Physiol Behav. 2006;87:789-793.

88. Kuo L, Czarnecka M, Kitlinska J, Tilan J, Kvetnanský R, Zukowska Z. Chronic stress, combined with a high-fat/high-sugar diet, shifts sympathetic signaling toward neuropeptide $Y$ and leads to obesity and the metabolic syndrome. Ann N Y Acad Sci. 2008;1148:232-237.

89. Elfhag K, Erlanson-Albertsson C. Sweet and fat taste preference in obesity have different associations with personality and eating behavior. Physiol Behav. 2006;88:61-66.

90. Salbe AD, DelParigi A, Pratley RE, Drewnowski A, Tataranni PA. Taste preferences and body weight changes in an obesity-prone population. Am J Clin Nutr 2004;79:372-378.

91. Epel E, Lapidus R, McEwen B, Brownell K. Stress may add bite to appetite in women: a laboratory study of stress-induced cortisol and eating behavior. Psychoneuroendocrinology 2001;26:37-49.

92. Ulrich-Lai YM, Christiansen AM, Ostrander MM, et al. Pleasurable behaviors reduce stress via brain reward pathways. Proceedings of the National Academy of Sciences 2010;107:20529-20534.

93. Leigh Gibson E. Emotional influences on food choice: Sensory, physiological and psychological 
pathways. Physiol Behav. 2006;89:53-61.

94. Vicennati V, Ceroni L, Gagliardi L, Gambineri A, Pasquali R. Response of the Hypothalamic-PituitaryAdrenocortical Axis to High-Protein/Fat and High-Carbohydrate Meals in Women with Different Obesity Phenotypes. J Clin Endocrinol Metab 2002;87:3984-3988.

95. Lacroix M, Gaudichon C, Martin A, et al. A long-term high-protein diet markedly reduces adipose tissue without major side effects in Wistar male rats. Am J Physiol Regul Integr Comp Physiol 2004;287:R934-942.

96. Gonzalez-Bono E, Rohleder N, Hellhammer DH, Salvador A, Kirschbaum C. Glucose but Not Protein or Fat Load Amplifies the Cortisol Response to Psychosocial Stress. Hormones and Behavior 2002;41:328-333.

97. Lemmens S, Born J, Martens E, Martens M, MS W-P. Influence of consumption of a high-protein vs. high-carbohydrate meal on the physiological cortisol and psychological mood response in men and women. PLoS One. 2011;6:e16826.

98. Lemmens S, Martens E, Born J, Martens M, MS W-P. Lack of effect of high-protein vs. highcarbohydrate meal intake on stress-related mood and eating behavior. Nutr J. 2011;10:136.

99. Lovallo WR, Farag NH, Vincent AS, Thomas TL, Wilson MF. Cortisol responses to mental stress, exercise, and meals following caffeine intake in men and women. Pharmacology Biochemistry and Behavior 2006;83:441-447.

100. Gibson EL, Checkley S, Papadopoulos A, Poon L, Daley S, Wardle J. Increased Salivary Cortisol Reliably Induced by a Protein-Rich Midday Meal. Psychosom Med 1999;61:214-224.

101. Slag MF, Ahmad M, Gannon MC, Nuttall FQ. Meal stimulation of cortisol secretion: a protein induced effect. Metabolism 1981;30:1104-1108.

102. Berthoud H-R. Neural control of appetite: cross-talk between homeostatic and non-homeostatic systems. Appetite 2004;43:315-317.

103. Finlayson G, King N, Blundell JE. Liking vs. wanting food: Importance for human appetite control and weight regulation. Neuroscience \& Biobehavioral Reviews 2007;31:987-1002.

104. Epstein LH, Truesdale R, Wojcik A, Paluch RA, Raynor HA. Effects of deprivation on hedonics and reinforcing value of food. Physiol Behav. 2003;78:221-227.

105. Langhans W, Geary N. Overview of the physiological control of eating. Forum Nutr. 2010;63:9-53.

106. Berridge KC. Food reward: Brain substrates of wanting and liking. Neuroscience \& Biobehavioral Reviews 1996;20:1-25.

107. Berthoud $\mathrm{H}$. Homeostatic and non-homeostatic pathways involved in the control of food intake and energy balance. Obesity 2006;14:197S-200S.

108. Berridge KC. Motivation concepts in behavioral neuroscience. Physiol Behav. 2004;81:179-209.

109. Finlayson G, King N, Blundell JE. Is it possible to dissociate 'liking' and 'wanting' for foods in humans? A novel experimental procedure. Physiol Behav. 2007;90:36-42.

110. Mela DJ. Eating for pleasure or just wanting to eat? Reconsidering sensory hedonic responses as a driver of obesity. Appetite 2006;47:10-17.

111. Stunkard A, S M. The three-factor eating questionnaire to measure dietary restraint, disinhibition and hunger. J Psychosom Res. 1985;29:71-83.

112. Robinson T, Berridge K. Incentive-sensitization and addiction. Addiction. 2001;96:103-114.

113. Cox DN, Perry L, Moore PB, Vallis L, Mela DJ. Sensory and hedonic associations with macronutrient and energy intakes of lean and obese consumers. International Journal of Obesity Related Metabolic Disorders 1999;23:403-410.

114. Cox DN, van Galen M, Hedderley D, Perry L, Moore PB, Mela DJ. Sensory and hedonic judgments of common foods by lean consumers and consumers with obesity. Obesity Research 1998;6:438-447.

115. Epstein LH, Truesdale R, Wojcik A, Paluch RA, Raynor HA. Effects of deprivation on hedonics and reinforcing value of food. Physiology \& Behavior 2003;78:221-227. 
116. Lemmens SG, Schoffelen PFM, Wouters L, et al. Eating what you like induces a stronger decrease of 'wanting' to eat. Physiol Behav. 2009;98:318-325.

117. Epstein LH, Wright SM, Paluch RA, et al. Food hedonics and reinforcement as determinants of laboratory food intake in smokers. Physiol Behav. 2004;81:511-517.

118. Yeomans M. Taste, palatability and the control of appetite. Proc Nutr Soc. 1998;57:609-615.

119. Nasser J. Taste, food intake and obesity. Obesity Reviews 2001;2:213-218.

120. De Graaf C. sensory responses, food intake and obesity. In: Mela DJ, ed. Food, diet and obesity. Cambridge, England: Woodland Publishing Limited, 2005:137-159.

121. Scruggs D, Buffington C, Cowan G. Taste Acuity of the Morbidly Obese before and after Gastric Bypass Surgery. Obesity Surgery 1994;4:24-28.

122. Bartoshuk LM, Duffy VB, Hayes JE, Moskowitz HR, Snyder DJ. Psychophysics of sweet and fat perception in obesity: problems, solutions and new perspectives. Philosophical Transactions of the Royal Society B: Biological Sciences 2006;361:1137-1148.

123. Finlayson G, King N, Blundell J. The role of implicit wanting in relation to explicit liking and wanting for food: Implications for appetite control. Appetite 2008;50:120-127.

124. Steiner J. Human facial expressions in response to taste and smell stimulation. Advances in Child Development and Behavior 1979;13:257-295.

125. Lappalainen R, Epstein LH. A behavioral economics analysis of food choice in humans. Appetite 1990;14:81-93.

126. O'Doherty JP. Reward representations and reward-related learning in the human brain: insights from neuroimaging. Current Opinion in Neurobiology 2004;14:769-776.

127. Berthoud H, Lenard N, Shin A. Food reward, hyperphagia, and obesity. Am J Physiol Regul Integr Comp Physiol. 2011;300:R1266-77.

128. Ogawa S, Lee T, Kay A, Tank D. Brain magnetic resonance imaging with contrast dependent on blood oxygenation. Proc Natl Acad Sci U S A. 1990;87:9868-9872.

129. Heeger D, Huk A, Geisler W, Albrecht D. Spikes Versus Bold: What Does Neuroimaging Tell Us About Neuronal Activity? Nat Neurosci. 2000;3:631-633.

130. Yang X, Hyder F, Shulman R. Functional MRI Bold Signal Coincides with Electrical Activity in the Rat Whisker Barrels. Magn Reson Med 1997;38:874-877.

131. Ogawa S, Menon R, Tank D, et al. Functional brain mapping by blood oxygenation level-dependent contrast magnetic resonance imaging. A comparison of signal characteristics with a biophysical model. Biophys J. 1993;64:803-812.

132. Volkow ND, Wang G-J, Baler RD. Reward, dopamine and the control of food intake: implications for obesity. Trends in Cognitive Sciences 2011;15:37-46.

133. Lattemann DF. Endocrine links between food reward and caloric homeostasis. Appetite 2008;51:452455.

134. Balleine B, Delgado M, Hikosaka O. The role of the dorsal striatum in reward and decision-making. J Neurosci. 2007;27:8161-8165.

135. Kelley AE, Baldo BA, Pratt WE, Will MJ. Corticostriatal-hypothalamic circuitry and food motivation: Integration of energy, action and reward. Physiol Behav. 2005;86:773-795.

136. Sanchez-Lasheras C, Christine Konner A, Bruning JC. Integrative neurobiology of energy homeostasisneurocircuits, signals and mediators. Frontiers in Neuroendocrinology 2010;31:4-15.

137. Born J, Lemmens S, Martens M, Formisano E, Goebel R, MS W-P. Differences between liking and wanting signals in the human brain and relations with cognitive dietary restraint and body mass index. Am J Clin Nutr. 2011;94:392-403.

138. Born JM, Martens MJI, Rutters F, Lemmens SGT, Goebel R, Westerterp-Plantenga MS. High HPAaxis activation disrupts the link between liking and wanting with liking and wanting related brain signaling. Physiol Behav. 2012;105:321-324. 
139. Born J, Martens M, Lemmens S, Goebel R, MS W-P. Protein v. carbohydrate intake differentially affects liking- and wanting-related brain signalling. Br J Nutr. 2012;[Epub ahead of print].

140. Stice E, Yokum S, Burger K, Epstein L, DM. S. Youth at risk for obesity show greater activation of striatal and somatosensory regions to food. J Neurosci. 2011;31:4360-4366.

141. Dawe S, Loxton NJ. The role of impulsivity in the development of substance use and eating disorders. Neuroscience \&amp; Biobehavioral Reviews 2004;28:343-351.

142. Gearhardt A, Yokum S, Orr P, Stice E, Corbin W, Brownell K. Neural correlates of food addiction. Arch Gen Psychiatry 2011;68:808-816.

143. Rothemund Y, Preuschhof C, Bohner G, et al. Differential activation of the dorsal striatum by highcalorie visual food stimuli in obese individuals. Neurolmage 2007;37:410-421.

144. Stice E, Spoor S, Bohon C, Veldhuizen M, DM S. Relation of reward from food intake and anticipated food intake to obesity: a functional magnetic resonance imaging study. J Abnorm Psychol. 2008;117:924-935.

145. Stice E, Yokum S, Bohon C, Marti N, Smolen A. Reward circuitry responsivity to food predicts future increases in body mass: Moderating effects of DRD2 and DRD4. Neurolmage 2010;50:1618-1625.

146. Stoeckel LE, Weller RE, Cook lii EW, Twieg DB, Knowlton RC, Cox JE. Widespread reward-system activation in obese women in response to pictures of high-calorie foods. Neurolmage 2008;41:636647.

147. Frankort A, Roefs A, Siep N, Roebroeck A, Havermans R, Jansen A. Reward activity in satiated overweight women is decreased during unbiased viewing but increased when imagining taste: an event-related fMRI study. Int J Obes 2011;36:627-637.

148. Martin LE, Holsen LM, Chambers RJ, et al. Neural Mechanisms Associated With Food Motivation in Obese and Healthy Weight Adults. Obesity 2009;18:254-260.

149. DelParigi A, Chen K, Salbe A, et al. Successful dieters have increased neural activity in cortical areas involved in the control of behavior. Int J Obes 2007;31:440-448.

150. DelParigi A, Chen K, Salbe A, et al. Persistence of abnormal neural responses to a meal in postobese individuals. Int J Obes Relat Metab Disord 2004;28:370-377.

151. McCaffery J, Haley A, Sweet $\mathrm{L}$, et al. Differential functional magnetic resonance imaging response to food pictures in successful weigh-loss maintainers relative to normal-weight and obese controls. Am J Clin Nutr 2009;90:928-934.

152. Sweet LH, Hassenstab JJ, McCaffery JM, et al. Brain response to food stimulation in obese, normal weight, and successful weight loss maintainers. Obesity 2011.

153. Volkow N, Wang G, Fowler J, Telang F. Overlapping neuronal circuits in addiction and obesity: evidence of systems pathology. Philos Trans R Soc Lond B Biol Sci. 2008;363:3191-200.

154. Berthoud H-R. Mind versus metabolism in the control of food intake and energy balance. Physiol Behav. 2004;81:781-793.

155. Yokum S, Ng J, Stice E. Attentional Bias to Food Images Associated With Elevated Weight and Future Weight Gain: An fMRI Study. Obesity 2011;19:1775-1783.

156. Le D, Pannacciulli N, Chen K, et al. Less activation in the left dorsolateral prefrontal cortex in the reanalysis of the response to a meal in obese than in lean women and its association with successful weight loss. Am J Clin Nutr. 2007;86:573-579.

157. Le D, Pannacciulli N, Chen K, et al. Less activation of the left dorsolateral prefrontal cortex in response to a meal: a feature of obesity. Am J Clin Nutr. 2006;84:725-731.

158. Tataranni P, Gautier J, Chen K, et al. Neuroanatomical correlates of hunger and satiation in humans using positron emission tomography. Proc Natl Acad Sci U S A. 1999;96:4569-4574.

159. Gautier J, Chen K, Salbe A, et al. Differential brain responses to satiation in obese and lean men. Diabetes. 2000;49:838-846.

160. Gautier J, Del Parigi A, Chen K, et al. Effect of satiation on brain activity in obese and lean women. 
Obes Res. 2001;9:676-684.

161. Wang G, Volkow N, Telang F, et al. Evidence of gender differences in the ability to inhibit brain activation elicited by food stimulation. Proc Natl Acad Sci U S A. 2009;106:1249-1254.

162. Batterink L, Yokum S, Stice E. Body mass correlates inversely with inhibitory control in response to food among adolescent girls: An fMRI study. Neurolmage 2010;52:1696-1703. 


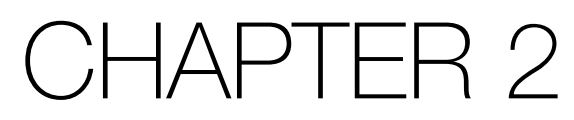

\section{A SOLID HIGH-PROTEIN MEAL EVOKES STRONGER HUNGER SUPPRESSION THAN A LIQUEFIED HIGH-PROTEIN MEAL}

Martens MJ, Born JM, Lemmens SG, Westerterp-Plantenga MS.

Obesity. 2011;19(3):522-527

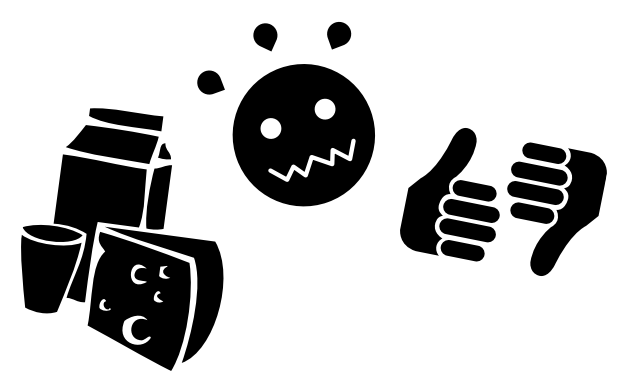




\section{ABSTRACT}

Hunger is a potential problem for compliance with an energy restricted diet. Relatively high-protein meal replacement products have been shown to diminish this problem; they are available as liquid and solid meals, yet their physical state can affect hunger suppression. The objective was to investigate differences in appetite profile and physiological parameters after consumption of a single-macronutrient, subject-specific, high-protein meal in liquefied versus solid form, controlled for energy density, weight and volume. Ten male subjects (age:21.1 \pm 3.9 y; BMl:22.4 $\pm 1.2 \mathrm{~kg} / \mathrm{m}^{2}$ ) were offered lunch subject-specifically as $15 \%$ of daily energy requirement, consisting of solid (steamed chicken breast $+750 \mathrm{ml}$ water) or liquefied protein (steamed chicken breast blended in $500 \mathrm{ml}$ water+250 $\mathrm{ml}$ water). Appetite profiles, insulin, glucose and ghrelin were measured over $3 \mathrm{~h}$. Comparing the solid versus liquefied condition, oral exposure time did not differ between conditions $(19.2 \pm 0.4 \mathrm{~min}$ and $18.8 \pm 0.6$ min respectively, $p=0.13)$. Area under the curve effects were observed for thirst; statistically significant condition $x$ time interactions and statistically significant differences at several time points were observed for desire to eat (condition $x$ time $p<0.05 ; 31 \pm 6 \mathrm{~mm}$ vs. $53 \pm 8 \mathrm{~mm} ; p<0.04$ at $115 \mathrm{~min}$ ) and thirst (condition $x$ time $p<0.01 ; 27 \pm 8 \mathrm{~mm}$ vs. $41 \pm 8 \mathrm{~mm} ; p<0.05$ at $30 \mathrm{~min}$ and $23 \pm 6 \mathrm{~mm}$ vs. $41 \pm 8 \mathrm{~mm} ; p<0.02$ at $70 \mathrm{~min}$ ) being lower, while hunger suppression $(79 \pm 3 \mathrm{~mm}$ and $52 \pm 10 \mathrm{~mm} ; \mathrm{p}<0.03$ at $20 \mathrm{~min}$ and $61 \pm 7 \mathrm{~mm}$ and $44 \pm 8 \mathrm{~mm} ; p<0.03$ at $115 \mathrm{~min}$ ) was higher in the solid condition. Glucose, insulin and ghrelin concentration curves were similar for both conditions. In conclusion, solid protein evokes a stronger suppression of hunger and desire to eat than liquefied protein. 


\section{INTRODUCTION}

Obesity is a major health concern with serious comorbidities $(1,2)$; it results from disturbance of energy balance, i.e. energy intake exceeding energy expenditure (3). Furthermore, hunger is a potential problem for compliance with an energy restricted diet. Proteins can suppress hunger despite negative energy balance (4) and because a hierarchy prevails for the satiating efficacies of the macronutrients protein, carbohydrates and fat, with protein being the most satiating and fat the least (5). Studies of satiating effects of protein often compare protein-containing drinks with carbohydrate-containing drinks (6-9). Effects of protein-containing drinks versus control drinks appear when sufficient protein and energy are present in the drinks (5). Bertenshaw et al. compared isoenergetic dairy fruit drink preloads $(300 \mathrm{ml}, 1.25 \mathrm{MJ})$ differing in macronutrient composition in normal-weight men (BMI $\left.22.6 \pm 0.4 \mathrm{~kg} / \mathrm{m}^{2}\right)$ and observed that significantly less energy was consumed at lunch $120 \mathrm{~min}$ after the protein (3.2 $\mathrm{MJ}$ ) compared with the control (3.5 MJ) and $\mathrm{CHO}$ preloads (3.6 MJ), without showing complete energy intake compensation (7). A study by Harper et al., comparing the effects of a sugar-sweetened beverage (cola) and a chocolate milk drink $(0.9 \mathrm{MJ}, 500 \mathrm{ml})$ in healthy subjects (BMI $22 \pm 2 \mathrm{~kg} / \mathrm{m}^{2}$ ) showed that satiety and fullness were significantly greater 30 minutes after consumption of chocolate milk than after cola, although no significant difference in energy intake occurred during lunch (3.2 MJ after chocolate milk versus 3.3 MJ after cola) (8). Soenen et al. found no difference in effects on appetite, energy intake, and energy intake compensation 50 minutes after consumption of $800 \mathrm{ml}$ milk (1.5 MJ), or carbohydrate drinks in their study in 40 young healthy normal-weight (BMI $22.1 \pm 1.9 \mathrm{~kg} /$ $\mathrm{m}^{2}$ ) men and women (9). A study by Bellissimo et al. in normal-weight and obese boys showed that 60 minutes after consumption of glucose and whey-protein drinks $(250 \mathrm{ml}$ 3.5 MJ), food intake was suppressed more by whey protein $(2.7 \mathrm{MJ})$ than by glucose (3.1 MJ) or control (3.6 MJ) drinks (6). A study by Dove et al. in 34 obese men and women (BMI $31.5 \pm 5.5 \mathrm{~kg} / \mathrm{m}^{2}$ ) compared two common breakfast beverages (1.1 MJ) and showed a significantly lower energy consumption 4 hours after a skimmed milk preload $(2.4 \mathrm{MJ})$ than after a fruit drink preload $(2.7 \mathrm{MJ})$; self-reported satiety was significantly higher throughout the morning after consumption of skimmed milk preload than after consumption of the fruit drink preload, with the differences becoming significantly larger over the 4 hours (10). Summarizing, despite some studies finding a decreased energy intake $(6,7,10)$ and an increased satiety $(8,10)$ after a protein preload when compared with a carbohydrate preload, not al studies could confirm these results. Soenen et al. and Harper at al. found no differences in energy intake and Soenen et al. also did not detect differences in appetite $(8,9)$.

Taken together, previous studies mostly investigated the satiating capacity of protein by comparing protein drinks with carbohydrate drinks. To our knowledge, no previous study compared liquid and solid food forms of protein to investigate satiety effects and 
the physiological background thereof. Only one previous study reported a comparison of high protein solid and beverage loads on appetite and energy intake using food items other than meal replacement products (11). The prior study found that the beverage food form (milk) elicited a weaker compensatory dietary response than the matched solid food form (cheese) and that total daily energy intake was significantly higher by $15 \%$ on days the beverage form was ingested, however they did not report any physiological parameters (11). Therefore, the objective of our study was to investigate differences in appetite profile and in relevant physiological parameters after consumption of a single macronutrient, subject-specific, protein meal in liquefied versus solid form, controlled for energy density, weight and volume. Appetite profiles as well as the physiological parameters insulin, glucose and ghrelin concentrations were measured over three hours.

\section{METHODS AND PROCEDURES}

\section{SUBJECTS}

Subjects were recruited by advertisements in local newspapers and on notice boards at Maastricht University, the Netherlands. Eleven subjects underwent an initial screening including body weight and height measurements and completed a questionnaire related to medical history, smoking behavior, alcohol consumption and physical activity. Ten healthy male subjects qualified for participation in this study. Based upon a study by Haber et al. (12) 10 men (age:21.1 $\pm 3.9 y$; BMl:22.4 $\pm 1.2 \mathrm{~kg} / \mathrm{m}^{2}$ ) participated in this study; according to a possible difference in satiety scores of 14 and a standard deviation of 14 , power analysis shows that with an $a$ of 0.05 and $b$ of 0.20 (power=1-b=0.80), at least 10 subjects are needed. Subject characteristics can be found in table 1 . The research procedures followed were in accordance with the Helsinki Declaration and were approved by the Medical Ethical Committee of Maastricht University. All subjects were informed on the purpose, procedures and potential risks of the study prior to signing the informed consent.

\section{EXPERIMENTAL DESIGN}

The study was conducted following a within-subject, randomized, crossover design. Subjects came to the university on two occasions (once a week during 2 weeks). On the day before the trial and during the trial they were not allowed to consume alcohol and to practice heavy exercise. On the morning of the visit subjects had to consume a predetermined amount of breakfast drink ('Goedemorgen', Campina) at home. After this, subjects were not allowed to eat or drink anything (except water) until arrival at the university at 12 PM. Upon arrival an intra-venous catheter (IV) was inserted for blood sampling. At 12:40 PM subjects got there subject-specific lunch composed of protein in a solid or liquefied texture, which they had to consume within $20 \mathrm{~min}$. Hereafter, twelve 
more blood samples were drawn for the measurement of plasma insulin, glucose and ghrelin concentrations. At 16:00 PM the catheter was removed and subjects could go home.

\section{MEALS}

\section{BREAKFAST}

Subjects had to consume a prescribed breakfast at home, composed of a commercially available breakfast drink called 'Goedemorgen' from the brand Campina. The amount consumed corresponded to $20 \%$ of the subjects' daily energy requirement (DER). Daily energy requirements were calculated individually for each of the recruited subjects by multiplying basal metabolic rate (BMR) by the appropriate physical activity factor (1.51.8), derived from the Baecke screening questionnaire (13). The BMR (kJ/day) was calculated according to the equation of Harris-Benedict (14) (Table 1).

Table 1. Subject characteristics.

\begin{tabular}{ll} 
Characteristics & Mean \pm SD \\
Male $(\mathrm{n})$ & 10 \\
Age (years) & $21.1 \pm 3.9$ \\
Height $(\mathrm{cm})$ & $178.5 \pm 3.7$ \\
Weight $(\mathrm{kg})$ & $71.5 \pm 5.0$ \\
Waist circumference $(\mathrm{cm})$ & $77.9 \pm 3.3$ \\
Hip circumference $(\mathrm{cm})$ & $86.2 \pm 6.2$ \\
$\mathrm{BMI}^{1}$ & $22.4 \pm 1.2$ \\
$\mathrm{BMR}^{2}$ & $7531.6 \pm 369.9$ \\
\hline
\end{tabular}

${ }^{1}$ Body Mass Index $=$ weight $(\mathrm{kg}) /$ height $(\mathrm{m})^{2}$

${ }^{2}$ Basal Metabolic Rate (kJ/day) calculated according to the equation of Harris-Benedict (14)

\section{LUNCH}

Lunch consisted of one of the following two conditions in random order; solid protein: whole steamed chicken breast or liquefied protein: blended steamed chicken breast. It is important to note that this is a comparison between a solid food and a soup, not a beverage. These meals were subject-specific and controlled for energy density, weight and volume. The solid meal consisted of food and $750 \mathrm{ml}$ water to drink; the liquefied meal consisted of food mixed with $500 \mathrm{ml}$ water and $250 \mathrm{ml}$ water to drink. These meals were rated beforehand on palatability using visual analogue scales in an independent panel of 12 subjects. There were no differences between the palatability rating of the solid protein meal (62 $\pm 2 \mathrm{~mm}$ VAS) and the liquefied protein meal $(60 \pm 3 \mathrm{~mm}$ VAS) The amount of lunch given was subject-specific, corresponding to $15 \%$ of their DER, again calculated individually according to the equation of Harris-Benedict and using the 
appropriate physical activity factor $(13,14)$. The solid meal had to be eaten with knife and fork and the liquefied meal had to be eaten with a spoon in order to keep rate of ingestion and oral exposure time the same. All subjects had to finish their meal within $20 \mathrm{~min}$. Measured oral exposure time in the solid and the liquefied condition was not statistically different $(19.2 \pm 0.4 \mathrm{~min}$ and $18.8 \pm 0.6$ min respectively, $\mathrm{p}=0.13)$.

\section{APPETITE PROFILE}

One hundred $\mathrm{mm}$ visual analog scales (VAS) were used to assess the appetite profile at baseline, and before every blood sample (15). The scales were anchored with opposing extremes of feelings of hunger, fullness and thirst. Subjects were instructed to make a single vertical mark at the appropriate point between the two anchors on each scale to indicate their subjective feelings. These VAS were completed at thirteen time points (at $10 \mathrm{~min}$ before the start of the lunch and at $20 \mathrm{~min}, 30 \mathrm{~min}, 40 \mathrm{~min}, 50 \mathrm{~min}, 60 \mathrm{~min}$, $70 \mathrm{~min}, 85 \mathrm{~min}, 100 \mathrm{~min}, 115 \mathrm{~min}, 130 \mathrm{~min}, 160 \mathrm{~min}$, and $190 \mathrm{~min}$ after the start of the lunch). All VAS were completed before blood sampling in order to prevent mutual effects.

\section{BLOOD SAMPLING}

At the beginning of the test session, 40 min before the lunch was served (12:00 AM), a polytetrafluoroethylene catheter was placed in the antecubital vein for blood sampling. During each test day, a first blood sample was drawn 10 min before the start of the lunch (at $-10 \mathrm{~min}$ ) and 12 blood samples were drawn after the start of the lunch (at $20 \mathrm{~min}, 30$ min, $40 \mathrm{~min}, 50 \mathrm{~min}, 60 \mathrm{~min}, 70 \mathrm{~min}, 85 \mathrm{~min}, 100 \mathrm{~min}, 115 \mathrm{~min}, 130 \mathrm{~min}, 160 \mathrm{~min}$, and $190 \mathrm{~min}$ ) for the measurement of plasma insulin, glucose and ghrelin concentrations. A blood sample for insulin and glucose was drawn $(8 \mathrm{ml})$ on all thirteen time points. A blood sample for ghrelin was drawn ( $3 \mathrm{ml}$ ) on 5 time points (at $-10 \mathrm{~min}, 20 \mathrm{~min}, 50 \mathrm{~min}, 85 \mathrm{~min}$, $160 \mathrm{~min}$ ). Blood samples were collected in tubes containing EDTA (BD vacutainer with EDTA, $10 \mathrm{ml}$ ) to prevent clotting. Blood plasma was obtained by centrifugation $\left(4{ }^{\circ} \mathrm{C}\right.$, 3000 r.p.m., $20 \mathrm{~min}$ ). All samples were frozen and stored at $-80^{\circ} \mathrm{C}$ until further analysis. Plasma glucose concentrations were analyzed enzymatically by using the hexokinase method (ABX Diagnostics, Montpellier, France). Plasma insulin concentrations were determined in our own laboratory from the plasma samples, by means of RIA according to the manufacturer's instructions (Human insulin-specific RIA kit, Millipore, Billerica, Massachusetts, USA). Plasma concentrations of active ghrelin were measured in our own laboratory by means of radio immuno assay (RIA) (Human ghrelin (active)-specific RIA kit, Millipore, Billerica, Massachusetts, USA). Plasma active ghrelin concentrations were measured in acidified plasma with $50 \mu \mathrm{l}$ of $1 \mathrm{~N} \mathrm{HCL}$ and addition of $10 \mu \mathrm{l}$ of phenylmethylsulfonyl fluoride per $1 \mathrm{ml}$ of plasma.

\section{STATISTICS}

Areas under the curve (AUC) were calculated for all hormone concentrations measured 
and for appetite profiles using the trapezoidal method. Data were analyzed using StatView 5.0 (SAS Institute Inc., Cary, NC, USA). Appetite profiles and blood values were tested with a student T-test to determine the differences between textures at all time points and for the AUC. Differences over time and between conditions (liquefied and solid) were determined using two-factor analysis of variance (ANOVA) with repeated measures. Bonferroni correction was used to prevent type I errors. All tests were twosided and differences were considered significant at $p<0.05$. Values are expressed as mean \pm standard error of the mean (SEM).

\section{RESULTS}

\section{APPETITE RATINGS}

After consumption of the lunch fullness and hunger suppression ratings significantly increased and hunger, desire to eat and thirst ratings significantly decreased over time $(p<0.0001)$ (Figure 1).

Statistically significant condition $x$ time interactions were found for desire to eat $(p<0.05)$ and thirst $(p<0.01)$, with desire to eat and thirst being rated higher over 2 hours in the liquefied condition. The AUC of the appetite ratings were not significantly different between the conditions, except for the thirst ratings, being higher in the liquefied condition than in the solid condition (respectively, 9069 1354 and $7221 \pm 956 ; p<0.05$ ). Hunger suppression was rated higher in the solid condition than in the liquefied condition $20 \mathrm{~min}$ (respectively, $79 \pm 3 \mathrm{~mm}$ and $52 \pm 10 \mathrm{~mm} ; \mathrm{p}<0.03$ ) and $115 \mathrm{~min}$ after the start of the lunch (respectively, $61 \pm 7 \mathrm{~mm}$ and $44 \pm 8 \mathrm{~mm} ; \mathrm{p}<0.03$ ). Furthermore, desire to eat was rated higher in the liquefied condition $(53 \pm 8 \mathrm{~mm})$ than in the solid condition $(31 \pm 6$ $\mathrm{mm}) 115 \mathrm{~min}$ after the start of the lunch $(\mathrm{p}<0.04)$. In addition, thirst was rated higher in the liquefied condition than in the solid condition at 30 (respectively, $41 \pm 8 \mathrm{~mm}$ and $27 \pm 8$ $\mathrm{mm} ; \mathrm{p}<0.05$ ) and $70 \mathrm{~min}$ (respectively, $41 \pm 8 \mathrm{~mm}$ and $23 \pm 6 \mathrm{~mm} ; \mathrm{p}<0.02$ ) after the start of the lunch. The slopes of the appetite ratings curves of the two protein forms were not significantly different.

\section{BLOOD PARAMETERS}

Blood parameters are represented in Figure 2. All blood parameters showed a significant effect over time $(p<0.05)$. Glucose concentration curves were similar for the liquefied and the solid condition; there was no statistically significant condition $\mathrm{x}$ time interaction. Moreover, the AUC were not significantly different between the conditions. Furthermore, insulin concentration curves were similar for both conditions; there was no statistically significant condition $\mathrm{x}$ time interaction. In addition, ghrelin concentration curves were similar for both conditions; there was no statistically significant condition $x$ time interaction and the AUC were not significantly different between the conditions. 

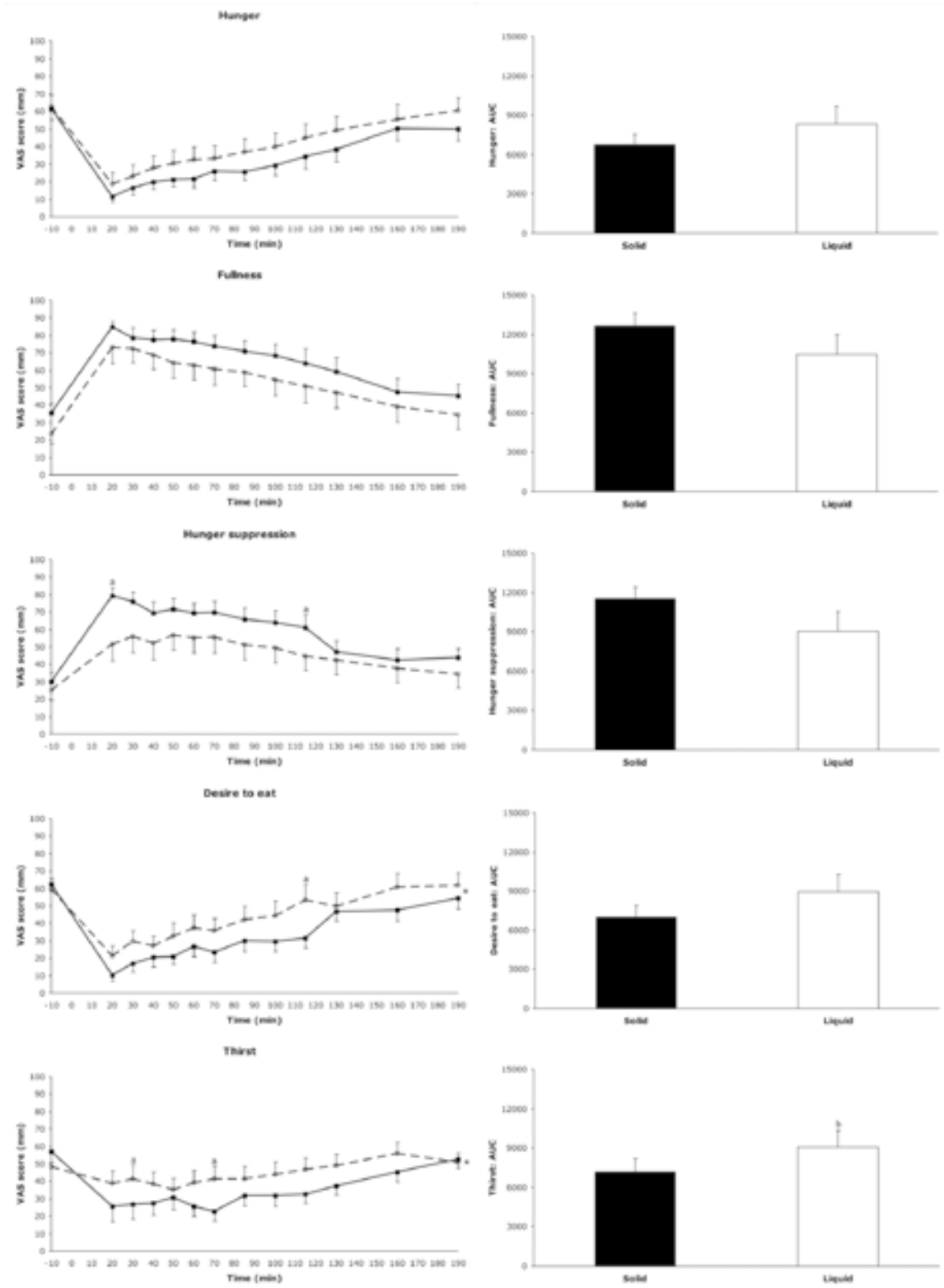

Figure 1. On the left: mean ( \pm SEM) visual analog scores for the appetite profile; hunger, fullness, hunger suppression, desire to eat and thirst for the solid (- -$)$ and the liquefied $(-\bigcirc-)$ condition. On the right: mean areas under the curve for the appetite profile for the solid $(\boldsymbol{\square})$ and the liquefied $(\square)$ condition. ${ }^{a}$ Indicates a significant difference between the solid and the liquefied condition at that time point $(p<0.05) .{ }^{b}$ Indicates a significant difference between the mean area under the curve for the solid and the liquefied condition $(p<0.05) .{ }^{*}$ Indicates significant condition $x$ time interactions $(p<0.03)$. 

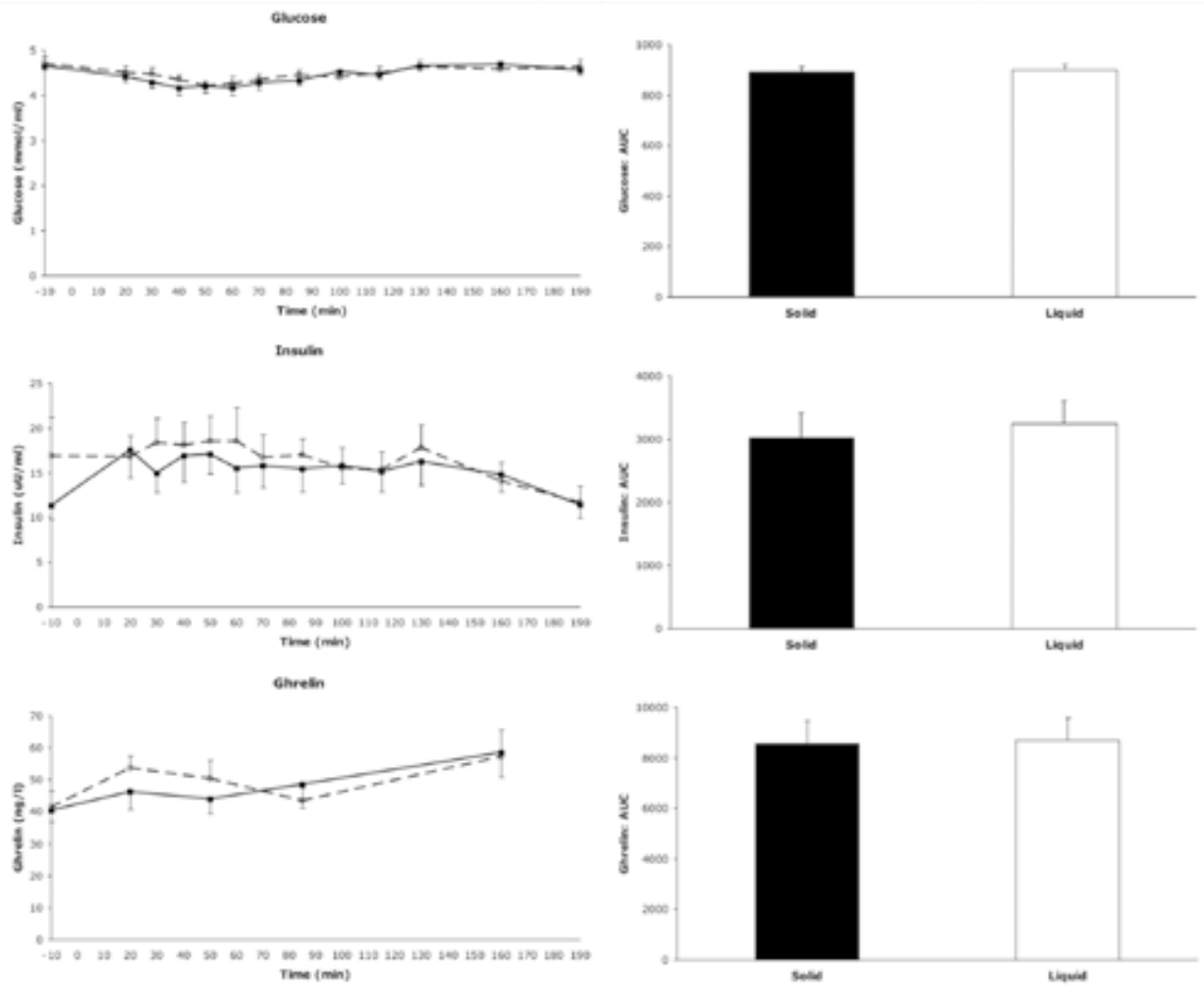

Figure 2. On the left: mean $( \pm$ SEM) values of glucose, insulin and ghrelin for the solid $(-\mathbf{-}-)$ and the liquefied (-○-) condition. On the right: mean areas under the curve for the blood values for the solid ( $\mathbf{\square})$ and the liquefied $(\square)$ condition.

\section{DISCUSSION}

The objective of our study was to compare appetite profiles and relevant physiological parameters after consumption of a single macronutrient, subject-specific, protein meal in liquefied versus solid form, controlled for energy density, weight and volume. Appetite profiles as well as the physiological parameters insulin, glucose and ghrelin concentrations were measured over three hours. For appetite profile, effects were found on desire to eat, hunger suppression and thirst. When compared with the liquefied condition, the solid condition suppressed desire to eat and hunger stronger at different time points. Subjects were thirstier after the liquefied condition. Probably, drinking the water separately instead of it being part of the liquefied mixture had quenched their thirst. Glucose, insulin and ghrelin concentration curves were similar for both conditions. The effect of the texture of protein was already observed as a satiation effect, with 
hunger suppression being larger immediately after the meal. Moreover, there was a significant condition $\mathrm{x}$ time effect over 2 hours due to the shift in satiation. Since after the meal the starting point for satiety development was different, and since this difference remained as a treatment $x$ time effect, the effect on satiety was secondary to the primary satiation effect. In addition to solid protein showing a stronger satiation effect, evidence for a stronger satiety effect than liquefied protein is given by a higher hunger suppression and a lower desire to eat at 115 min after the meal.

Satiety is logically important for successful weight loss. Relatively high-protein meal replacement products are available as liquid and solid (shakes and bars) meals and the physical state of food has been hypothesized to affect the intensity and duration of satiety in adults $(12,16-23)$. Our results confirm previous studies comparing textures of relatively high-protein meal replacement products. They found that the solid meal replacement product was able to evoke more satiety than the liquid one $(24,25)$. In the study by Tieken et al. they found a lower post-prandial hunger response following the solid versus the liquid meal replacement $(p<0.005)$, which remained below baseline over $4 \mathrm{~h}(\mathrm{p}<0.05)$; similar responses were observed with the desire to eat (25). In a first study by Mattes and Rothacker 84 adults (age: $48 \pm 13$ years; BMl: $30.7 \pm 6.6 \mathrm{~kg} / \mathrm{m}^{2}$ ) ingested $325-\mathrm{ml}(220 \mathrm{kcal})$ shakes that were matched on weight, volume, temperature, energy, macronutrient content, energy density, rate of consumption, cognitive expectations, palatability, appearance, and requirements for mechanical processing, but varied in viscosity; appetitive ratings were obtained over the subsequent $4 \mathrm{~h}$ (26). They reported that the thickness of meal replacement diet shakes had a direct and significant effect on hunger intensity during the first $2 \mathrm{~h}$ and that hunger intensity scores for liquid meal replacements were significantly below baseline for $3 \mathrm{~h}$ following consumption (26). A follow-up study by Rothacker et al. used a similar protocol to investigate meal replacement bars designed for overweight consumers; 108 subjects (age: $50 \pm 17$ years; BMI: $32.6 \pm$ $\left.7.3 \mathrm{~kg} / \mathrm{m}^{2}\right)$ replaced 1 or 2 meals per day over 6 weeks by a meal replacement bar (250 kcal) and hunger assessments were made (24). They found that hunger and desire to eat ratings remained significantly below baseline for $5 \mathrm{~h}$ following consumption and stomach fullness scores were significantly above baseline for $5 \mathrm{~h}$ (24). From these two studies they concluded that meal replacement bars allowed a gain of two added hours of satiety compared to liquid meal replacements $(24,26)$. Our results also confirm a previous study by Mourao et al. who used more every-day and dietary relevant food items (milk and cheese) to compare high protein solid and beverage loads on appetite and intake (11). They found that the beverage food form elicited a weaker compensatory dietary response than the matched solid food form and that total daily energy intake was significantly higher by $15 \%$ on days the beverage form was ingested, however they did not report any physiological parameters (11)

To our knowledge no previous study concentrated on the effect of high-protein solid versus liquefied meals on physiological parameters. We did not detect differences in 
glucose, insulin and ghrelin concentration in response to the high-protein liquefied versus solid meals. Glucose and insulin are more important in carbohydrate metabolism and will react more to a high-carbohydrate meal and may in this case be less relevant. Ghrelin is an orexigenic hormone produced primarily by the stomach and proximal small intestine; it functions oppositely to satiation peptides (27). It can increase food intake in diverse species (28), including humans (29), and is the only known hormone to do so. Contrary to satiation peptides, ghrelin increases Gl motility and decreases insulin secretion. Also in contrast to satiation peptides, circulating levels peak shortly before meals and are suppressed by ingested nutrients; carbohydrates are more effective in suppressing ghrelin than proteins, which are more effective than lipids (30).

To improve this study the measurement of cholecystokinin (CCK) and glucagon-like peptide-1 (GLP-1) would have been instructive. Intestinal CCK is especially secreted in response to luminal lipids and proteins (30). Through endocrine and/or neural mechanisms, CCK regulates many Gl functions, including satiation (30). GLP-1 is a satiety peptide involved in the ileal break by engaging a behavioral brake on eating (30). Primarily L cells in the distal small intestine and colon produce GLP1. Ingested nutrients, especially fats and carbohydrates, stimulate GLP1 secretion (30). However, we were not able to measure CCK and GLP-1 due to technical problems. We were not allowed by medical ethical committee to draw the necessary amount of blood and furthermore it is not permitted to use trasylol as inhibitor anymore.

The improvements of design in this study compared with other studies are: 1) giving exactly the same foods in solid and liquefied form with the same amount of water in total (750 ml to drink; or $500 \mathrm{ml}$ homogenized $+250 \mathrm{ml}$ to drink); 2) using a subject specific design in which the subjects received an amount of lunch corresponding to their daily energy requirement. In this way the VAS were controlled for energy requirement and they did not reflect differences between subjects but between conditions.

Taken together, we found a hunger suppression effect during the meal interval of the texture of protein. This effect was already observed as a satiation effect, with hunger suppression being larger immediately after the meal, and translated in an overall higher suppression of hunger and desire to eat during the meal-interval in the solid protein condition. In conclusion, a solid protein meal is able to evoke stronger hunger suppression during the meal interval than a liquefied protein meal.

\section{ACKNOWLEDGEMENTS}

We thank our subjects for their participation in this study. Furthermore, we thank J. Stegen for analyzing the plasma samples. The study was designed by MSWP and MJIM. MJIM, supervised by MSWP, carried out the study, collected and analyzed the data and wrote the largest part of the manuscript. SGTL and JMB reviewed the manuscript. None of the authors has any conflict of interest. 


\section{REFERENCES}

1. Pi-Sunyer FX. Medical hazards of obesity. Ann. Intern. Med. 1993;119:655-60.

2. Seidell JC. Obesity in Europe. Obes. Res 1995;3:89-93S.

3. Joosen A, Westerterp K. Energy expenditure during overfeeding. Nutrition \& Metabolism 2006;3:25.

4. Westerterp-Plantenga MS, Nieuwenhuizen A, Tome D, Soenen S, Westerterp KR. Dietary Protein, Weight Loss, and Weight Maintenance. Annual Review of Nutrition 2009;29:21-41.

5. Soenen S, Westerterp-Plantenga MS. Proteins and satiety: implications for weight management. Curr Opin Clin Nutr Metab Care. 2008;11:747-51.

6. Bellissimo N, Desantadina MV, Pencharz PB, Berall GB, Thomas SG, Anderson GH. A comparison of short-term appetite and energy intakes in normal weight and obese boys following glucose and wheyprotein drinks. Int J Obes 2007;32:362-371.

7. Bertenshaw EJ, Lluch A, Yeomans MR. Satiating effects of protein but not carbohydrate consumed in a between-meal beverage context. Physiology \& Behavior 2008;93:427-436.

8. Harper A, James A, Flint A, Astrup A. Increased satiety after intake of a chocolate milk drink compared with a carbonated beverage, but no difference in subsequent ad libitum lunch intake. Br. J. Nutr. 2007;97:579-83.

9. Soenen S, Westerterp-Plantenga MS. No differences in satiety or energy intake after high-fructose corn syrup, sucrose, or milk preloads. Am J Clin Nutr 2007;86:1586-1594.

10. Dove ER, Hodgson JM, Puddey IB, Beilin LJ, Lee YP, Mori TA. Skim milk compared with a fruit drink acutely reduces appetite and energy intake in overweight men and women. Am J Clin Nutr 2009;90:70-75.

11. Mourao DM, Bressan J, Campbell WW, Mattes RD. Effects of food form on appetite and energy intake in lean and obese young adults. Int J Obes 2007;31:1688-95.

12. Haber GB, Heaton KW, Murphy D, Burroughs LF. Depletion and disruption of dietary fibre: effects on satiety, plasma-glucose, and serum-insulin The Lancet 1977;310:679-682.

13. Philippaerts RM, Westerterp KR, Lefevre J. Doubly Labeled Water Validation of three Physical Activity Questionnaires. Int J Sports Med 1999;20:284-289.

14. Harris JA, Benedict FG. A Biometric Study of Human Basal Metabolism. Proc Natl Acad Sci 1918;4:370-3.

15. Flint A, Raben A, Blundell JE, Astrup A. Reproducibility, power and validity of visual analogue scales in assessment of appetite sensations in single test meal studies. nt $\mathrm{J}$ Obes Relat Metab Disord. 2000;24:38-48.

16. Almiron-Roig E, Chen Y, Drewnowski A. Liquid calories and the failure of satiety: how good is the evidence? Obesity Reviews 2003;4:201-212.

17. Himaya A, Louis-Sylvestre J. The Effect of Soup on Satiation. Appetite 1998;30:199-210.

18. Kissileff HR. Effects of physical state (liquid-solid) of foods on food intake: procedural and substantive contributions. Am J Clin Nutr 1985;42:956-965.

19. Kissileff HR, Gruss LP, Thornton J, Jordan HA. The satiating efficiency of foods. Physiology \& Behavior 1984;32:319-332.

20. Mattes R. Soup and satiety. Physiology \& Behavior 2005;83:739-747.

21. Rolls BJ, Fedoroff IC, Guthrie JF, Laster LJ. Foods with different satiating effects in humans. Appetite 1990;15:115-126.

22. Zijlstra N, Mars M, de Wijk RA, Westerterp-Plantenga MS, de Graaf C. The effect of viscosity on ad libitum food intake. Int J Obes 2007;32:676-683.

23. Zijlstra N, Mars M, de Wijk RA, Westerterp-Plantenga MS, Holst JJ, de Graaf C. Effect of viscosity on appetite and gastro-intestinal hormones. Physiology \& Behavior 2009;97:68-75. 
24. Rothacker DQ, Watemberg S. Short-term hunger intensity changes following ingestion of a meal replacement bar for weight control. International Journal of Food Sciences and Nutrition 2004;55:223226.

25. Tieken SM, Leidy HJ, Stull AJ, Mattes RD, Schuster RA, Campbell WW. Effects of Solid versus Liquid Meal-replacement Products of Similar Energy Content on Hunger, Satiety, and Appetite-regulating Hormones in Older Adults. Horm Metab Res. 2007;39:389-394.

26. Mattes $\mathrm{RD}$, Rothacker D. Beverage viscosity is inversely related to postprandial hunger in humans. Physiology \& Behavior 2001;74:551-557.

27. Cummings DE, Foster-Schubert KE, Overduin J. Ghrelin and energy balance: focus on current controversies. Curr. Drug Targets 2005;6:153-169.

28. Tschop M. SDL, Heiman M.L. Ghrelin induces adiposity in rodents. Nature 2000;407:908-913.

29. Wren AM, Seal LJ, Cohen MA, et al. Ghrelin enhances appetite and increases food intake in humans. J Clin Endocrinol Metab 2001;86:5992.

30. Cummings DE, Overduin J. Gastrointestinal regulation of food intake. J Clin Invest 2007;117:13-23. 


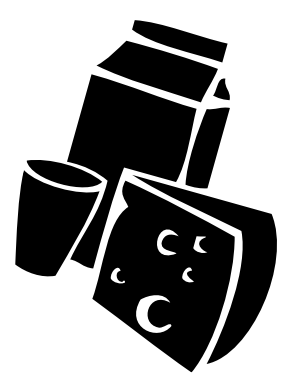

40 


\section{CHAPTER 3}

\section{SATIATING CAPACITY AND POST-PRANDIAL RELATIONSHIPS BETWEEN APPETITE PARAMETERS AND GUT-PEPTIDE CONCENTRATIONS WITH SOLID AND LIQUEFIED CARBOHYDRATE}

Martens MJ, Lemmens SG, Born JM, Westerterp-Plantenga MS.

PLoS-One, 2012;7(7.) Epub 2012 Jul 26. 


\section{ABSTRACT}

Background: Differences in satiating capacity of liquid and solid meals are unclear.

Objective: Investigating appetite parameters, physiological measurements and withinsubject relationships after consumption of a single macronutrient, subject-specific carbohydrate meal in liquefied versus solid form, controlled for energy density, weight and volume.

Design: In a cross-over design, ten male subjects (age $=21.1 \pm 3.9 \mathrm{y}, \mathrm{BMI}=22.4 \pm 1.2 \mathrm{~kg}$ / $\mathrm{m}^{2}$ ) consumed a solid (CS, whole peaches $+750 \mathrm{ml}$ water) and liquefied carbohydrate (CL, peach blended in $500 \mathrm{ml}$ water $+250 \mathrm{ml}$ water) lunch. Appetite profiles, insulin-, glucose- and ghrelin concentrations were measured over three hours. Post-prandial relationships between appetite and blood parameters were calculated using subjectspecific regression analyses.

Results: Fullness ratings were higher in the $\mathrm{CL}(85 \pm 5 \mathrm{~mm})$ compared to the CS condition $(73 \pm 8 \mathrm{~mm})$ at $20 \mathrm{~min}(\mathrm{p}<0.03)$. Glucose concentrations peaked 20 to $30 \mathrm{~min}$ after the start of the lunch in the CL condition, and 30 to $40 \mathrm{~min}$ after start of the CS condition. Correspondingly, insulin concentrations were peaked at 20-30 min in the CL condition, and at 30-40 min in the CS condition. AUC or condition $x$ time interactions were not different comparing the $C L$ and the $C S$ condition. Insulin was significantly higher in the $C S$ compared to the CL condition $40 \mathrm{~min}$ after the start of the lunch $(\mathrm{p}<0.05)$. Fullness scores were significantly related to insulin concentrations but not to glucose concentrations; desire to eat scores were significantly associated with ghrelin concentrations in both, the $\mathrm{CL}$ and the CS condition. The relationship between fullness scores and glucose concentrations was not statistically significant.

Conclusion: Liquefied and solid carbohydrate meals do not differ in satiating capacity, supported by appetite profile and relevant blood parameters. Postprandially, fullness and desire to eat were associated with respectively insulin and ghrelin concentrations. 


\section{INTRODUCTION}

Obesity results from an imbalance of energy intake and energy expenditure (1). One explanation for the rise in energy intake during the last decade may be the increased consumption of calorically sweetened beverages or other energy-yielding liquids $(2,3)$. There has been an undeniable temporal association between the growing consumption of sweetened beverages and the rise in obesity rates, particularly among adolescents and young adults (4). Physiological mechanisms by which the body senses ingested energy are reported to be less precise for energy contained in liquid beverages as opposed to solid foods $(5,6)$. However, the mechanisms underlying the differences in satiation and satiety responses comparing liquid and solid foods have not been clarified yet. There is some evidence that liquids are more satiating than solids (7-10). For example, Mattes et al. observed that spoon-ingested soup loads (liquefied apple) led to reductions in hunger ratings comparable to those observed in response to the matching solid food (apples) (11). Highest hunger ratings were observed when the liquid food was drunk (apple beverage) (11). Those results support the notion that soups have a higher satiety value than beverages, despite their fluid form.

Opposing those results are studies that demonstrate that solid foods are more satiating than liquids $(6,10-13)$. It is suggested that the higher satiety evoked by solid foods is -at least in part- due to the longer oral exposure time caused by chewing $(12,14)$, while another study suggests that the eating mode of consumption plays a role in the higher satiating value of solids (15). Still other studies did not find differences in the satiation capacity of beverages and solid foods (16).

The comparison of these studies is often difficult due to the use of different or not comparable foods, i.e. foods that differ along other dimensions than texture evoke responses that cannot solely be ascribed to the food form.

Very few studies so far have included physiological parameters to examine the difference in satiety and satiating capacity of liquid and solid foods. Appetite related biomarkers involved in those differences may include ghrelin-, glucose- and insulin. Haber et al. found that with the rate of ingestion equalized, apple juice was significantly less satiating when compared to apple puree, while apple puree was less satiating than whole apples; both puree and juice condition were associated with disturbances in glucose homeostasis (12). Zijlstra et al. found that products with similar palatability, macronutrient composition and energy density but different texture lead to significant differences in intake, with the liquid product being consumed more (14). In contrast to Haber et al., they found no differences in plasma-glucose concentrations (17).

As Lemmens et al. (18) already summarized, possible intra-individual relations between VAS and physiological measurements remain unclear. Some studies show no relation between appetite ratings and ghrelin, glucose or insulin concentrations $(19,20)$, while others do find associations between appetite ratings and ghrelin or insulin concentration 
$(21,22)$. Studies assessing the relationship between appetite and gut-peptides would greatly benefit from the inclusion of the factor time in a within subject approach (1926). While energy requirements differ between subjects due to differences in body size, muscle mass, gender, etc., changes in appetite parameters do not necessarily have to; a subject feels satiated to a certain extent when his/her subject specific energy requirement is met to a certain extent. This illustrates, why possible relationships between appetite ratings and changes in glucose- and gut-hormone concentrations should be assessed intra-individually when investigating the relationship of appetite ratings and gut peptides. Taken together, due to the use of a mixture of macronutrients or hardly comparable foods it has been difficult to discriminate between satiating effects of liquid and solid food-textures in the past. Furthermore, the lack of an intra-individual approach to assess the relationship between appetite ratings and physiological measurements made it difficult to explain differences in texture induced satiety.

Therefore, the objective of our study was to investigate differences in appetite profile and in relevant physiological parameters and to study the within-subject relationships between both, comparing a liquefied and solid carbohydrate meal.

\section{METHODS AND PROCEDURES}

\section{ETHICS STATEMENT}

This study was conducted according to the guidelines laid down in the Declaration of Helsinki and the Medical Ethical Committee of Maastricht University approved all procedures involving human subjects. All subjects were informed on the purpose, procedures and potential risks of the study. Written informed consent was obtained from all subjects.

\section{PARTICIPANTS}

Participants were recruited by advertisements in local newspapers and on notice boards at Maastricht University, the Netherlands. Eleven subjects underwent an initial screening including body weight and height measurements and completed a questionnaire related to medical history, smoking behavior, alcohol consumption, eating behavior and physical activity. Ten healthy male subjects qualified for participation in this study. Power calculation was based on results of related studies. Assuming a mean difference of 14 for satiety ratings, as well as a standard deviation of 14 calculations showed that with an $\alpha$ of 0.05 (power $=1-\beta=0.80$ ), at least 10 subjects were needed. Glucose and insulin concentrations were utilized for power calculation in addition to satiety ratings (12). All subjects were identified as normal breakfast and lunch consumers. Subject characteristics can be found in Table 1. 
Table 1. Participant characteristics.

\begin{tabular}{ll} 
Characteristics & Mean \pm SD \\
\hline Male $(\mathrm{n})$ & 10 \\
Age (years) & $21.1 \pm 1.3$ \\
Height $(\mathrm{cm})$ & $178.5 \pm 1.2$ \\
Weight $(\mathrm{kg})$ & $71.5 \pm 1.7$ \\
Waist circumference $(\mathrm{cm})$ & $77.9 \pm 1.1$ \\
Hip circumference $(\mathrm{cm})$ & $86.2 \pm 2.1$ \\
$\mathrm{BMI}^{1}$ & $22.4 \pm 0.4$ \\
$\mathrm{BMR}^{2}$ & $7531.6 \pm 29.5$ \\
\hline
\end{tabular}

${ }^{1}$ Body Mass Index $=$ weight $(\mathrm{kg}) /$ height $(\mathrm{m})^{2}$

${ }^{2}$ Basal Metabolic Rate ( $\mathrm{JJ} /$ day) calculated according to the equation of Harris-Benedict (27)

\section{EXPERIMENTAL DESIGN}

The experimental design of the study is depicted in Figure 1. The study was conducted in a within-subject, randomized, crossover design. Subjects came to the university twice. Visits were separated by one week. On the day before the trial and during the trial, they were not allowed to consume alcohol or to engage in heavy exercise. On the morning of the test day subjects consumed a predetermined amount of a fluid breakfast at home. After this, subjects were not allowed to eat or drink anything (except water) until arrival at the university at 12 PM. Upon arrival an intra-venous catheter (IV) was inserted for blood sampling. At 12:30 PM, a baseline blood sample for the measurement of plasma insulin, glucose and active ghrelin concentrations was drawn. At 12:40 PM subjects received a subject-specific (based on individual energy requirements) lunch composed of carbohydrates in a solid or liquefied texture, which they had to consume within 20 min. After lunch, twelve blood samples were drawn for the measurement of plasma insulin, glucose and active ghrelin concentrations. At 4 PM, the catheter was removed and subjects were free to leave the laboratory.

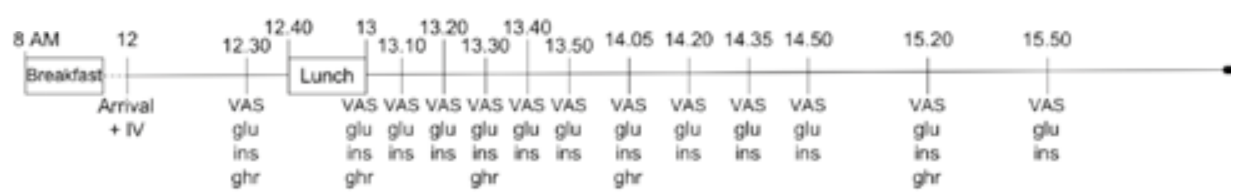

Figure 1. Timeline representing the study design. VAS = visual analog scales on appetite, IV = Intravenous catheter placement, glu = glucose blood sample, ins = insulin blood sample, ghr = active ghrelin blood sample. 


\section{MEALS}

\section{BREAKFAST}

Subjects had to consume a prescribed breakfast at home, composed of a commercially available breakfast drink called 'Goedemorgen' (Campina, The Netherlands). The amount prescribed was based on $20 \%$ of the subjects' daily energy requirement (DER), which corresponded to a mean intake \pm SEM of $2636.1 \pm 43.2 \mathrm{~kJ}$ and $840.1 \pm 13.8 \mathrm{ml}$. Daily energy requirements were calculated individually for each of the recruited subjects by multiplying basal metabolic rate (BMR) with the appropriate physical activity factor (1.5-1.8), derived from the Baecke screening questionnaire (28). The BMR (kJ/day) was calculated according to the equation of Harris-Benedict (27) (Table 1).

\section{LUNCH}

Lunch consisted of one of the following two conditions presented to the participant in random order; solid carbohydrate (CS): whole, peeled peaches or liquefied carbohydrate (CL): blended peeled peaches. Peaches consisted of $54 \%$ sucrose, $31 \%$ fructose, and $15 \%$ glucose (29). The energy content of these meals was subject-specific and controlled for energy density, weight and volume. The solid meal consisted of food and $750 \mathrm{ml}$ water to drink; the liquefied meal consisted of food mixed with $500 \mathrm{ml}$ water and $250 \mathrm{ml}$ water to drink.

The amount of lunch was based on $15 \%$ of DER, using the equation of Harris-Benedict and the appropriate physical activity factor $(27,28)$. This resulted in a lunch with a mean \pm SEM energy content of $1977.6 \pm 32.4 \mathrm{~kJ}$ and a mean \pm SEM weight of $727.0 \pm 11.9$ grams. The solid meal had to be eaten with knife and fork and the liquefied meal had to be eaten with a spoon in order to equalize rate of ingestion and oral exposure time. All subjects had to finish their meal within $20 \mathrm{~min}$.

The meals were rated for palatability before consumption using visual analogue scales (VAS) by an independent panel of 12 subjects. This panel, was asked how palatable the foods were, after thoroughly experiencing their taste and texture. Palatability was rated on a 100 mm VAS, anchored with 'not palatable at all' and 'extremely palatable'.

\section{APPETITE PROFILE}

One hundred mm VAS were used to assess the appetite profile at baseline, and before every blood sample (30). The scales were anchored with opposing extremes of feelings of fullness, desire to eat and thirst. Subjects were instructed to make a single vertical mark at the appropriate point between the two anchors on each scale to indicate their subjective feelings. These VAS were completed at thirteen time points (at $10 \mathrm{~min}$ before the start of the lunch and at $20 \mathrm{~min}, 30 \mathrm{~min}, 40 \mathrm{~min}, 50 \mathrm{~min}, 60 \mathrm{~min}, 70 \mathrm{~min}, 85 \mathrm{~min}, 100$ $\mathrm{min}, 115 \mathrm{~min}, 130 \mathrm{~min}, 160 \mathrm{~min}$, and $190 \mathrm{~min}$ after the start of the lunch). All VAS were completed before blood sampling in order to prevent mutual effects. 


\section{BLOOD SAMPLING}

At the beginning of the test session, 40 min before lunch was served (12 PM), a polytetrafluoroethylene catheter was placed in the antecubital vein for blood sampling $\left(B D\right.$ Venflon ${ }^{\mathrm{TM}}$ ). During each test day, a baseline blood sample was drawn 10 min before the start of the lunch (at -10 min). Subsequently, twelve more blood samples were drawn after the start of the lunch (at $20 \mathrm{~min}, 30 \mathrm{~min}, 40 \mathrm{~min}, 50 \mathrm{~min}, 60 \mathrm{~min}, 70 \mathrm{~min}, 85 \mathrm{~min}$, $100 \mathrm{~min}, 115 \mathrm{~min}, 130 \mathrm{~min}, 160 \mathrm{~min}$, and $190 \mathrm{~min}$ ) for the measurement of plasma insulin, and glucose concentrations. A blood sample for active ghrelin was drawn (3 $\mathrm{ml})$ five times (at -10 min, $20 \mathrm{~min}, 50 \mathrm{~min}, 85 \mathrm{~min}, 160 \mathrm{~min}$ ). Blood samples were collected in tubes containing EDTA (BD vacutainer with EDTA, $10 \mathrm{ml}$ ) to prevent clotting. Blood plasma was obtained by centrifugation ( $4^{\circ} \mathrm{C}, 3000$ r.p.m., $20 \mathrm{~min}$ ). All samples were frozen and stored at $-80{ }^{\circ} \mathrm{C}$ until further analysis. Plasma glucose concentrations were analyzed enzymatically by using the hexokinase method (ABX Diagnostics, Montpellier, France); the coefficient of variation (CV) was 0,63\%. Plasma insulin concentrations were determined in our own laboratory by means of RIA according to the manufacturer's instructions (Human insulin-specific RIA kit, Millipore, Billerica, Massachusetts, USA); the CV was $3,68 \%$. Plasma concentrations of active ghrelin were measured in our own laboratory by means of radioimmuno assay (RIA) (Human ghrelin (active)-specific RIA kit, Millipore, Billerica, Massachusetts, USA); the CV was 3,70\%. Plasma active ghrelin concentrations were measured in acidified plasma with $50 \mu \mathrm{l}$ of $1 \mathrm{~N} \mathrm{HCL}$ and addition of $10 \mu \mathrm{l}$ of phenylmethylsulfonyl fluoride per $1 \mathrm{ml}$ of plasma.

\section{STATISTICS}

Data were analyzed using StatView 5.0 (SAS Institute Inc., Cary, NC, USA). Areas under the curve were calculated using the trapezoidal method. Differences over time and between conditions (liquefied and solid) were determined using two-factor analysis of variance (ANOVA) with repeated measures. A student's T-test was used to determine the differences between textures at all time points and for the AUC. Following the method previously described by Lemmens et al. (18) the magnitude of the within-subject relationship between changes in VAS scores and blood values were assessed. This method entails the calculation of regression slopes and the regression between VAS scores and blood values for each subject separately, for the corresponding measuring moments (fullness vs. glucose concentrations, fullness vs. insulin concentrations and desire to eat vs. active ghrelin concentrations). After that it is tested if the means of the regression slopes are significantly different from zero (Student's one-sample t-tests) and thus whether the relationships between VAS scores and blood parameter concentrations are statistically significant. Paired Student's t-tests were used to test whether the observed slopes and $\mathrm{R}^{2}$ values differed between meal conditions. All tests were two-sided and differences were considered significant at $p<0.05$. Values are expressed as mean \pm standard error of the mean (SEM). 


\section{RESULTS}

Measured oral exposure time in the solid and the liquefied condition was not statistically different (19.0 $\pm 0.3 \mathrm{~min}$ and $18.3 \pm 0.3 \mathrm{~min}$ respectively, $\mathrm{p}=0.14)$.

No statistically significant differences between the palatability ratings of the CS meal (62 $\pm 4 \mathrm{~mm}$ VAS) and the CL meal (62 $\pm 3 \mathrm{~mm}$ VAS) were observed based on the panel ratings preceding the experiment.

\section{APPETITE RATINGS}

After lunch fullness ratings significantly increased and desire to eat and thirst ratings significantly decreased over time $(p<0.0001)$. Peak or nadir of the ratings occurred at the end of the lunch, 20 min after the start (Figure 2).

There were no statistically significant condition $x$ time interactions for any of the appetite ratings, except for thirst $(p<0.03)$. Moreover, the $A \cup C$ for the appetite ratings were not different between conditions, except for the thirst ratings where the AUC for thirst was higher in the liquefied condition compared to the solid condition $(p<0.05)$. Fullness was rated higher in the CL condition $(85 \pm 5 \mathrm{~mm})$ compared to the CS condition $(73 \pm 8 \mathrm{~mm})$, 20 min after the start of the lunch $(p<0.03)$, when subjects finished eating. Thirst ratings were higher in the CL condition than in the CS condition at 100, 130 and 160 min after the start of the lunch $(p<0.03)$.

\section{BLOOD PARAMETERS}

Blood parameters are represented in Figure 2. Time was a significant factor for all blood parameters $(p<0.0001)$. After consumption of the lunch, glucose concentrations peaked 20-30 min after the start of the lunch in the CL condition $(5.9 \pm 0.3-6.3 \pm 0.6 \mathrm{mmol} / \mathrm{ml})$. In the CS condition glucose concentrations peaked at 30-40 min after the start of the lunch $(6.3 \pm 0.6-6.2 \pm 0.6 \mathrm{mmol} / \mathrm{ml})$. Insulin concentrations peaked $20-30 \mathrm{~min}$ after the start of the lunch in the CL condition (47.8 $\pm 6.7-50.9 \pm 6.6 \mathrm{uU} / \mathrm{ml})$ and $30-40 \mathrm{~min}$ after the start of the lunch in the CS condition (56.6 $\pm 7.3-58.1 \pm 5.4 \mathrm{uU} / \mathrm{ml})$. AUC's of glucose- and of insulin concentrations were not significantly different between conditions and there was no statistically significant condition $\mathrm{x}$ time interactions. Insulin concentrations were significantly higher in the CS condition compared to the CL condition at 40 min after the start of the lunch $(p<0.05)$. Active ghrelin concentrations were similar for both conditions; there was no statistically significant condition $x$ time interaction and the AUC was not significantly different between the conditions.

\section{RELATIONSHIPS BETWEEN APPETITE RATINGS AND BLOOD PARAMETERS}

Following the method by Lemmens et al. (18) physiological intra-individual significant relationships between VAS scores and blood values were assessed, as described in the statistics section (Figure 3). Relationships were assessed for fullness vs. insulin 
concentrations, for desire to eat vs. active ghrelin concentrations and for fullness vs. glucose concentrations. There were no statistically significant differences between the slopes or the $\mathrm{R}^{2}$ values comparing meal conditions. The relationship between fullness scores and insulin concentrations was significant in both the $C L$ (slope $=0.8 \pm 0.1, p<0.0005$, $R^{2}=0.4 \pm 0.1$ ) and the CS condition (slope $=0.6 \pm 0.2, p<0.005, R^{2}=0.4 \pm 0.1$ ). Similarly, the relationship between 'desire to eat' scores and ghrelin concentrations was significant in the $\mathrm{CL}$ (slope $=0.9 \pm 0.4, p<0.05, R^{2}=0.3 \pm 0.1$ ) as well as in de $C S$ condition (slope $=0.7 \pm 0.3$, $\left.p<0.05, R^{2}=0.3 \pm 0.1\right)$. Fullness scores were not related to glucose concentrations in neither condition (CL: slope $=4.2 \pm 3.2, p=0.2$; $C S$ : slope $=0.6 \pm 4.2, p=0.9)$.
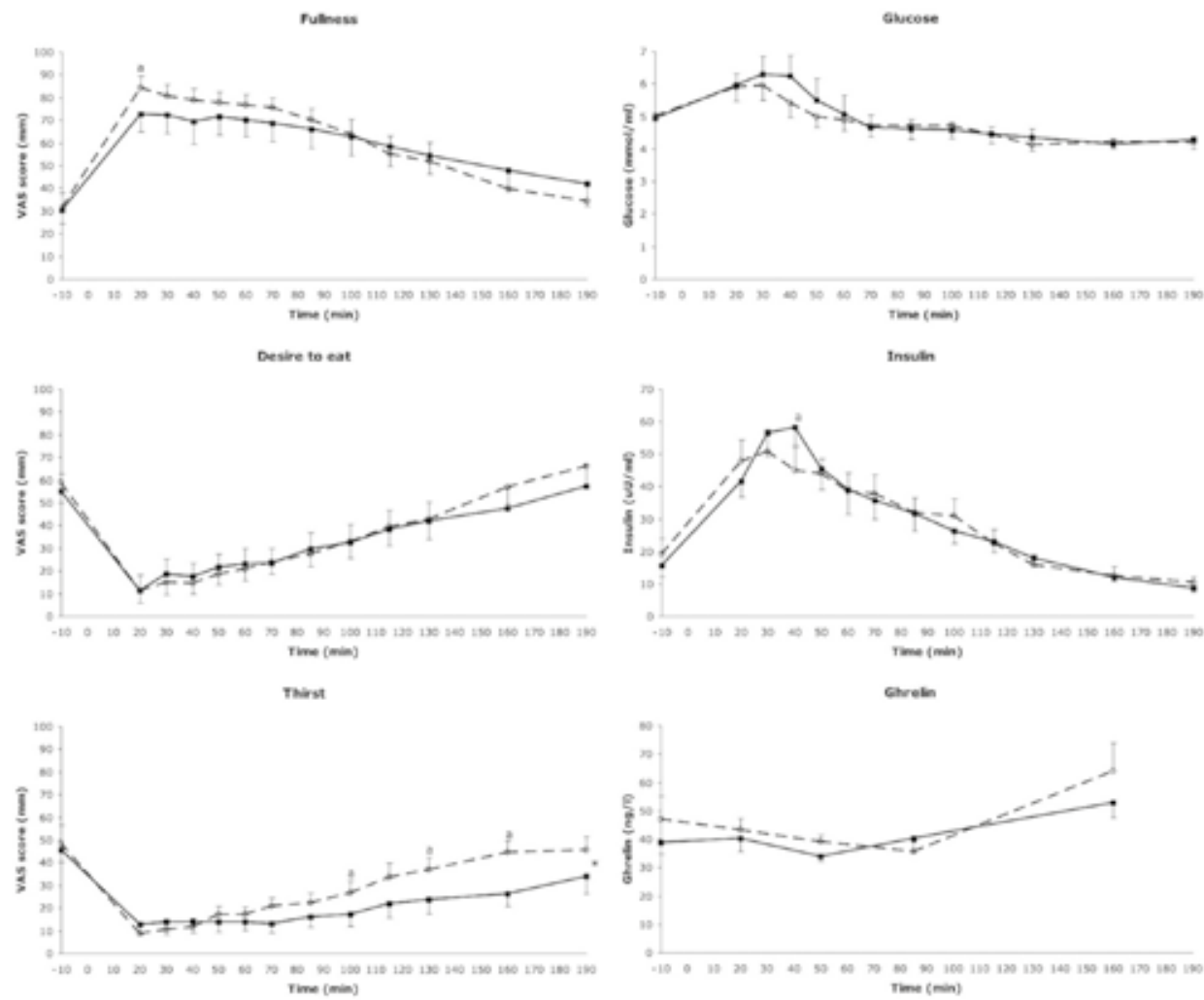

Figure 2. Appetite profiles and blood values. On the left: mean $( \pm$ SEM) visual analog scale scores for the appetite profiles; hunger, fullness, hunger suppression, desire to eat and thirst for the solid $(-\mathbf{-}-)$ and the liquefied (-O-) condition. On the right: mean $( \pm$ SEM) plasma glucose, insulin and active ghrelin concentrations for the solid (- - ) and the liquefied (- $\bigcirc-)$ condition. ${ }^{\text {a }}$ Indicates a significant difference between the solid and the liquefied condition at that time point $(p<0.05)$. Indicates significant condition $x$ time interactions $(p<0.03)$. 

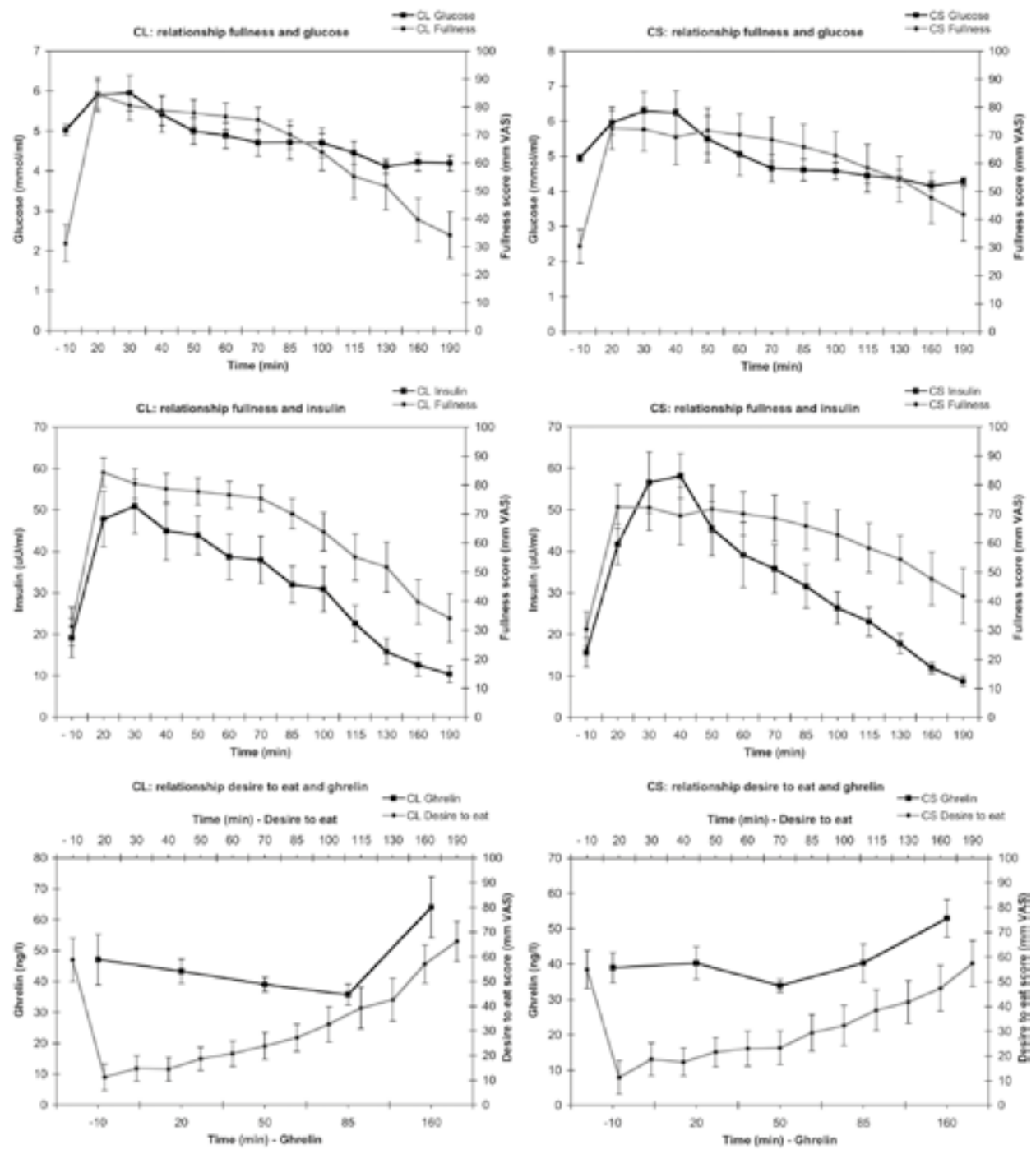

Figure 3. Visual representation of the relationships between the blood values (-口-) and the visual analog scales (VAS, - - ) in the liquefied (CL) and the solid (CS) conditions.

\section{DISCUSSION}

The objective of this study was to investigate the relationship of appetite and physiological parameters comparing a carbohydrate meal in liquefied versus solid form, while the meal was controlled for energy density, weight and volume.

Specific attention was given to the within-subject relationships of appetite parameters 
and glucose-, insulin- and active ghrelin-concentrations. The current study addresses controversies in the existing literature by:

1) giving the same foods in solid and liquefied form with the same amount of total water ( $750 \mathrm{ml}$ to drink; or $500 \mathrm{ml}$ homogenized $+250 \mathrm{ml}$ to drink);

2) utilizing a subject specific design in which subjects received an amount of food bases in their daily energy requirements.

Due to the study design, VAS were controlled for energy requirement and did reflect differences between conditions rather than between subjects. Moreover, when comparing the change in VAS appetite scores with changes in blood parameter concentrations, a statistical approach was used to analyze the possible within subject relationships of these dynamics, including the factor time.

The present study did not find any significant differences in peak-values, AUC or condition $\mathrm{x}$ time interactions for fullness and desire to eat. Although insulin reached a significantly lower value in the CL condition at $40 \mathrm{~min}$ after the start of the lunch, no significant differences were found for any of the blood parameters comparing AUC's and no condition $x$ time interactions were found. Based on those results, the liquefied carbohydrate meal and the solid carbohydrate meal can be considered as equally satiating, supported by a lack of differences in appetite and relevant blood parameters. However, despite that overall conclusion, 20 minutes after the start of the lunch, fullness ratings were higher in the liquefied condition compared to the solid condition. A possible explanation for this effect may be that homogenization can influence gastric emptying and thereby increase satiation and satiety ratings more than the fluid and solid components served separately $(9,31)$. For example, Santangelo et al. evaluated the effects of the same meal in solid-liquid and in homogenized form on satiety and gastric emptying rate (31). They found that a vegetable-rich meal was significantly more satiating in a homogenized form than in a solid-liquid state, probably due to a change in gastric emptying time when the food was consumed in the homogenized form $(9,10$, $31)$. In the current study, a separation of liquid and fluid components for gastric transit may have contributed the delayed peak in glucose and insulin concentrations and the higher insulin concentration in the solid condition compared to the liquefied condition, 40 minutes after the start of the lunch.

The within-subject analysis showed corresponding changes in VAS and insulin and ghrelin concentrations. Desire to eat scores and active ghrelin concentrations declined at the same time, and showed a significant relationship in both meal conditions.

Fullness scores and insulin concentrations increased in parallel and showed a significant relationship in both meal conditions, implying a role for insulin in fullness perception. In a meta-analysis, Flint et al. already showed that the postprandial insulin response is associated with a decrease in hunger and increases in satiety ratings (22). In contrast to our study results, Zijlstra et al. found that a semi-solid product appeared to be more satiating than a liquid product. However, that finding was not substantiated by a difference 
in glucose, insulin or ghrelin concentrations (17). Similar to our results, Haber et al., found similar increases in plasma-glucose concentrations independent of condition and comparable increases in insulin concentrations after fast puree and apples (12).

Studies comparing solid or semi-solid foods often explain their differences in appetite scores by; 1 ) the need to chew fiber (12) or 2) a longer oral exposure time (32). The difference with our study is thus the lack of fiber in peeled peaches and the lack of significant differences in oral processing time. The results of our appetite scores in response to the conditions are similar to those of Mattes et al. who found a similar reduction in hunger and increase in fullness in a liquefied meal (11).

Thirst was higher in the liquefied condition as shown by AUC and condition $\mathrm{x}$ time interaction. Previous research already showed that drinking water separately with the meal vs. water consumption in the food suppressed thirst more (15). When thirst is not quenched by water in the meal, this could be due to a different mouth feel, which leads to secondary thirst as described according to Fitzsimons $(33,34)$.

Although our analyses of regression slopes and $\mathrm{R}^{2}$ values showed a relationship between VAS appetite scores and insulin and ghrelin concentrations, the mean explained variation was low (35\%). Therefore, we conclude that this relationship is not applicable as a biomarker to the individual level. However, the magnitude of this correlation is sufficient to discriminate intervention-related satiating effects at a group-level.

From a methodological point of view it would have been interesting to additionally use a peach juice as a liquid meal, similar to the use of apple juice in the paper of Mattes et al. (11). As described in the introduction, they observed the weakest satiety effect in the liquid condition (apple beverage). However, in a drinking condition not only the texture is different but also the mode of consumption, therefore it is difficult to disentangle the cause of observed differences in satiation capacity (15). The lack of differences in the appetite profile between the liquefied and solid condition in the current study could also be macronutrient specific. Previous studies reported that solid protein evokes a stronger suppression of hunger and desire to eat compared to liquefied or liquid protein $(35,36)$. Based on the current results it can be concluded that liquefied and solid carbohydrate meals do not differ in their satiating effects, as evidenced by the lack of differences in appetite profile and relevant blood parameters. Postprandially, fullness and desire to eat were associated with respectively insulin and ghrelin concentrations.

\section{ACKNOWLEDGEMENTS}

We thank our subjects for their participation in this study. Furthermore, we thank J. Stegen for analyzing the plasma samples and Dr. T.C. Adam for editing the English text of the manuscript. The study was designed by MSWP and MJIM. MJIM, supervised by MSWP, carried out the study, collected and analyzed the data and wrote the largest part of the manuscript. SGTL and JMB reviewed the manuscript. None of the authors has any 
conflict of interest. No funding was received.

\section{REFERENCES}

1. Joosen A, Westerterp K. Energy expenditure during overfeeding. Nutrition \& Metabolism 2006;3:25.

2. Olsen NJ, Heitmann BL. Intake of calorically sweetened beverages and obesity. Obesity Reviews 2008;10:68-75.

3. Malik VS, Schulze MB, Hu FB. Intake of sugar-sweetened beverages and weight gain: a systematic review. Am J Clin Nutr 2006;84:274-288.

4. Flegal KM, Carroll MD, Ogden CL, Curtin LR. Prevalence and Trends in Obesity Among US Adults, 1999-2008. JAMA;303:235-241.

5. Mattes RD. Dietary Compensation by Humans for Supplemental Energy Provided as Ethanol or Carbohydrate in Fluids. Physiology \& Behavior 1996;59:179-187.

6. DiMeglio DP, Mattes RD. Liquid versus solid carbohydrate: effects on food intake and body weight. Int J Obes Relat Metab Disord 2000;24:794-800.

7. Kissileff HR. Effects of physical state (liquid-solid) of foods on food intake: procedural and substantive contributions. Am J Clin Nutr 1985;42:956-965.

8. Rolls BJ, Bell EA, Thorwart ML. Water incorporated into a food but not served with a food decreases energy intake in lean women. Am J Clin Nutr 1999;70:448-455.

9. Himaya A, Louis-Sylvestre J. The Effect of Soup on Satiation. Appetite 1998;30:199-210.

10. Almiron-Roig E, Chen Y, Drewnowski A. Liquid calories and the failure of satiety: how good is the evidence? Obesity Reviews 2003;4:201-212.

11. Mattes R. Soup and satiety. Physiology \& Behavior 2005;83:739-747.

12. Haber GB, Heaton KW, Murphy D, Burroughs LF. Depletion and disruption of dietary fibre: effects on satiety, plasma-glucose, and serum-insulin The Lancet 1977;310:679-682.

13. Tournier A, Louis-Sylvestre J. Effect of the physical state of a food on subsequent intake in human subjects. Appetite 1991;16:17-24.

14. Zijlstra N, Mars M, de Wijk RA, Westerterp-Plantenga MS, de Graaf C. The effect of viscosity on ad libitum food intake. Int J Obes 2007;32:676-683.

15. Martens MJI, Westerterp-Plantenga MS. Mode of Consumption Plays a Role in Alleviating Hunger and Thirst. Obesity 2011 ; In press.

16. Almiron-Roig E, Flores SY, Drewnowski A. No difference in satiety or in subsequent energy intakes between a beverage and a solid food. Physiology \& Behavior 2004;82:671-677.

17. Zijlstra N, Mars M, de Wijk RA, Westerterp-Plantenga MS, Holst JJ, de Graaf C. Effect of viscosity on appetite and gastro-intestinal hormones. Physiology \& Behavior 2009;97:68-75.

18. Lemmens SG, Martens EA, Kester AD, Westerterp-Plantenga MS. Changes in gut hormone and glucose concentrations in relation to hunger and fullness. The American Journal of Clinical Nutrition 2011;94:717-25.

19. Maffeis C, Surano MG, Cordioli S, Gasperotti S, Corradi M, Pinelli L. A High-fat vs. a Moderate-fat Meal in Obese Boys: Nutrient Balance, Appetite, and Gastrointestinal Hormone Changes. Obesity 2009;18:449-455.

20. Smeets AJ, Soenen S, Luscombe-Marsh ND, Ueland ñ, Westerterp-Plantenga MS. Energy Expenditure, Satiety, and Plasma Ghrelin, Glucagon-Like Peptide 1, and Peptide Tyrosine-Tyrosine Concentrations following a Single High-Protein Lunch. The Journal of Nutrition 2008;138:698-702.

21. Erdmann J, Hebeisen Y, Lippl F, Wagenpfeil S, Schusdziarra V. Food intake and plasma ghrelin response during potato-, rice- and pasta-rich test meals. European Journal of Nutrition 2007;46:196- 
203.

22. Flint A, Gregersen N, Gluud L, et al. Associations between postprandial insulin and blood glucose responses, appetite sensations and energy intake in normal weight and overweight individuals: a meta-analysis of test meal studies. British Journal of Nutrition 2007;98:17-25.

23. Adam T, Westerterp-Plantenga M. Nutrient-stimulated GLP-1 release in normal-weight men and women. Horm Metab Res 2005;37:111-7.

24. Diepvens K, Haberer D, Westerterp-Plantenga M. Different proteins and biopeptides differently affect satiety and anorexigenic/orexigenic hormones in healthy humans. Int $\mathrm{J}$ Obes 2007;32:510-518.

25. Guo Y, Ma L, Enriori PJ, et al. Physiological Evidence for the Involvement of Peptide YY in the Regulation of Energy Homeostasis in Humans[ast]. Obesity 2006;14:1562-1570.

26. le Roux CW, Batterham RL, Aylwin SJB, et al. Attenuated Peptide YY Release in Obese Subjects Is Associated with Reduced Satiety. Endocrinology 2006;147:3-8.

27. Harris JA, Benedict FG. A Biometric Study of Human Basal Metabolism. Proc Natl Acad Sci 1918;4:370-3.

28. Philippaerts RM, Westerterp KR, Lefevre J. Doubly Labeled Water Validation of three Physical Activity Questionnaires. Int J Sports Med 1999;20:284-289.

29. Byrnel D, Nikolic A, Burns E. Variability in Sugars, Acids, Firmness, and Color Characteristics of 12 Peach Genotypes. J. AMER. Soc. HORT. SCI. 1991;116:1004-1006.

30. Flint A, Raben A, Blundell JE, Astrup A. Reproducibility, power and validity of visual analogue scales in assessment of appetite sensations in single test meal studies. nt $\mathrm{J}$ Obes Relat Metab Disord. 2000;24:38-48.

31. Santangelo A, Peracchi M, Conte D, Fraquelli M, Porrini M. Physical state of meal affects gastric emptying, cholecystokinin release and satiety. Br J Nutr 1998;80:521-7.

32. Zijlstra N, de Wijk R, Mars M, Stafleu A, de Graaf C. Effect of bite size and oral processing time of a semisolid food on satiation. Am J Clin Nutr 2009;90:269-275.

33. Fitzsimons JT. The hypothalamus and drinking. Br Med Bull 1966;22:232-237.

34. $\quad$ Fitzsimons JT. Thirst. Physiol. Rev. 1972;52:468-561.

35. Martens MJ, Lemmens SG, Born JM, Westerterp-Plantenga MS. A solid high-protein meal evokes stronger hunger suppression than a liquefied high-protein meal. Obesity 2011;19:522-7.

36. Mourao DM, Bressan J, Campbell WW, Mattes RD. Effects of food form on appetite and energy intake in lean and obese young adults. Int J Obes 2007;31:1688-95. 


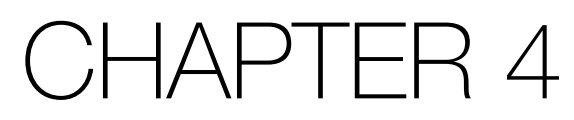

\section{MODE OF CONSUMPTION PLAYS A ROLE IN ALLEVIATING HUNGER AND THIRST}

Martens MJ, Westerterp-Plantenga MS.

Obesity 2012;20(3):517-524 


\section{ABSTRACT}

While studying the effect of structure on satiety, effects of mode of consumption, additional water to drink and thirst have been neglected. The objective was to assess effects of structure, mode of consumption of food, and additional drinking of water on fullness and thirst. In study 1 twenty subjects (BMI $22.5 \pm 0.5 \mathrm{~kg} / \mathrm{m}^{2}$; age $21.4 \pm 3 \mathrm{yrs}$ ), underwent consumption conditions; SEW: Solids to Eat $+750 \mathrm{ml}$ Water to drink; LEW: Liquefied soup to Eat including $500 \mathrm{ml}$ water $+250 \mathrm{ml}$ Water separately to drink; LDW: the same as LEW but served as drinks; SE, LE, and LD: the same as previous but without water to drink. In study 2 a subset of subjects underwent consumption conditions: Solid Carbohydrate, Solid Protein, Solid Fat: the same as SEW, but for each macronutrient separately; Liquified Carbohydrate, Liquified Protein, Liquified Fat:the same as LEW, but for each macronutrient separately. Appetite, insulin-, glucose- and ghrelin-concentrations were measured.

Eating, independently of structure, suppressed desire to eat more than drinking $(p<0.01)$. Drinking water separately vs. water consumption in the food suppressed thirst more $(p<0.001)$. Regarding protein, satiety was higher in the solid vs. liquefied condition, while blood parameters were not significantly different. Only after drinking a meal most subjects $(80 \%)$ wanted to consume more of the same meal, in order to alleviate hunger (63\%) or quench thirst (37\%).

We conclude that mode of consumption plays a role in alleviating hunger and thirst. Subjects required further consumption after drinking the meal, motivated by hunger or thirst, showing that drinking a meal causes confusion that may imply a risk of overconsumption. 


\section{INTRODUCTION}

Functional foods designed for weight loss are often available in liquid and solid structures (shakes and bars). The effect structure of food on satiety and energy intake has already been extensively researched (1-13). However, the effect of mode of consumption and additional water to drink on hunger and thirst has been neglected when comparing different structures.

Foods may be differentiated from beverages based on physical form, however a classification on this basis may be modified by mode of consumption (eating or drinking). The same consumption can be classified as a drink or as a soup depending on the delivery to the oral cavity by a particular vessel (e.g., glass, mug or bowl) or utensil (e.g. spoon or straw).

Structure seems to play an important role in food intake regulation. It has been shown that liquid foods elicit weaker suppressive appetite responses and a weaker compensatory response in energy intake than solid or semi-solid foods $(1,2,7,13,14)$. Some of these studies suggest that the higher satiety evoked by solid foods, when compared with liquid foods, at least partly, depends on the need to chew, which causes longer oral exposure time $(2,11,12)$. Other studies show that liquids are more satiating than solids, however, these studies use a soup to consume liquids in comparison to a solid meal preload $(1,5$, 15). While there are compelling data that energy-yielding beverages have weak satiety properties $(1,2,7,13,14)$, the opposite has been noted in several studies of $\operatorname{soup}(1,3$, $4,6,15)$. For example, Kissileff et al. studied the effect of two equicaloric preloads (115 kcal) on subsequent intake and found that a tomato soup preload reduced subsequent intake of a second course more than did cheese on crackers plus apple juice (5). This confirms that soups have a higher satiety value than drinks despite their fluid form and that soup has to be differentiated from beverages. Several researchers have proposed that cognitive factors likely contribute to the high satiety value of soups $(13,15)$. Soup does not only imply a mode of consumption different from a drink, but may also be viewed as a meal component ingested to address sensations of hunger as compared to a beverage, which is used to satisfy thirst (6).

Thirst is a subjective perception that provides the urge for humans and animals to consume fluids (16). It is a physiological state that is often difficult to diagnose but a system that is very finely controlled (17). From a purely physiological point of view the regulation of thirst is absolutely necessary for the correct functioning of our "milieu intérieur" (18), yet despite this humans appear to respond inappropriately to thirst signals (17). This inappropriate reaction may have undesirable consequences related to overweight and obesity (17).

Approaching hunger, which is related to eating, and thirst, which is related to drinking, at the same time is complicated. Eaten foods contain water (19) and generate water endogenously during their metabolism, while on the other hand, drinking certain 
beverages provides energy (20) and essential nutrients. This shows that the principles of eating foods or drinking beverages may exert effects contributing vice versa, namely to water- and nutrient-ingestion respectively. Here the mode of consumption is not straightforwardly in line with the expected functions (21). The question remains whether physiological consequences may differ according to the mode of consumption.

Our research question focuses upon the behavioral and physiological consequences of mode of consumption, structure, and thirst. In order to assess effects of structure more thoroughly, we assessed structure effects within the same mode of consumption (eating and not drinking) for each macronutrient separately. From the literature it appears that mainly mixed macronutrient meals have been tested in this respect (1). For single macronutrients emphasize has been on carbohydrate $(2,14,22)$ and only 1 study assessed effects of structure in single macronutrient meals for each macronutrient separately (6). Since the results of the study by Mattes et al. have not been confirmed yet, we also addressed the research question for each macronutrient separately.

\section{METHODS AND PROCEDURES}

\section{SUBJECTS}

Subjects were recruited by advertisements in local newspapers and on notice boards at Maastricht University, the Netherlands. Twenty-one subjects underwent an initial screening including body weight and height measurements and completed a questionnaire related to medical history, smoking behavior, alcohol consumption and physical activity. Twenty healthy male subjects (age $21.4 \pm 3 \mathrm{yrs}$; height $180.5 \pm 3 \mathrm{~cm}$; body-weight $73.1 \pm 3 \mathrm{~kg}$; waist $79.2 \pm 1 \mathrm{~cm}$; hip $87.1 \pm 2 \mathrm{~cm}$; BMI $22.5 \pm 0.5 \mathrm{~kg} / \mathrm{m}^{2}$ ) qualified for participation in the study; a random subset of 10 men (age: $21.1 \pm 3.9 \mathrm{y}$; BMI: $22.4 \pm 1.2$ $\mathrm{kg} / \mathrm{m}^{2}$ ) participated in the second study. According to a possible difference in satiety scores of 14 and a standard deviation of 14 power analysis showed that with an $\alpha$ of 0.05 and $\beta$ of 0.20 (power $=1-\beta=0.80$ ), at least 10 subjects were needed (2). The research procedures followed were in accordance with the Helsinki Declaration and were approved by the Medical Ethical Committee of Maastricht University. All subjects were informed on the purpose, procedures and potential risks of the study prior to signing the informed consent.

\section{EXPERIMENTAL DESIGN}

The study was conducted following a within-subject, randomized, crossover design. The timeline of both studies is provided in Figure 1. Subjects came to the university six times, once a week, at a fixed day each week. In both studies they arrived at 8 AM for their pre-determined amount of a commercially available breakfast drink ('Goedemorgen', Campina) that comprised $20 \%$ of their subject-specific daily energy requirement (DER). 


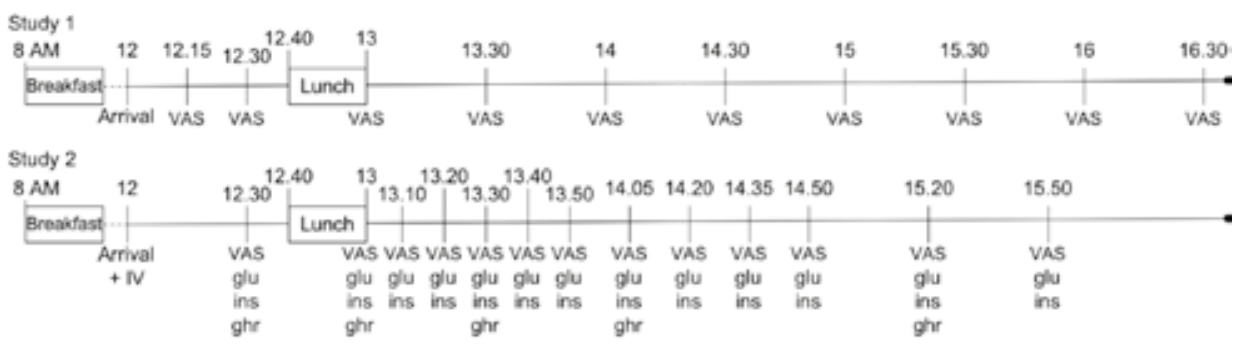

Figure 1. Timeline representing the study design. VAS = visual analog scales on appetite, IV = Intravenous catheter placement, glu = glucose blood sample, ins = insulin blood sample, ghr = ghrelin blood sample.

After this, subjects were not allowed to eat or drink anything until their next arrival at 12 PM. Only in study 2 an intra-venous catheter (IV) was inserted for blood sampling upon arrival. In both studies subjects got there subject-specific lunch at 12:40 PM, which comprised $15 \%$ of their DER (mean \pm SD for all subjects: $1977.4 \pm 102.4 \mathrm{~kJ}$ ). DER were calculated individually for each of the recruited subjects by multiplying basal metabolic rate (BMR) by the appropriate physical activity factor derived from the Baecke screening questionnaire (mean for all subjects: 1.5-1.8) (23). The BMR was calculated according to the equation of Harris-Benedict (mean \pm sd for all subjects: $7531.6 \pm 390.0 \mathrm{~kJ} /$ day) (24). Time of consumption was used as a proxy for measured oral exposure time and was calculated as the time needed to consume the lunch (11).

\section{MEALS}

In study 1 lunch consisted of one of the following six conditions in random order: SEW: a Solid fruit salad consisting of apples, raw apricots and bananas, offered on a plate, to be Eaten with a fork and $750 \mathrm{ml}$ Water, offered in glasses to drink; LEW: a Liquefied cold soup of the same fruit mixture, now blended with $500 \mathrm{ml}$ water, offered in a bowl, to be Eaten with a spoon and $250 \mathrm{ml}$ Water, offered in a glass to drink; LDW: a Liquefied cold Drink of the same fruit mixture, again blended with $500 \mathrm{ml}$ water, this time offered in a glass, to drink and $250 \mathrm{ml}$ Water offered in a glass, to drink separately. The last three conditions; SE, LE and LD, were the same as the previous three but without the separate water to drink.

In study 2 lunch consisted of one of the following six single macronutrient conditions in random order; SC: Solid Carbohydrate consisting of whole peaches; SP: Solid Protein consisting of whole steamed chicken breast; SF: Solid Fat consisting of whole steamed high-fat pork belly; LC: Liquefied Carbohydrate: blended peaches; LP: Liquefied Protein: blended steamed chicken breast; LF: Liquefied Fat: blended steamed high-fat pork belly. All solid single macronutrient conditions were offered on a plate, to be eaten with a fork, and $750 \mathrm{ml}$ of water offered in glasses to drink, comparable to the SEW condition. All liquefied 
single macronutrient conditions were mixed with $500 \mathrm{ml}$ water, offered in a bowl, to be eaten with a spoon and $250 \mathrm{ml}$ of water offered separately in a glass to drink, comparable to the LEW condition.

All meals were subject-specifically calculated, according to their energy requirement, and controlled for energy density weight and volume. In all conditions lunches had to be consumed within 20 minutes.

All meals had been rated beforehand on palatability using visual analogue scales in an independent panel of 12 subjects. This panel, with comparable subject characteristics, was offered the meals in randomized order and independently of each other. The question was asked how palatable the consumption was experienced, after thoroughly experiencing its taste and structure. They rated palatability on a $100 \mathrm{~mm}$ visual analogue scale (VAS), anchored with not palatable at all and extremely palatable. No statistically significant differences between the solid meals $(63 \pm 3 \mathrm{~mm} V A S)$, the liquefied soups $(62 \pm 3 \mathrm{~mm}$ VAS) or the liquefied drinks (63 $\pm 3 \mathrm{~mm}$ VAS) appeared, nor between the palatability ratings of the solid protein meal $(62 \pm 2 \mathrm{~mm} V A S)$, the liquefied protein meal $(60 \pm 3 \mathrm{~mm}$ VAS), the solid carbohydrate meal $(62 \pm 4 \mathrm{~mm}$ VAS), the liquefied carbohydrate meal $(62 \pm 3 \mathrm{~mm}$ VAS), the solid fat meal $(62 \pm 2 \mathrm{~mm}$ VAS) and the liquefied fat meal $(61 \pm 3 \mathrm{~mm}$ VAS). The palatability of the water also did not differ significantly between conditions.

\section{APPETITE PROFILE}

The appetite profile was assessed using scores on the factors desire to eat, hunger, fullness, satiety, thirst and desire to drink, using $100 \mathrm{~mm}$ visual analog scales (VAS). The scales were anchored with opposing extremes of feelings of desire to eat, hunger, fullness, satiety, thirst and desire to drink. However, subjects scored hunger the same as desire to eat, also for satiety the same score was given as for fullness and for desire to drink the same score was given as for thirst. Therefore, the appetite profile data are shown as the scores on desire to eat, fullness and thirst. Subjects were instructed to make a single vertical mark at the appropriate point between the two anchors on each scale to indicate their subjective feelings. In the first study this was executed at 10 timepoints, namely twice at baseline with $15 \mathrm{~min}$ in between, and 8 after lunch, with $30 \mathrm{~min}$ in between. In the second study also one hundred mm VAS were used to assess the appetite profile at baseline, and before every blood sample (25). In this study VAS were completed at thirteen time points, namely at $10 \mathrm{~min}$ before the start of the lunch and at 20 min, $30 \mathrm{~min}, 40 \mathrm{~min}, 50 \mathrm{~min}, 60 \mathrm{~min}, 70 \mathrm{~min}, 85 \mathrm{~min}, 100 \mathrm{~min}, 115 \mathrm{~min}, 130 \mathrm{~min}, 160 \mathrm{~min}$, and $190 \mathrm{~min}$ after the start of the lunch. The VAS were completed before blood sampling in order to prevent mutual effects.

In addition, in study 1,2 hrs after the start of the lunch, at 14:40 PM the question was asked whether the subjects would like to consume more of the same lunch. If the answer was yes, the next question was why they would like to consume more, with the choices: a) to alleviate hunger; b) to quench thirst; c) both a and b. 


\section{BLOOD SAMPLING}

In study 2, at the beginning of the test session, 40 min before the lunch was served (12 AM), a polytetrafluoroethylene catheter was placed in the antecubital vein for blood sampling. During each test day, a first blood sample was drawn 10 min before the start of the lunch and 12 blood samples were drawn after the start of the lunch for the measurement of plasma insulin, glucose and ghrelin concentrations. Blood samples were collected in tubes containing EDTA (BD vacutainer with EDTA, $10 \mathrm{ml}$ ) to prevent clotting. Blood plasma was obtained by centrifugation $\left(4^{\circ} \mathrm{C}, 3000\right.$ r.p.m., $\left.20 \mathrm{~min}\right)$. All samples were frozen and stored at $-80{ }^{\circ} \mathrm{C}$ until further analysis. Plasma glucose concentrations were analyzed enzymatically by using the hexokinase method (ABX Diagnostics, Montpellier, France); the coefficient of variation (CV) was 0,63\%. Plasma insulin concentrations were determined in our own laboratory from the plasma samples, by means of RIA according to the manufacturer's instructions (Human insulin-specific RIA kit, Millipore, Billerica, Massachusetts, USA); the CV was 3,68\%. Plasma concentrations of active ghrelin were measured in our own laboratory by means of radio immuno assay (RIA) (Human ghrelin (active)-specific RIA kit, Millipore, Billerica, Massachusetts, USA); the CV was 3,70\%. Plasma active ghrelin concentrations were measured in acidified plasma with $50 \mu \mathrm{l}$ of 1 $\mathrm{N} \mathrm{HCL}$ and addition of $10 \mu \mathrm{l}$ of phenylmethylsulfonyl fluoride per $1 \mathrm{ml}$ of plasma.

\section{STATISTICS}

For both studies, areas under the curve (AUC) were calculated using the trapezoidal method. Appetite profiles were calculated at baseline, at the final time-point, at the peak or nadir and of the AUC. This was executed for all conditions of both studies and for the macronutrients taken together in study 2. Comparisons of the variables were made between the conditions for each of the appetite profile factors, using analysis of variance (ANOVA) repeated measures.

In study 1 relevant post-hoc comparisons were made between the conditions using Scheffe $F$ with ANOVA repeated measures, this to assess the effect of mode of consumption, structure and the effect of additional water to drink. From the answers on the questions, the percentage of subjects who wanted to consume more was calculated, as well as the percentage of subjects who wanted more to alleviate hunger, to quench thirst, or to suppress both.

In study 2 differences in blood values and appetite profile over time and differences, between structures for all macronutrients together were determined using two-factorial ANOVA repeated measures. Differences between structures for each macronutrient separately were analyzed using ANOVA repeated measures. For post-hoc tests Scheffe F was applied.

Data from both studies were analyzed using StatView 5.0 (SAS Institute Inc., Cary, NC, USA). All tests were two-sided and differences were considered significant at $p<0.05$. Values are expressed as mean \pm standard deviation (SD) or mean \pm standard error of the mean (SEM). 


\section{RESULTS}

\section{STUDY 1}

Measured times of consumption, used as a proxy for oral exposure times (mean \pm SEM) in study 1 were not significantly different; SEW: $18.0 \pm 0.7 \mathrm{~min}$, LEW: $19.1 \pm 0.9 \mathrm{~min}$, LDW: $15 \pm 0.4 \mathrm{~min}, \mathrm{SE}: 19.1 \pm 0.8 \mathrm{~min}, \mathrm{LE}: 18.3 \pm 0.8 \mathrm{~min}, \mathrm{LD}: 15.8 \pm 0.6 \mathrm{~min}$.

There were no differences between appetite ratings at baseline, but the final scores, peaks/nadirs and AUC of the scores on desire to eat, fullness and thirst differed between conditions (Table 1).

Post-hoc, all conditions were compared for each appetite-profile factor, with respect to final scores, peak/nadirs, and AUC. The relevant post-hoc comparisons and all $p$-values with respect to mode of consumption (eating or drinking; LDW vs. LEW and LD vs. LE), structure (solid/liquefied; SEW vs. LEW) and mode of consumption combined with structure (SEW vs. LDW) within offering the same amount of water and nutrients are given in the footnotes of table 1.

Furthermore, relevant post-hoc comparisons with respect to additional water to drink or not (SEW vs. SE, LEW vs. LE and LDW vs. LD), within the same mode of consumption, are given in the footnotes of table 1.

With respect to mode of consumption, surprisingly desire to eat appeared to increase in the drinking conditions (LDW and LD) compared to the eating conditions (LEW and LE) while fullness decreased likewise, but less strongly. For desire to eat as well as fullness, this was indicated by the nadir/peak, final scores and AUC. Thirst did not differ significantly between these conditions where the same amount of nutrients and water were offered in different modes of consumption.

Comparing effects of structure within the same mode of consumption, namely eating (SEW vs. LEW), neither desire to eat nor fullness appeared to differ in any aspect between the solid food and liquefied soup. Thirst appeared to be decreased in the solid condition, with $750 \mathrm{ml}$ water offered separately, when compared to the liquefied soup with $250 \mathrm{ml}$ water offered separately, but only as indicated by nadir

Comparing effects of structure as well as mode of consumption (SEW vs. LDW), surprisingly desire to eat appeared to be increased and fullness appeared to be decreased in the liquefied drink condition compared to the solid condition, as indicated by final scores, peak/nadir and AUC. Thirst appeared to be decreased in the solid condition, with $750 \mathrm{ml}$ water to drink offered separately, compared to the liquefied drink condition with $250 \mathrm{ml}$ water offered separately, but only as indicated by the nadir.

Comparing effects of additional water to drink (SEW vs. SE, LEW vs. LE and LDW vs. LD), neither desire to eat nor fullness was affected within the same mode of consumption and structure. With respect to thirst, a strong effect in all aspects (final score, AUC) appeared, i.e. thirst was less suppressed when no separate glass of water was offered with the solid meal, with the liquefied soup or with the liquefied drink. 
With respect to the question whether the subjects would like to consume more of the same lunch, asked two hours after the start of the lunch, $5 \%$ of the subjects answered yes, after each of the four eating conditions. The reason given was to alleviate hunger. After drinking the liquefied drink in the conditions LDW and LD, 16 subjects, or $80 \%$ answered yes. From these subjects, 6 subjects or $37 \%$ wanted to consume more to quench their thirst and 10 subjects or $63 \%$ wanted more to alleviate their hunger.

\section{STUDY 2}

Measured times of consumption, used as a proxy for oral exposure times (mean \pm SEM) in study 2 were also not significantly different; SC: $19.0 \pm 0.9 \mathrm{~min}, \mathrm{SP}: 19.2 \pm 0.4 \mathrm{~min}, \mathrm{SF}$ : $19.2 \pm 0.9 \mathrm{~min}, \mathrm{LC}: 18.3 \pm 0.8 \mathrm{~min}$, LP: $18.8 \pm 0.6 \mathrm{~min}$, LF: $18.3 \pm 1.2 \mathrm{~min}$.

At first, study 2 was analyzed with taking all macronutrients together and comparing the liquefied soup condition with the solid condition. Results were comparable with study 1. There were no differences between appetite ratings at baseline (Table 2). In the solid compared to the liquefied condition the fullness ratings were significantly higher as indicated by the final values and the AUC (Table 2). Furthermore, in the solid condition compared to the liquefied condition the thirst ratings were significantly lower as indicated by the final and the AUC values (Table 2).

There were no statistically significant condition $\mathrm{x}$ time interactions, nor differences in AUC for any of the blood parameters when taking all macronutrients together and comparing the liquefied with the solid condition (Figure 2). Post-hoc, no differences were found at any of the time points (Figure 2). When analyzing structure effects for each macronutrient separately no statistically significant condition $\mathrm{x}$ time interactions or differences in AUC where found for any of the blood parameters.

Next, the appetite profile was compared for every macronutrient separately. For carbohydrate, in the liquefied compared to the solid condition no differences in desire to eat were found. Furthermore the fullness ratings differed only with respect to the peak values $\left(\mathrm{LC}=84 \pm 15, \mathrm{SC}=72 \pm 23 \mathrm{mmVAS}\right.$; $\mathrm{p}<0.05, \mathrm{~F}_{1,9}=7.2$ ). For protein, statistically significant condition $x$ time interactions were found for desire to eat $(p<0.05)$, with desire to eat being rated higher over 2 hours in the liquefied condition. Concerning fullness, in the liquefied compared to the solid condition fullness ratings were not significantly different with respect to AUC and final ratings, yet the fullness was rated significantly lower in the liquefied condition as indicated by the peak values ( $L P=57 \pm 27, S P=79 \pm 13$ mmVAS; $p<0.05, F_{1,8}=7.1$ ). For fat, in the liquefied compared to the solid condition no differences in desire to eat were found. Furthermore the fullness ratings differed only with respect to the final values ( $L F=22 \pm 25, S F=32 \pm 22$ mmVAS; $p<0.01, F_{1,9}=10.5$ ).

The effect of structure on thirst was similar in all macronutrients, thirst always being higher in the liquefied condition. For carbohydrate protein and fat in the liquefied compared to the solid condition the thirst ratings were significantly higher as indicated by significant condition $x$ time effects $(p<0.03)$. For carbohydrate and protein this was also indicated 
by significantly higher AUC values (LC=5818 $\pm 2604, S C=4306 \pm 2905 \mathrm{mmVAS} .200 \mathrm{~min}$; $\mathrm{p}<0.05, \mathrm{~F}_{1,9}=5.2$ and $\left.\mathrm{LP}=9069 \pm 3967, \mathrm{SP}=7221 \pm 3024 \mathrm{mmVAS} .200 \mathrm{~min} ; \mathrm{p}<0.05, \mathrm{~F}_{1,9}=5.3\right)$. The same structure effect on the thirst ratings was also observed in the fat conditions, as indicated by the final values $\left(L F=59 \pm 20, S F=43 \pm 22\right.$ mmVAS; $\left.p<0.05, F_{1,9}=7.5\right)$. The $A U C$ values in the fat condition showed a similar trend $(L F=8879 \pm 3374, S F=6578 \pm 3818$ mmVAS.200min), but this was not statistically significant $\left(p=0.07, F_{1,9}=4.2\right)$.

Table 1. Appetite profile: desire to eat, fullness and thirst of the conditions in study 1

\begin{tabular}{llll} 
Condition & SEW & LEW & LDW \\
Desire to eat & & & \\
Baseline & $64 \pm 2$ & $64 \pm 1$ & $64 \pm 2$ \\
Final & $64 \pm 3$ & $64 \pm 2$ & $68 \pm 2^{1, \mathrm{a}}$ \\
Peak/nadir & $28 \pm 1$ & $27 \pm 2$ & $38 \pm 1^{4, \mathrm{e}}$ \\
AUC & $10228 \pm 431$ & $9125 \pm 368$ & $1198 \pm 539^{8, \mathrm{j}}$ \\
Fullness & & & \\
Baseline & $30 \pm 2$ & $30 \pm 1$ & $30 \pm 2$ \\
Final & $31 \pm 2$ & $31 \pm 2$ & $29 \pm 1^{2, \mathrm{c}}$ \\
Peak/nadir & $71 \pm 3$ & $71 \pm 3$ & $66 \pm 2^{5,9}$ \\
AUC & $4812 \pm 63$ & $4812 \pm 63$ & $4336 \pm 46^{9,1}$ \\
Thirst & & & \\
Baseline & $76 \pm 2$ & $75 \pm 2$ & $76 \pm 1$ \\
Final & $76 \pm 2$ & $77 \pm 2$ & $76 \pm 1$ \\
Peak/nadir & $42 \pm 2^{\mathrm{i}}$ & $46 \pm 1^{6}$ & $48 \pm 2^{6}$ \\
AUC & $10683 \pm 421$ & $10789 \pm 422$ & $10798 \pm 485$ \\
\hline
\end{tabular}

SEW: Solid food to eat and $750 \mathrm{ml}$ water to drink; LEW: Liquefied food mixed with $500 \mathrm{ml}$ water to eat, and 250 $\mathrm{ml}$ water to drink; LDW: Liquefied food mixed with $500 \mathrm{ml}$ water to drink and $250 \mathrm{ml}$ water to drink; SE: Solid food to eat; LE: Liquefied food mixed with $500 \mathrm{ml}$ water to eat; LD: Liquefied food mixed with $500 \mathrm{ml}$ water to drink. For each condition magnitudes of $100 \mathrm{~mm}$ VAS values at baseline, at the final time point, peak/nadir and AUC (mmVAS.240min) are given. Data are mean \pm SD. $N=20$ subjects.

Comparisons between conditions for each appetite-profile factor:

- Baseline: $\mathrm{ns}$ for all factors.

- Final scores: ${ }^{1)}$ Desire to eat: $p<0.0001, F_{5,95}=32.5 ;{ }^{2)}$ Fullness: $p<0.01, F_{5,95}=3.9$; ${ }^{3)}$ Thirst: $p<0.0001, F_{5,95}=97.4$

- Final vs. baseline: 1) Desire to eat: $\left.p<0.0001, F_{5,95}=25.9 ;{ }^{2}\right)$ Fullness: $p<0.01, F_{5,95}=2.8$; ${ }^{3)}$ Thirst: $p<0.0001, F_{5,95}=72.8$

- Peak/nadir: ${ }^{4)}$ Desire to eat: $p<0.0001, F_{5,95}=30.3 ;{ }^{5)}$ Fullness: $p<0.01, F_{5,95}=4.4 ;{ }^{6)}$ Thirst: $p<0.0001, F_{5,95}=103.6$

- AUC: ${ }^{8)}$ Desire to eat: $p<0.0001, F_{5,95}=29.4 ;{ }^{9)}$ Fullness: $p<0.01, F_{5,95}=4.1$; ${ }^{10)}$ Thirst: $p<0.0001, F_{5,95}=87.1$. 


\section{Condition}

SE

\section{LE}

LD

\section{Desire to eat}

Baseline

Final

Peak/nadir

AUC

Fullness

Baseline

Final

Peak/nadir

AUC

Thirst

Baseline

Final

Peak/nadir

AUC
$64 \pm 2$

$65 \pm 3$

$38 \pm 1$

$10192 \pm 497$

$30 \pm 1$

$30 \pm 2$

$70 \pm 3$

$4872 \pm 64$

$76 \pm 2$

$86 \pm 3^{3, n}$

$86 \pm 4^{6, n}$

$12829 \pm 603^{10, n}$
$64 \pm 2$

$64 \pm 2$

$30 \pm 2$

$10126 \pm 458$
$64 \pm 2$

$71 \pm 3^{1, b}$

$73 \pm 3^{4, f}$

$11164 \pm 582^{8, k}$
$30 \pm 1$

$30 \pm 1$

$70 \pm 3$

$4808 \pm 46$

$76 \pm 1$

$81 \pm 3^{3,0}$

$73 \pm 3^{6,0}$

$15082 \pm 719^{10, ~ 。 ~}$
$30 \pm 1$

$29 \pm 1^{2, d}$

$62 \pm 3^{5, \mathrm{~h}}$

$3872 \pm 36^{9}$, m

Post-hoc comparisons; Scheffe F.:

- Mode of consumption:

- Final scores: Desire to eat: ${ }^{\text {a) }}$ LDW vs. LEW: $F=6.8$;

b) LD vs. LE: $F=19.5$; Fullness: ${ }^{c}$ LDW vs. $L E W: F=2.8$;

d) LD vs. LE: $F=3.1$; Thirst: ns.

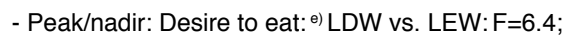

f) LD vs. LE: F=17.9; Fullness: 9) LDW vs. LEW: $F=2.7$;

h) LD vs. LE: $F=3.2$; Thirst: ns.

- AUC:Desire to eat: ${ }^{j)}$ LDW vs. LEW: $F=6.9$; ${ }^{k}$ LD vs. LE: $F=17.8$; Fullness: ") LDW vs. LEW: $F=2.9$; $^{\text {m) }}$ LD vs.

LE: $F=16.2$; Thirst: ns.

- Texture (LEW vs. SEW):

- Desire to eat, Fullness and Thirst: all ns; except:

Peak/nadir: Thirst: ${ }^{\text {i) }} \mathrm{F}=3.4$;

- Mode of consumption and texture (LDW vs. SEW):

- Final scores: Desire to eat: ${ }^{\text {a) }} F=5.5$; Fullness:

c) $\mathrm{F}=2.6$; Thirst: $n s$.

- Peak/nadir: Desire to eat: ${ }^{\text {e) }} F=5.2$; Fullness: ${ }^{\text {g) }} F=2.4$; Thirst: i) $\mathrm{F}=3.6$.

- AUC:Desire to eat: i) F=6.4; Fullness:") $F=2.8$; Thirst: ns. - Effects of additional water to drink:

- Comparisons: SEW vs. SE; LEW vs. LE; LDW vs.

LD, for Desire to eat; Fullness: ns with respect to all aspects.

- For Thirst: Final scores: ${ }^{n)}$ SEW vs. SE: $F=53.0$;

o) LEW vs. LE: $F=18.0$; ${ }^{\text {p) }}$ LDW vs. LD: $F=16.5$; Nadir:

n) SEW vs. $S E: F=49.7$; ${ }^{\circ}$ LEW vs. $L E: F=17.4$; ${ }^{\text {p) }}$ LDW vs. $L D: F=16.8$. 
Table 2. Appetite profile: desire to eat, fullness and thirst from all macronutrients together.

\begin{tabular}{lll} 
Condition & Solid & Liquefied \\
Desire to eat & & \\
Baseline & $59 \pm 17$ & $62 \pm 20$ \\
Final & $59 \pm 22$ & $67 \pm 24$ \\
Peak/nadir & $14 \pm 16$ & $18 \pm 17$ \\
AUC & $7759 \pm 3566$ & $9079 \pm 4055$ \\
Fullness & & \\
Baseline & $31 \pm 17$ & $28 \pm 17$ \\
Final & $39 \pm 23$ & $30 \pm 25^{1}$ \\
Peak/nadir & $75 \pm 16$ & $72 \pm 22$ \\
AUC & $10986 \pm 3653$ & $9743 \pm 4437^{2}$ \\
Thirst & & \\
Baseline & $50 \pm 20$ & $50 \pm 22$ \\
Final & $43 \pm 22$ & $52 \pm 18^{3}$ \\
Peak/nadir & $18 \pm 17$ & $23 \pm 21$ \\
AUC & $6035 \pm 3405$ & $7922 \pm 3580^{4}$ \\
\hline
\end{tabular}

The solid food was to eat and served with $750 \mathrm{ml}$ water to drink and the liquefied food was blended with $500 \mathrm{ml}$ water to eat, served with $250 \mathrm{ml}$ water to drink. Per condition magnitudes of $100 \mathrm{~mm}$ VAS at baseline, at the final time point, peak/nadir and AUC (mmVAS.200min) values are given. Data are mean $\pm S D$. N=10 subjects.

Comparisons between conditions for each appetite-profile factor:

- Baseline: ns for all factors.

- Final scores: ${ }^{1)}$ Fullness: $p<0.05, F_{1,9}=8.7 ;{ }^{3)}$ Thirst: $p<0.01, F_{1,9}=9.2$.

- Peak/nadir: ns for all factors.

- AUC: ${ }^{2)}$ Fullness: $p<0.05, F_{1,9}=5.4{ }^{4)}$ Thirst: $p<0.05, F_{1,9}=8.8$.

\section{DISCUSSION}

The objective of this study was to asses how mode of consumption, structure and additional water to drink influences behavioral and physiological parameters of eating and drinking behavior.

The effects found in the first study on desire to eat and fullness were caused by mode of consumption and not by structure. This is indicated by the fact that an effect of structure on desire to eat and fullness was only observed when also mode of consumption differed (SEW vs. LDW), but not when only structure differed (SEW vs. LEW). This underscores that consuming a meal as a drink, although containing the same amount of calories is experienced differently from consuming a meal by eating with a fork or a 

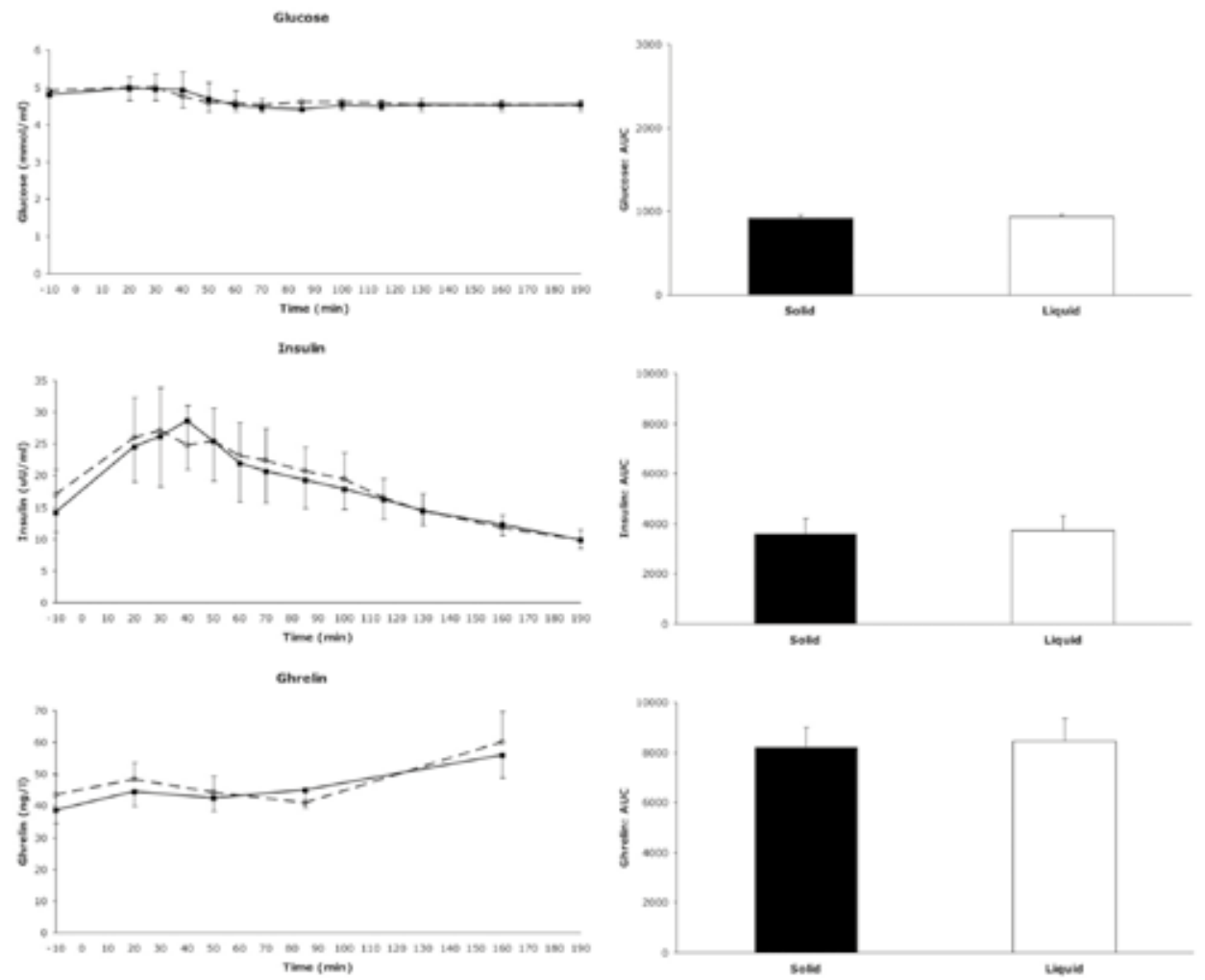

Figure 2. Blood values of study 2 comparing structures for all macronutrients together. On the left: mean $( \pm$ SEM) plasma glucose, insulin and ghrelin concentrations for the solid $(-\mathbf{\square}-)$ and the liquefied (-○-) condition. On the right: mean areas under the curve for the blood values for the solid (घ) and the liquefied $(\square)$ condition.

spoon, independently of the structure. Previous studies support this finding by showing that beverages elicit weak compensatory dietary responses $(8,26,27)$. Secondary, oral exposure time could be of importance. Although not significant, the measured time of consumption, which was used as a proxy for oral exposure time, was lower in the drinking conditions. The role oral exposure time can play was shown by the studies of Zijlstra et al. $(11,28)$. They observed that liquid, semi-liquid and semi-solid products with similar palatability, macronutrient composition and energy density lead to significant higher intake of the liquid product (11). They suggest that this decreased satiation can be partially explained by the higher eating rate of liquids, which influences the transit time in the oral cavity (11). In a more recent study they found that greater oral sensory exposure by eating with small bite sizes and thus increasing oral processing time, 
significantly decreases food intake (28), underscoring that longer oral exposure may lead to increased satiation.

Concerning the findings on thirst a distinction has to be made between the total amount of water (SEW, LEW and LDW vs. SE, LE and LD) and the amount of water served separately with the meal or as water in the meal (SEW vs. LEW and LDW).

With regard to the total amount of water no differences in desire to eat or fullness were observed with any of the meals but thirst was always suppressed more when additional water to drink was provided. Therefore, this study shows that drinking additional water with a meal primarily quenches thirst and does not affect hunger. Previous studies nonetheless showed that water consumed with a meal reduces subjective ratings of hunger and increases ratings of satiety during a meal $(29,30)$. In the study by DellaValle et al. they found in forty-four women higher mean ratings of fullness after an ad libitum lunch if water $(350 \mathrm{ml})$ was served with the meal compared to without serving water (29). They found that after lunch mean ratings of fullness were higher for the water condition than for the no-beverage condition (29). The study by Lappalainen et al. showed in eight women that drinking two glasses of water with breakfast affects subjective feelings of hunger and satiety during the meal, but this effect was not maintained after the meal. These studies only found effects of drinking water on satiation but not on satiety, thereby confirming our results.

Taken together, the findings on thirst in relation to the total amount of water are straightforward; thirst relatively increased when no additional water was provided to drink. As to findings on thirst in relation to the amount of water served separately with the meal or as water in the meal, the results are less straightforward. The expectation would be that if the total amount of water is the same and especially when everything has to be drunk that thirst would be quenched the same or more. However, this is not the case; when everything has to be drunk, thirst is not significantly different compared to the condition where the mixed part has to be spooned (LDW vs. LEW) and thirst is even higher compared to the condition were the solid food is served separately from the water (LDW vs. SEW). These results were only supported by significant differences in the nadir values but are confirmed in the second study by significant differences in AUC and final values. These results show that thirst is mainly quenched by water served separately with a meal and less by water in the meal. When thirst is not quenched by water in the meal this could be due to a different mouth feel, which leads to secondary thirst as described according to Fitzsimons.

Concerning the answers to the question if subjects wanted to consume more, the majority of subjects wanted to consume more of the same meal, when the meal had to be drunk and this to alleviate their hunger. This confirms studies that show that beverages elicit weak compensatory dietary responses $(8,26,27)$.

Furthermore, the effects of conditions SEW, LEW and LDW on thirst and fullness show that the liquefied drink is not viewed as food, since it causes less fullness, but it is also 
not viewed as a drink, since it quenches thirst less. Consequently, the motivation to consume more of a drink could be a mixture of hunger and thirst. The results indicate that distinctions between perception of hunger and thirst and eating and drinking indeed are blurred when modes of consumption do not correspond.

We further investigated different structures of separate macronutrients within the same mode of consumption because it appears from literature that mainly mixed macronutrient meals have been tested in this respect (1). For single macronutrients an emphasize has been on carbohydrate $(2,14,22)$ and only 1 study by Mattes et al. assessed effects of structure in single macronutrient meals for each macronutrient separately (6). Furthermore, we were intrigued by the lack of differences in desire to eat and fullness between structures in the same mode of consumption (SEW vs. LEW). Although these results were in line with the results of Mattes et al. who also observed that soups led to reductions in hunger and increases in fullness that were comparable to solid foods. First of all, findings on thirst of the first study were confirmed in this second study: in the liquefied conditions, for all macronutrients together as well as for the macronutrients separately, thirst was higher when less additional water was offered to drink separately and more was in the food.

In study 2 we additionally detected macronutrient specific structure effects within the same mode of consumption. In the carbohydrate and fat conditions hardly any structure effects were observed, while in the protein conditions the solid meal seemed to cause a higher satiation. We speculate that these results may show that the structure effect on appetite can be macronutrient specific, with possibly a larger effect of protein. This structure effect on appetite with high-protein meals was already previously shown (31). These results were however not supported by the blood parameters, which were not significantly different. Furthermore, these results differ slightly from those of Mattes et al. and Haber et al. $(2,6)$. They both found that an apple soup was less satiating than apples and Mattes et al. did not find any differences in hunger or fullness ratings between a high-protein solid (chicken) and liquefied (chicken soup) meal or between a high fat solid (peanuts) and liquefied (peanut soup) meal $(2,6)$. Furthermore, Haber et al. detected differences in glucose but not in insulin concentrations (2). A limitation of both studies is that the effects of food properties on the regulation of appetite were assessed only by using subjective appetite profiles and not also by measuring subsequent food intake (32). However, this limitation was partly addressed in the first study by asking the question whether they wanted to eat more of the same meal.

To conclude: mode of consumption plays an important role in alleviating hunger and thirst, since food consumption alleviates hunger mainly by eating while thirst is mainly quenched by drinking water separately. Further consumption after drinking the meal was required by the majority of subjects, motivated by either hunger or thirst, showing that drinking a meal causes confusion that may imply a risk of over-consumption. Moreover, the structure effect on appetite could be macronutrient specific. 


\section{ACKNOWLEDGEMENTS}

We thank our subjects for their participation in this study. Furthermore, we thank J. Stegen for analyzing the plasma samples and M. de Vries for executing the practical work of study 1 . The study was designed by MSWP and MJIM. MJIM carried out study 2. MJIM and MSWP analyzed the data and wrote the manuscript together. No funding was received.

\section{REFERENCES}

1. Almiron-Roig E, Chen Y, Drewnowski A. Liquid calories and the failure of satiety: how good is the evidence? Obesity Reviews 2003;4:201-212.

2. Haber GB, Heaton KW, Murphy D, Burroughs LF. Depletion and disruption of dietary fibre: effects on satiety, plasma-glucose, and serum-insulin The Lancet 1977;310:679-682.

3. Himaya A, Louis-Sylvestre J. The Effect of Soup on Satiation. Appetite 1998;30:199-210.

4. Kissileff HR. Effects of physical state (liquid-solid) of foods on food intake: procedural and substantive contributions. Am J Clin Nutr 1985;42:956-965.

5. Kissileff HR, Gruss LP, Thornton J, Jordan HA. The satiating efficiency of foods. Physiology \& Behavior 1984;32:319-332.

6. Mattes R. Soup and satiety. Physiology \& Behavior 2005;83:739-747.

7. Mattes RD, Rothacker D. Beverage viscosity is inversely related to postprandial hunger in humans. Physiology \& Behavior 2001;74:551-557.

8. Mourao DM, Bressan J, Campbell WW, Mattes RD. Effects of food form on appetite and energy intake in lean and obese young adults. Int J Obes 2007;31:1688-95.

9. Rolls BJ, Fedoroff IC, Guthrie JF, Laster LJ. Foods with different satiating effects in humans. Appetite 1990;15:115-126.

10. Tieken SM, Leidy HJ, Stull AJ, Mattes RD, Schuster RA, Campbell WW. Effects of Solid versus Liquid Meal-replacement Products of Similar Energy Content on Hunger, Satiety, and Appetite-regulating Hormones in Older Adults. Horm Metab Res. 2007;39:389-394.

11. Zijlstra N, Mars M, de Wijk RA, Westerterp-Plantenga MS, de Graaf C. The effect of viscosity on ad libitum food intake. Int J Obes 2007;32:676-683.

12. Zijlstra N, Mars M, de Wijk RA, Westerterp-Plantenga MS, Holst JJ, de Graaf C. Effect of viscosity on appetite and gastro-intestinal hormones. Physiology \& Behavior 2009;97:68-75.

13. Tournier A, Louis-Sylvestre J. Effect of the physical state of a food on subsequent intake in human subjects. Appetite 1991;16:17-24.

14. DiMeglio DP, Mattes RD. Liquid versus solid carbohydrate: effects on food intake and body weight. Int J Obes Relat Metab Disord 2000;24:794-800.

15. Rolls BJ, Bell EA, Thorwart ML. Water incorporated into a food but not served with a food decreases energy intake in lean women. Am J Clin Nutr 1999;70:448-455.

16. McKinley MJ, Johnson AK. The Physiological Regulation of Thirst and Fluid Intake. News Physiol Sci 2004;19:1-6.

17. Thornton S. Thirst and hydration: Physiology and consequences of dysfunction. Physiology \& Behavior 2010;100:15-21.

18. Bernard C. Leçons sur les phénomènes de la vie communs aux animaux et aux végétaux. 2 ed. Paris: Baillière, 1878-1879:112-113. 
19. Meier JJ, Nauck MA, Pott A, et al. Glucagon-Like Peptide 2 Stimulates Glucagon Secretion, Enhances Lipid Absorption, and Inhibits Gastric Acid Secretion in Humans. Gastroenterology 2006;130:44-54.

20. Popkin BM, Nielsen SJ. The sweetening of the world's diet. Obes Res 2003;11:1325-32.

21. Mattes RD. Hunger and thirst: issues in measurement and prediction of eating and drinking. Physiol Behav 2010;100:22-32.

22. Bolton RP, Heaton KW, Burroughs LF. The role of dietary fiber in satiety, glucose, and insulin: studies with fruit and fruit juice. Am J Clin Nutr. 1981;34:211-7.

23. Philippaerts RM, Westerterp KR, Lefevre J. Doubly Labeled Water Validation of three Physical Activity Questionnaires. Int J Sports Med 1999;20:284-289.

24. Harris JA, Benedict FG. A Biometric Study of Human Basal Metabolism. Proc Natl Acad Sci 1918;4:370-3.

25. Flint A, Raben A, Blundell JE, Astrup A. Reproducibility, power and validity of visual analogue scales in assessment of appetite sensations in single test meal studies. nt $\mathrm{J}$ Obes Relat Metab Disord. 2000;24:38-48.

26. De Castro JM. The effects of the spontaneous ingestion of particular foods or beverages on the meal pattern and overall nutrient intake of humans. Physiol Behav. 1993;53:1133-44.

27. Mattes RD. Dietary Compensation by Humans for Supplemental Energy Provided as Ethanol or Carbohydrate in Fluids. Physiology \& Behavior 1996;59:179-187.

28. Zijlstra N, de Wijk R, Mars M, Stafleu A, de Graaf C. Effect of bite size and oral processing time of a semisolid food on satiation. Am J Clin Nutr 2009;90:269-275.

29. DellaValle DM, Roe LS, Rolls BJ. Does the consumption of caloric and non-caloric beverages with a meal affect energy intake? Appetite 2005;44:187-193.

30. Lappalainen R, Mennen L, van Weert L, Mykkänen H. Drinking water with a meal: a simple method of coping with feelings of hunger, satiety and desire to eat. Eur J Clin Nutr 1993;47:815-9.

31. Martens MJ, Lemmens SG, Born JM, Westerterp-Plantenga MS. A solid high-protein meal evokes stronger hunger suppression than a liquefied high-protein meal. Obesity 2011;19:522-7.

32. Blundell J, De Graaf C, Hulshof T, et al. Appetite control: methodological aspects of the evaluation of foods. Obesity Reviews;11:251-270. 


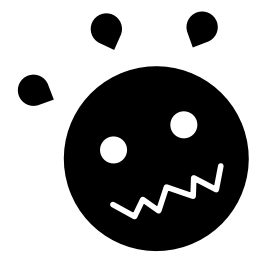




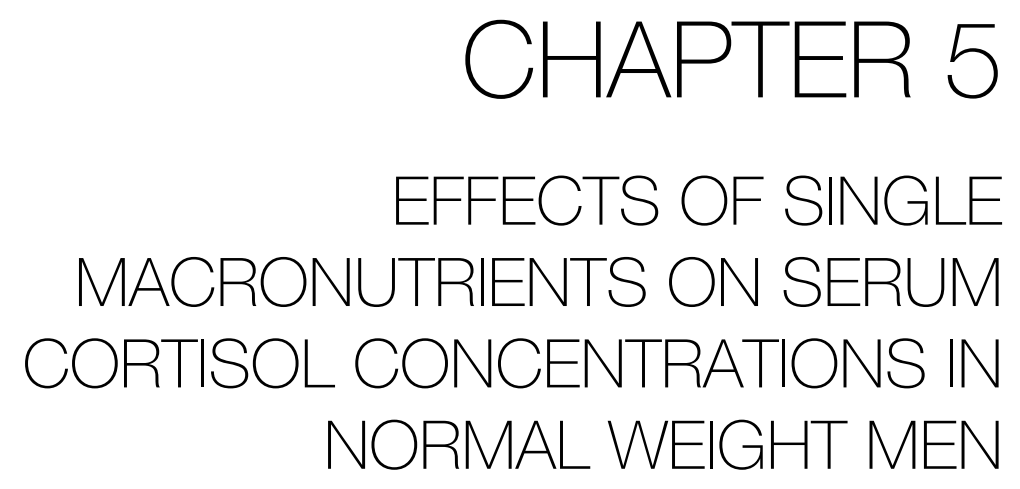

Martens MJ, Rutters F, Lemmens SG, Born JM, Westerterp-Plantenga MS.

Physiol Behav. 2010;101(5):563-567 


\section{ABSTRACT}

A previous study reported that a high carbohydrate meal, in contrast to a high protein/ fat meal, significantly increased cortisol concentrations in visceral obese subjects. The objective of this study was to identify effects of single macronutrients on plasma cortisol concentrations. Ten male subjects (age $27.3 \pm 7.4 \mathrm{y}, \mathrm{BMI} 22.1 \pm 1.7 \mathrm{~kg} / \mathrm{m}^{2}$ ) were studied in a randomized cross-over design on four days around lunchtime after consuming breakfast matched for daily energy requirements (DER $20 \%$ ). For lunch they consumed one liter of a shake (DER $18 \%$ ) containing either fat, protein or carbohydrate, with a raspberry taste and similar hedonic value $(59 \pm 2 \mathrm{~mm}$ on a $100 \mathrm{~mm}$ VAS), using water as control. Serum cortisol concentrations were measured before lunch and during three hours following lunch. Baseline cortisol concentrations did not differ among treatments. The protein as well as the fat lunch caused a significant decrease in cortisol concentrations when compared to the carbohydrate lunch, and showed no difference from the control condition $(p<0.05)$. The cortisol response in the protein condition ( $A U C=37024 \pm 3518 \mathrm{nmol} / \mathrm{L}$.min) and in the fat condition (AUC=35977 $\pm 3562 \mathrm{nmol} / \mathrm{L}$. $\mathrm{min}$ ) were significantly smaller when compared with the cortisol response in the carbohydrate condition ( $A U C=47310 \pm 3667$ $\mathrm{nmol} /$ L.min) $(\mathrm{p}<0.03$ ), but did not differ from the control condition (AUC=32784 \pm 1683 $\mathrm{nmol} / \mathrm{L} . \mathrm{min}$ ). The cortisol response in the carbohydrate condition was significantly higher when compared with the response in the control condition $(p<0.004)$. We conclude that cortisol concentrations decreased after protein or fat intake, which was not different from control; this decrease was prevented by carbohydrate intake. 


\section{INTRODUCTION}

Obesity is a global epidemic that results from disturbance of the energy balance, i.e. energy intake exceeding energy expenditure $(1,2)$. The cause of obesity is diverse and complex and can be attributed to physiological, environmental, neuro-endocrine and genetic factors (1). Evidence of the involvement of the neuro-endocrine system of the hypothalamus pituitary adrenal (HPA) axis in body-weight regulation is found in two extremes of plasma cortisol levels in humans; Addison's disease (hypocortisolism) that has been related to weight loss, and Cushing's syndrome (hypercortisolism) that has been related to rapid weight gain $(3,4)$. The cascade of the HPA axis beholds that the hypothalamus produces corticotropin-releasing hormone $(\mathrm{CRH})$, which subsequently stimulates the production of adrenocorticotropin (ATCH) from the anterior pituitary, which in turn will stimulate the synthesis and release of cortisol by the adrenal cortex (5). Support for the involvement of the HPA axis in body-weight regulation is found in humans with visceral fat accumulation. Visceral fat accumulation in obese subjects is related to altered HPA axis functioning, such as decreased salivary and serum cortisol levels (6-8), increased urinary secretion of cortisol $(9,10)$, decreased cortisol variability $(6,11,12)$ and enhanced cortisol awakening response (13). Implications for behavior related to the involvement of the HPA axis functioning in bodyweight regulation are that the HPA axis is involved in the regulation of energy intake. Most of the data directly indicating a crucial role of the HPA axis in the regulation of food intake are derived from animal studies, showing that the anorectic effects of adrenalectomy can be reversed by corticosterone replacement $(14,15)$. Human studies support the orexigenic effect of cortisol, as cortisol administration stimulates food intake (16). The orexigenic effect of cortisol may underlie the reported increase of energy intake after stress, as psychological stress seems to increase the intake frequency, increase the amount of food taken in (1719), and alter food preference towards intake of sweet and fat foods (20). Taken together, the HPA axis functioning plays an important role in the regulation of energy balance and body-weight; it is, however, not completely clear whether the HPA axis is causally or coincidentally related to the development of obesity. Furthermore, in light of the connection between HPA axis functioning and body-weight regulation, there is a need for information related to the regulation of meal-induced cortisol secretion because of its possible clinical implications and potential as a clinical marker of health. Descriptions of the macronutrient related, meal-induced cortisol secretion in the literature are limited. However, a study by Vicennati et al. already showed that a high carbohydrate meal, in contrast to a high protein/fat meal significantly increased cortisol levels in female visceral obese subjects (21). Moreover, Lacroix et al. showed that in rats a high protein diet reduced cortisol levels (22). To further elucidate the role of single macronutrients in meal-induced cortisol secretion, the objective of this study was to identify effects of protein and fat in comparison to carbohydrate on cortisol concentrations and find a macronutrient composition that may relatively decrease cortisol concentrations and in this way cause weight loss. 


\section{METHODS AND PROCEDURES}

\section{SUBJECTS}

Twelve healthy, normal weight male subjects were recruited by advertisements in local newspapers and on notice boards at the university and hospital. Only male subjects were recruited to avoid possible influences of the menstrual cycle on cortisol concentrations. Subjects underwent initial screening, including measurement of body weight and height and completion of a questionnaire to assess their medical history. Exclusion criteria were use of medication, heavy exercising, smoking, and allergy for any of the products used in the study. In total ten healthy male subjects (age 27 \pm 7 y (mean $\pm S D$, range 21-44 y)) with a BMI of $22.1 \pm 1.7 \mathrm{~kg} / \mathrm{m}^{2}$ (mean $\pm \mathrm{SD}$, range $20.1-24.6 \mathrm{~kg} / \mathrm{m}^{2}$ ) participated. The Medical Ethical Committee of the Maastricht University approved the study, and informed written consent was obtained from all subjects before the first test day. Subject characteristics are described in Table 1.

\section{EXPERIMENTAL DESIGN}

The study was conducted following a randomized, crossover design. Subjects reported to the laboratory on four occasions with at least one washout-day in between. Every test day subjects consumed a prescribed breakfast at home and were given a shake as lunch in the laboratory. To measure cortisol concentrations an intravenous (IV) catheter was placed for blood sampling. Blood samples were taken five times during each session. A schematic overview of the study design is given in Table 2.

\section{MEALS}

\section{BREAKFAST}

Before 9 AM subjects consumed a prescribed breakfast at home composed of a commercially available breakfast drink ('Goedemorgen', Campina). They were instructed

Table 1. Mean $( \pm S D)$ subject characteristics

\section{Subject characteristics}

\begin{tabular}{ll} 
Male $(\mathrm{n})$ & 10 \\
Age (years) & $27 \pm 7$ \\
Height $(\mathrm{cm})$ & $179.0 \pm 7.0$ \\
Weight $(\mathrm{kg})$ & $71.1 \pm 9.0$ \\
BMI $\left(\mathrm{kg} / \mathrm{m}^{2}\right)$ & $22.1 \pm 1.7$ \\
Waist circumference $(\mathrm{cm})$ & $76.9 \pm 5.3$ \\
Hip circumference $(\mathrm{cm})$ & $87.1 \pm 4.1$ \\
Waist-hip ratio & $0.9 \pm 0.0$ \\
\hline
\end{tabular}


Table 2. Schematic overview of the study design

\begin{tabular}{ll} 
Time & Action \\
9.00 & Breakfast at home \\
11.45 & Placing IV \\
12.15 & $1^{\text {st }}$ blood sample \\
12.20 & Start of the lunch \\
12.30 & End of the lunch \\
13.00 & $2^{\text {nd }}$ blood sample \\
13.30 & $3^{\text {rd }}$ blood sample \\
14.00 & $4^{\text {th }}$ blood sample \\
14.30 & $5^{\text {th }}$ blood sample \\
\hline
\end{tabular}

to consume an amount, corresponding to $20 \%$ of the estimated subjects' daily energy requirement (DER). DER was calculated individually for each recruited subject by multiplying the calculated basal metabolic rate (BMR) by the appropriate physical activity factor (1.5-1.8), derived from the Baecke screening questionnaire (23). BMR (kJ/day) was calculated according to the equation of Harris-Benedict (24).

\section{LUNCH}

The lunch shake was different every test day and contained one single macronutrient namely, carbohydrate, protein, fat or the control condition water. Subjects received $18 \%$ of their DER, which on average corresponded to $2306 \pm 77 \mathrm{~kJ}$ (mean \pm SEM, range 18612672 kJ)). The carbohydrate lunch was produced using Fantomalt (Nutricia Advanced Medical Nutrition), which contains dextrin and maltose; the protein lunch was produced using Protifar Plus (Nutricia Advanced Medical Nutrition), which contains milk protein; and the fat lunch was produced using sunflower oil. Macronutrients were mixed with water to result in an energy density of $2 \mathrm{~kJ}$ per gram. For taste, a calorie-free raspberry taste (Diaran, Céréal) was used. The control condition consisted of water. Subjects were blinded for the condition and lunches were offered in a randomized order. Lunches were given at a fixed time and subjects had to consume the lunch within 10 minutes. Subjects were presented the drinks in a container closed with a lid and they were asked to carefully shake the drink each time before drinking, in this way the water and macronutrient were kept mixed. The macronutrient lunches were matched for flavor, which was confirmed by testing them in an independent panel of ten subjects. They assessed the hedonic value using visual analog scales (VAS). The triangle taste test was used for difference testing (25): each participant was presented with three shakes, two the same and one different in all possible combinations and asked to taste all three shakes and choose the one that was different from the other two. In total they received 12 presentations (two randomized 
presentations of the six possible combinations). A correct response for 8 of 12 trials was significantly different from chance at the $5 \%$ level. The panel was not able to distinguish the shakes (maximum number of correct answers was 3 ); they always mentioned the same raspberry taste. There were no differences between the hedonic value of the water $(60 \pm 2 \mathrm{~mm}$ VAS), the carbohydrate shake $(60 \pm 3 \mathrm{~mm}$ VAS), the fat shake $(59 \pm 1 \mathrm{~mm}$ VAS) and the protein shake $(58 \pm 2 \mathrm{~mm}$ VAS) $(p=0.3)$. To detect possible trends for differences in pleasantness we also did a post-hoc test with Bonferroni correction and for each comparison $\mathrm{p}>0.1$.

\section{CORTISOL}

At the beginning of the test session an intravenous catheter was placed in the antecubital vein. A blood sample of $2 \mathrm{ml}$ to obtain $1 \mathrm{ml}$ of serum for cortisol measurement was drawn five times: one baseline sample 30 minutes after placing the IV ( 5 minutes before lunch), and four samples, every 30 minutes for two hours, following the end of the lunch. Blood was transferred into a serum tube (BD Vacutainer with separation gel, $8.5 \mathrm{ml}$, Franklin Lakes, NJ, USA). Blood serum was obtained by centrifugation ( ${ }^{\circ} \mathrm{C}, 3000$ r.p.m. $10 \mathrm{~min}$ ). All samples were frozen and stored at $-80^{\circ} \mathrm{C}$ until analysis. Serum cortisol concentrations were determined by radio immuno assay (Département des Sciences Functionnelles, B41-Physiologie de Reproduction, Liège, Belgium). Cortisol samples were taken around lunch to avoid the morning cortisol peak and to be able to detect smaller changes that can be caused by different macronutrients.

\section{STATISTICS}

Areas under the curve (AUC) were calculated for all hormones measured using the trapezoidal method. Data were analyzed using StatView 5.0 (SAS Institute Inc., Cary, NC, USA). All tests were two-sided and differences were considered significant at $p<0.05$. Cortisol concentration measurements and hedonic value were analyzed using factorial ANOVA with or without repeated measures. Values are expressed as mean \pm standard deviation (SD).

\section{RESULTS}

No differences were observed between the cortisol concentrations at baseline. It could be that anxiety at the first session meant a greater stress response on that day, but analysis by day regardless of treatment revealed no differences in the cortisol response between test days ( $p>0.9$ ). In response to the different lunches, cortisol concentrations changed in different ways. Comparing the four conditions over time, using ANOVA repeated measures, we observed a significant condition $x$ time effect $\left(F_{[12,124]}=2.0 ; p<0.05\right)$. Posthoc, the cortisol response in the protein condition ( $A U C=37024 \pm 3518 \mathrm{nmol} / \mathrm{L} . \mathrm{min}$ ) and 


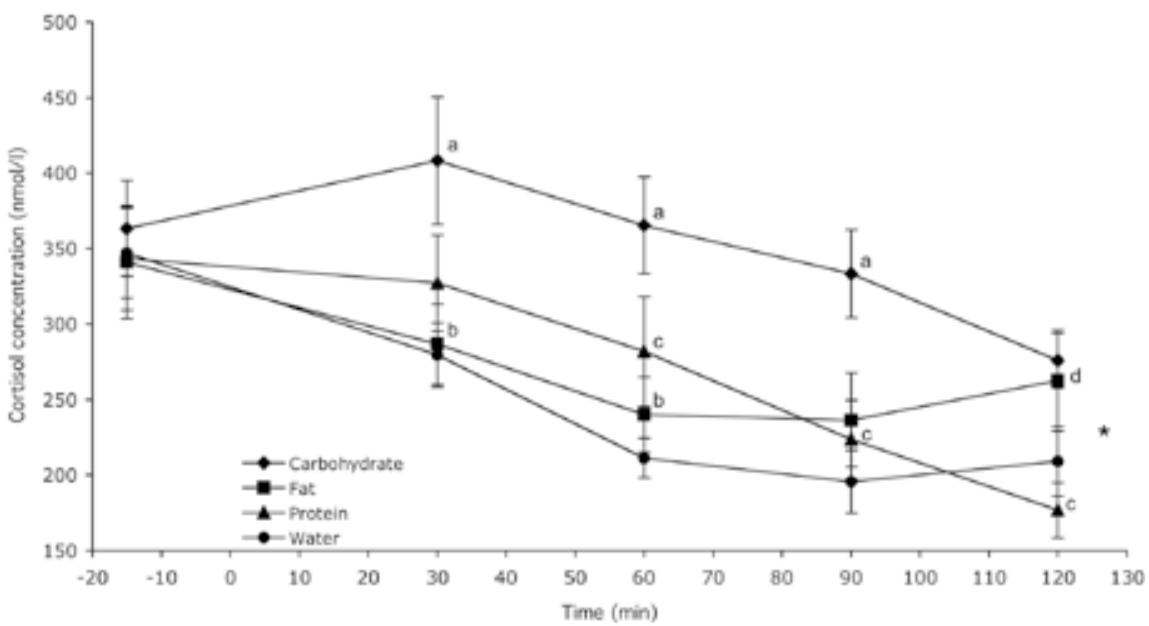

Figure 1. Cortisol concentrations from $15 \mathrm{~min}$. before lunch until $120 \mathrm{~min}$. after lunch and area under the curve for cortisol (mean \pm SEM). a $p<0.05$ for differences between the control condition water and the carbohydrate condition. $\mathrm{b} p<0.05$ for differences between the carbohydrate condition and the fat condition. $c p<0.05$ for differences between the carbohydrate condition and the protein condition. $d$ $p<0.05$ for differences between the protein condition and the fat condition. ${ }^{*} p<0.05$ for overall group $x$ time interaction.

in the fat condition ( $A \cup C=35977 \pm 3562 \mathrm{nmol} / \mathrm{L}$. $\min$ ) were significantly smaller when compared with the cortisol response in the carbohydrate condition (AUC=47310 \pm 3667 $\mathrm{nmol} / \mathrm{L} . \mathrm{min})(\mathrm{p}<0.05)$, but did not differ from the control condition (AUC=32784 \pm 1683 $\mathrm{nmol} /$ L.min) (Figure 1). The cortisol response in the carbohydrate condition was significantly higher when compared with the response in the control condition $(p<0.01)$ (Figure 1).

Post-hoc comparisons revealed that the largest increase in cortisol occurred between 0 and 30 minutes in the carbohydrate condition. After 30,60 and 90 minutes, cortisol concentrations were significantly higher in the carbohydrate condition compared with the control condition $(\mathrm{p}<0.05)$. After 30 and 60 minutes, cortisol concentrations were significantly higher in the carbohydrate condition compared with the fat condition $(p<0.05)$. At 60, 90 and 120 minutes, cortisol concentrations were significantly higher in the carbohydrate condition compared with the protein condition $(p<0.05)$. After 120 minutes, cortisol concentrations were significantly higher in the fat condition compared with the protein condition $(\mathrm{p}<0.05)$. Taken together, the protein as well as the fat condition showed no difference from the control condition, only carbohydrate caused an increase in cortisol concentration when compared to the control condition. 


\section{DISCUSSION}

This study revealed that when using single macronutrients, carbohydrate intake prevents the cortisol decrease seen in the control condition of water intake, whereas this decrease was not affected by protein or fat intake. Furthermore, protein and fat intake did not cause a statistically significant increase in cortisol concentrations when compared with water. A significant overall decrease in cortisol concentrations over time was seen. This suggests a normal decrease from the morning cortisol peak.

The results presented in this study are supported by previous studies; in a rat study it has been shown that a high protein diet reduces HPA axis activity, indicated by reduced cortisol concentrations (22) and in female visceral obese women it was shown that a high carbohydrate meal significantly increased HPA axis activity, as shown as increased cortisol concentrations (21). Alternative views include the possibility that so-called "comfort foods" reduce the activity of the chronic-stress response, which has been seen in animal models (26). Most of the studies performed until now investigated the effect of mixed meals, long-term diets or the nasogastric administration of proteins on HPA axis activity by measuring cortisol concentrations (27-29). Moreover, these studies differ from our study e.g. because in some studies no control group was used. In a study by Markus et al. they used mixed meals and showed that in subjects with a high stress-proneness the cortisol level only increased after stress induction on a day with a carbohydrate poor and protein rich diet, while a carbohydrate rich and protein poor diet caused a decrease in cortisol level after stress induction (27). A study by Stimson et al. revealed that a long-term low carbohydrate diet, but not a moderate carbohydrate diet, was able to alter cortisol metabolism in obese men, causing enhanced cortisol regeneration by 11 beta-HSD1 and reduced cortisol inactivation by A-ring reductases in the liver (28). Furthermore, there is some evidence that cortisol secretion is stronger after intake of protein-rich meals than after intake of carbohydrate-rich meals (29-31). Gibson et al. and Slag et al. showed significant increases in salivary cortisol after a high-protein meal and Benedict el al. found an increase in serum cortisol concentrations after nasogastric administration of casein (29-31). Taken together, the results of the studies performed until now are contradictory; one study indicates that HPA axis activity increases with a low carbohydrate diet (28), another study finds an increase in HPA axis activity in visceral obese women after a high carbohydrate meal, yet another indicates that HPA axis activity decreases after a carbohydrate rich and protein poor mixed meal (27) and others find that HPA axis activity increases after a protein-rich meal $(30,31)$, while a rat study shows that a high protein diet reduces cortisol concentrations (22). However, these results cannot be directly compared with our results because they used a different study population (rats or obese men or women) or they used mixed-meals, long-term diets or nasogastric administration of proteins.

To our knowledge this is the first study investigating the effect of single macronutrients 
on HPA axis activity in humans. The HPA axis activity stimulating effect of carbohydrates found in this study could explain the vicious circle seen in obesity, in which stress is followed by eating comfort food, high in sugar, which again causes stress that further increases HPA axis activity and thus cortisol concentrations. A possible hypothesis for the prevention of a decrease HPA axis activity after the carbohydrate lunch is that the fast increase in glucose in the blood, following ingestion of carbohydrates, is perceived as not pleasant by the body. It has already been shown that glucose but not protein or fat amplifies the HPA axis activity to psychosocial stress (32). The prevention of decrease in HPA axis activity, which is seen in this study, may also inhibit insulin, which starts to increase within a few seconds after the increase in glucose (33). Normally, insulin causes the cells to take up glucose from the blood. Yet in this case, the maintained cortisol levels diminish the action of insulin, and therefore blood glucose concentrations might decrease much slower than normal. Another effect of the high glucose concentration in the blood is the increase in serotonin (34). Serotonin contributes to pleasant feelings. However serotonin can also induce cortisol release by stimulating the serotonergic receptors in the hippocampus (35), leading to maintained cortisol levels and subsiding pleasant feelings. Taken together, people who eat carbohydrate-rich (comfort) food because they are stressed might feel better after the fast glucose peak because of the increase in serotonin, but due to maintaining relatively high HPA axis activity and thus cortisol levels the pleasant feelings will subside. Possibly, by eating more carbohydrate rich foods as a consequence, a vicious circle might occur. This circle has previously been described in emotional eaters (36).

It should be kept in mind that the meals used here were identical to each other in terms of hedonic value and removing carbohydrates from real-life nutrition may impact stress differently. Furthermore, it could be that the gastric consequences of a high carbohydrate load leads to possible unpleasant effects. However, in this case none of the subjects reported any adverse effects of the shakes.

To conclude, cortisol concentrations decreased after protein or fat intake, which was not different from control; this decrease was prevented by carbohydrate intake.

\section{ACKNOWLEDGEMENTS}

We thank our subjects for their participation in this study. We thank J Sulon for analyzing the serum cortisol samples. The study was designed by MSWP, MJIM and FR. MJIM (supervised by MSWP) carried out the study, collected and analyzed the data and wrote the largest part of the manuscript. SGTL, FR and JMB reviewed the manuscript. 


\section{REFERENCES}

1. World. Health Organisation. Obesity: preventing and managing the global epidemic. Technical report series 894, World Health Organisation, Geneva, Switzerland 2000.

2. Joosen A, Westerterp K. Energy expenditure during overfeeding. Nutrition \& Metabolism 2006;3:25.

3. Lépez M, Caamaño E, Romero C, Fiedler J, Araya V. Salivary cortisol among subjects with and without Cushing syndrome. Rev Med Chil. 2010;138:168-74.

4. Neary N, Nieman L. Adrenal insufficiency: etiology, diagnosis and treatment. Curr Opin Endocrinol Diabetes Obes. 2010;17:217-23.

5. Nieuwenhuizen AG, Rutters F. The hypothalamic-pituitary-adrenal-axis in the regulation of energy balance. Physiology \& Behavior 2008;94:169-177.

6. Ljung T, Holm G, Friberg $P$, et al. The activity of the hypothalamic-pituitary-adrenal axis and the sympathetic nervous system in relation to waist/hip circumference ratio in men. Obes Res 2000;8:48795.

7. Thomas GT, Amy BOD, Andre BA, Alvin MM, John BM. Cortisol levels and measures of body composition in middle-aged and older men. Clinical Endocrinology 2007;67:71-77.

8. Misra M, Bredella MA, Tsai P, Mendes N, Miller KK, Klibanski A. Lower growth hormone and higher cortisol are associated with greater visceral adiposity, intramyocellular lipids, and insulin resistance in overweight girls. Am J Physiol Endocrinol Metab 2008;295:E385-392.

9. MÂrin P, Darin N, Amemiya T, Andersson B, Jern S, Bj^rntorp P. Cortisol secretion in relation to body fat distribution in obese premenopausal women. Metabolism 1992;41:882-886.

10. Pasquali R, Cantobelli S, Casimirri F, et al. The hypothalamic-pituitary-adrenal axis in obese women with different patterns of body fat distribution. J Clin Endocrinol Metab 1993;77:341-346.

11. Garcla-Prieto MD, TĖbar FJ, Nicol·s F, LarquÈ E, Zamora S, Garaulet M. Cortisol secretary pattern and glucocorticoid feedback sensitivity in women from a Mediterranean area: relationship with anthropometric characteristics, dietary intake and plasma fatty acid profile. Clinical Endocrinology 2007;66:185-191.

12. Putignano $P$, Dubini A, Toja $P$, et al. Salivary cortisol measurement in normal-weight, obese and anorexic women: comparison with plasma cortisol. Eur J Endocrinol 2001;145:165-171.

13. Therrien F, Drapeau V, Lupien SJ, et al. Awakening cortisol response in relation to psychosocial profiles and eating behaviors. Physiology \& Behavior 2008;93:282-288.

14. la Fleur SE. The effects of glucocorticoids on feeding behavior in rats. Physiology \& Behavior 2006;89:110-114.

15. la Fleur SE, Akana SF, Manalo SL, Dallman MF. Interaction between Corticosterone and Insulin in Obesity: Regulation of Lard Intake and Fat Stores. Endocrinology 2004;145:2174-2185.

16. Tataranni PA, Larson DE, Snitker S, Young JB, Flatt JP, Ravussin E. Effects of glucocorticoids on energy metabolism and food intake in humans. Am J Physiol Endocrinol Metab 1996;271:E317-325.

17. Heatherton TF, Herman CP, Polivy J. Effects of physical threat and ego threat on eating behavior. J Pers Soc Psychol 1991;60:138-43.

18. Epel E, Lapidus R, McEwen B, Brownell K. Stress may add bite to appetite in women: a laboratory study of stress-induced cortisol and eating behavior. Psychoneuroendocrinology 2001;26:37-49.

19. Mitchell SL, Epstein LH. Changes in taste and satiety in dietary-restrained women following stress. Physiology \& Behavior 1996;60:495-499.

20. Oliver G, Wardle J, Gibson EL. Stress and Food Choice: A Laboratory Study. Psychosom Med 2000;62:853-865.

21. Vicennati V, Ceroni L, Gagliardi L, Gambineri A, Pasquali R. Response of the Hypothalamic-PituitaryAdrenocortical Axis to High-Protein/Fat and High-Carbohydrate Meals in Women with Different 
Obesity Phenotypes. J Clin Endocrinol Metab 2002;87:3984-3988.

22. Lacroix M, Gaudichon C, Martin A, et al. A long-term high-protein diet markedly reduces adipose tissue without major side effects in Wistar male rats. Am J Physiol Regul Integr Comp Physiol 2004;287:R934-942.

23. McArdle WD, Katch FI, Katch VL. Exercise Physiology. 1996;4th ed. Baltimore: Williams and Watkins.

24. Harris JA, Benedict FG. A Biometric Study of Human Basal Metabolism. Proc Natl Acad Sci 1918;4:370-3.

25. Pepino MY, Finkbeiner S, Beauchamp GK, Mennella JA. Obese Women Have Lower Monosodium Glutamate Taste Sensitivity and Prefer Higher Concentrations Than Do Normal-weight Women. Obesity;18:959-965.

26. Dallman MF, Pecoraro N, Akana SF, et al. Chronic stress and obesity: a new view of "comfort food". Proc Natl Acad Sci U S A 2003;100:11696-701.

27. Markus CR, Panhuysen G, Tuiten A, Koppeschaar H, Fekkes D, Peters ML. Does Carbohydraterich, Protein-poor Food Prevent a Deterioration of Mood and Cognitive Performance of Stress-prone Subjects when Subjected to a Stressful Task? Appetite 1998;31:49-65.

28. Stimson $\mathrm{RH}$, Johnstone AM, Homer NZM, et al. Dietary Macronutrient Content Alters Cortisol Metabolism Independently of Body Weight Changes in Obese Men. J Clin Endocrinol Metab 2007;92:4480-4484.

29. Benedict C, Hallschmid M, Scheibner J, et al. Gut Protein Uptake and Mechanisms of Meal-Induced Cortisol Release. J Clin Endocrinol Metab 2005;90:1692-1696.

30. Gibson EL, Checkley S, Papadopoulos A, Poon L, Daley S, Wardle J. Increased Salivary Cortisol Reliably Induced by a Protein-Rich Midday Meal. Psychosom Med 1999;61:214-224.

31. Slag MF, Ahmad M, Gannon MC, Nuttall FQ. Meal stimulation of cortisol secretion: a protein induced effect. Metabolism 1981;30:1104-8.

32. Gonzalez-Bono E, Rohleder N, Hellhammer DH, Salvador A, Kirschbaum C. Glucose but Not Protein or Fat Load Amplifies the Cortisol Response to Psychosocial Stress. Hormones and Behavior 2002;41:328-333.

33. Strack AM, Sebastian RJ, Schwartz MW, Dallman MF. Glucocorticoids and insulin: reciprocal signals for energy balance. Am J Physiol Regul Integr Comp Physiol 1995;268:R142-149.

34. Orosco M, Gerozissis K. Macronutrient-induced cascade of events leading to parallel changes in hypothalamic serotonin and insulin. Neuroscience \& Biobehavioral Reviews 2001;25:167-174.

35. Sobczak SA, Honig MD, Nicolson NA, Riedel WJ. Effects of Acute Tryptophan Depletion on Mood and Cortisol Release in First-degree Relatives of Type I and Type II Bipolar Patients and Healthy Matched Controls. Neuropsychopharmacology 2002;27:834-842.

36. Nguyen-Michel ST, Unger JB, Spruijt-Metz D. Dietary correlates of emotional eating in adolescence. Appetite 2007;49:494-499. 



\section{CHAPTER 6}

\section{LIKING AND THE OROSENSORY PERCEPTION OF FOOD IN A STRESS VERSUS REST CONDITION IN OVERWEIGHT AND NORMAL WEIGHT PARTICIPANTS}

Martens MJ, Born JM, Lemmens SG, Adam TC, Westerterp-Plantenga MS.

Food Qual Prefer 2012;26(2):252-258 


\section{ABSTRACT}

Stress and increased body weight may lead to decreased sensory or hedonic perception. Rewarding value of food consists of liking and wanting; this study emphasizes characterization of orosensory perception and liking during stress. The effect of stress on orosensory attributes of food and liking was tested in overweight and normal weight participants. Thirty-nine participants $(26 \mathrm{f} / 13 \mathrm{~m}$, age $30 \pm 11 \mathrm{y}), 24$ normal weight (BMI $22 \pm 2 \mathrm{~kg} / \mathrm{m}^{2}$, waist/hip-ratio $0.78 \pm 0.02$ ) and 15 visceral-overweight (BMI $29 \pm 2 \mathrm{~kg} / \mathrm{m}^{2}$, waist/hip-ratio $0.87 \pm 0.02$ ) tasted 67 food items randomly in a rest and stress condition, subsequently rating orosensory attributes (i.e. sweetness, bitterness, saltiness, sourness, umami, creaminess, crispiness) and liking using visual analog scales. Stress was induced using an unsolvable math task in a noisy context. In overweight participants, orosensory perception was less pronounced, especially with respect to sweetness. Liking was related to orosensory perception, the relationships were the same in both conditions. Liking was scored lower by overweight vs. normal weight participants. Stress vs. rest reduced orosensory perception in normal weight participants. Stress vs. rest reduced liking equally for normal weight and overweight participants. In conclusion, our results show that orosensory perception and liking of food are reduced in overweight compared to normal weight participants; the latter is especially emphasized during stress. 


\section{INTRODUCTION}

Food intake is regulated homeostatically as well as non-homeostatically (1). Stressinduced eating beyond homeostatic needs may contribute to the development of obesity through a greater preference for foods high in sugar and fat (2). The effect of stress on food intake has been discussed controversially. Increased food intake as well as decreased food intake has been reported depending on parameters such as dietary restraint, gender and body weight (3-6). However, chronic stress has been associated with greater weight gain among participants who are already overweight or obese (3, $7,8)$. Previous studies also show that obese individuals may consume more food in response to acute stress compared with lean individuals. Together this suggests that stress-induced eating may play a role in the development of obesity $(2,3,9,10)$. From animal studies we know that pleasurable behaviors such as palatable food intake contribute to stress reduction through the recruitment of brain reward pathways (11).

Unraveling the involvement of food reward during stress may open an avenue to understanding the impact of food reward on eating behavior (1, 12-14).

According to the incentive salience concept by Berridge et al. the rewarding value of food is divided into two components: 'liking' and 'wanting' (1, 14-18). Liking is the hedonic or affective process of palatability/pleasure/displeasure, often associated with the orosensory stimulation by food, and 'wanting' is the motivational incentive component consisting of the non-affective, purely motivational process of appetite or craving (1, 14-18). Wanting translates affect into the action of obtaining food (1, 14-18). 'Liking' and 'wanting' often go hand in hand, yet it is important to differentiate between the influence of 'liking' and 'wanting' on food intake (19). The literature concerning liking is contradictory. Several studies reported that individuals rate liking at a constant level across several food items, irrespective of weight status or satiety state $(13,17,20-22)$. Other studies did find differences in liking ratings after a meal $(15,23)$. The current study focuses solely on the 'liking' component of food reward and the associated orosensory perception of food. Liking in this study is defined according to Berridge et al., as the pleasantness of taste of the food present in the mouth (16).

Bartoshuk et al. suggested that obese people live in different oro-hedonic and oro-sensory worlds compared to non-obese (24). Furthermore, several studies compared sensory thresholds in lean and obese subjects $(25,26)$, finding differences after gastric bypass surgeries (25-27). Not much is known about the relationship of stress and 'liking'. Their is some evidence that sweetness, and sensory cues to high energy density, can mitigate effects of stress via the brain's reward system (28). This suggests that orosensory attributes of liking may change during stress.

Taken together, the aim of the current study is to examine if stress affects orosensory perception and subsequently liking in both, normal weight and overweight subjects. Therefore, we firstly investigated how different orosensory attributes of food are rated 
by overweight and normal weight subjects. Furthermore, we characterized how these orosensory attributes of food are correlated with liking, in overweight compared to normal weight participants during rest or stress. Lastly, we assessed the effect of stress on orosensory perception and on liking in overweight vs. normal weight participants.

\section{METHODS AND PROCEDURES}

\section{PARTICIPANTS}

The study was approved by the Medical Ethical Committee of Maastricht University. Forty-four participants were recruited by advertisements in local newspapers and on notice boards at Maastricht University and Maastricht University Medical Center. Potential participants underwent an initial screening including measurement of body weight and height and completion of a questionnaire related to medical history. Exclusion criteria were vegetarianism, smoking, illnesses that require the use of regular medication, a history of eating disorders, weight change of more than $5 \mathrm{~kg}$ during the last 6 months, diabetes, an allergy for any of the products used in the study, and anything with a possible effect on taste and/or appetite (e.g. braces, smell disorders, etc.). Only viscerally overweight participants, defined by a waist circumference of $\geq 80 \mathrm{~cm}$ in women and $\geq 90$ $\mathrm{cm}$ in men (29), were included, as chronic stress has been particularly associated with visceral fat accumulation and obesity $(2,30,31)$. Informed, written consent was obtained from all participants before the first test day. In total thirty nine healthy participants (26

Table 1. participant characteristics $(M e a n \pm S D)$

\begin{tabular}{lll}
\hline Participant characteristics & Normal weight & Overweight \\
\hline Male $(\mathrm{n})$ & 7 & 6 \\
Female $(\mathrm{n})$ & 17 & 9 \\
Age $($ years $)$ & $27.0 \pm 9.0^{*}$ & $35.7 \pm 12.7$ \\
Height $(\mathrm{cm})$ & $171.5 \pm 9.8$ & $173.3 \pm 7.8$ \\
Weight $(\mathrm{kg})$ & $65.5 \pm 8.4^{*}$ & $87.3 \pm 9.4$ \\
BMI $(\mathrm{kg} / \mathrm{m} 2)$ & $22.2 \pm 1.9^{*}$ & $29.0 \pm 2.0$ \\
Waist circumference $(\mathrm{cm})$ & $74.4 \pm 6.9^{\star}$ & $94.5 \pm 8.3$ \\
Hip circumference $(\mathrm{cm})$ & $94.7 \pm 7.3^{*}$ & $108.8 \pm 6.0$ \\
Waist-hip ratio & $0.79 \pm 0.08^{\star}$ & $0.87 \pm 0.09$ \\
TFEQ-score: $\mathrm{F} 1$ & $5.3 \pm 2.2$ & $5.0 \pm 1.4$ \\
TFEQ-score: F2 & $4.1 \pm 2.4$ & $4.5 \pm 0.7$ \\
TFEQ-score: F3 & $4.8 \pm 3.4$ & $5.0 \pm 1.4$ \\
\hline
\end{tabular}

* Significantly different between normal weight and overweight $(p<0.02)$. TFEQ: Three Factor Eating questionnaire (Dutch translation); F1: Factor 1, restraint; F2: Factor 2, disinhibition; F3: Factor 3, hunger motivation. 
females, 13 males, age $30 \pm 11$ y (mean $\pm S D$, range 17-54 y)) were included in the study: twenty-four normal weight (NW) participants with a BMI of $22 \pm 2 \mathrm{~kg} / \mathrm{m}^{2}$ (mean $\pm S D$, range $20-25 \mathrm{~kg} / \mathrm{m}^{2}$ ) and fifteen viscerally overweight (VO) participants with a BMI of $29 \pm 2 \mathrm{~kg} /$ $\mathrm{m}^{2}$ (mean $\pm S D$, range $26-34 \mathrm{~kg} / \mathrm{m}^{2}$ ). Participants were unrestrained eaters according to a validated Dutch translation of the Three Factor Eating Questionnaire (32, 33). Subject characteristics are described in Table 1.

\section{EXPERIMENTAL DESIGN}

The study consisted of a randomized crossover design. All participants came to the university for a total of six times between 12:00 and 13:00 PM. They were allowed to eat their own breakfast around 9 AM, after which they were instructed not to eat or drink anything for three hours and until the beginning of the test. To avoid possible satiation effects, which can influence liking or orosensory perception, the total of 67 food items were divided into 22 or 23 items per session, over three test days, and repeated for the rest and stress conditions. The order of the test days and conditions were randomized in a counter-balanced way across individuals from both test groups (normal weight and viscerally overweight) to account for order effects. However, the presentation order of the food samples on each test day was fixed.

\section{PILOT FOR THE ESTABLISHMENT OF OROSENSORY ATTRIBUTES}

Previously, during a preliminary test in a rest condition, an independent panel of 20 subjects (BMl:24.0 $\pm 3.4 \mathrm{~kg} / \mathrm{m}^{2}$, age: $30.3 \pm 10.0 \mathrm{y}$ ), judged a randomized presentation of pictures of the same food items on expected liking. Thereafter, they judged perceived liking of these food items using the same method as in the main experiment. Furthermore, this panel chose the orosensory attributes that they thought contributed most to the liking of the food items. These orosensory attributes were used in the main study.

\section{SCREENING VISIT}

During this screening visit, participants familiarized themselves with the task and with the definition of the orosensory attributes (crispiness, creaminess, umami, sweetness, bitterness, saltiness, and sourness), using verbal examples, as described in Table 2. Participants were also familiarized with the computerized VAS and were given a description of 'liking' according to Berridge $(14,16,18)$ in layman's terms (Table 2).

Before inclusion, participants had to confirm their familiarity with all food items using a questionnaire on familiarity with pictures of the food items.

\section{TEST VISIT}

Sessions started by filling out computerized 100mm Visual Analog Scales (VAS) for appetite. Subsequently, liking and the intensity of the orosensory properties of the food items were measured using computerized $100 \mathrm{~mm}$ VAS. The total of 67 food items 
Table 2. definitions and verbal examples used for familiarization with liking and the orosensory attributes

\begin{tabular}{|c|c|c|}
\hline Attribute & Definition & Verbal examples \\
\hline Liking & $\begin{array}{l}\text { The pleasantness of taste of the food in } \\
\text { your mouth }\end{array}$ & $\begin{array}{l}\text { How much do you like } \\
\text { the food in your mouth, } \\
\text { not how much do you } \\
\text { want to eat it }\end{array}$ \\
\hline Sweetness & $\begin{array}{l}\text { The amount of sweet taste detected from } \\
\text { the food in your mouth }\end{array}$ & Sugar \\
\hline Bitterness & $\begin{array}{l}\text { The amount of bitter taste detected from } \\
\text { the food in your mouth }\end{array}$ & Caffeine, grapefruit \\
\hline Saltiness & $\begin{array}{l}\text { The amount of salty taste detected from the } \\
\text { food in your mouth }\end{array}$ & Salt \\
\hline Sourness & $\begin{array}{l}\text { The amount of sour taste detected from the } \\
\text { food in your mouth }\end{array}$ & Citric acid \\
\hline Umami & $\begin{array}{l}\text { The amount of umami taste detected from } \\
\text { the food in your mouth }\end{array}$ & $\begin{array}{l}\text { Flavour enhancers, } \\
\text { monosodium glutamate }\end{array}$ \\
\hline Creaminess & $\begin{array}{l}\text { The degree to which the sample feels } \\
\text { creamy on any mouth surface }\end{array}$ & Whipped cream \\
\hline Crispiness & $\begin{array}{l}\text { The force and noise with which a product } \\
\text { breaks or fractures (rather than deforms) } \\
\text { when chewed with the molar teeth }\end{array}$ & $\begin{array}{l}\text { Fresh crackers, fresh } \\
\text { bread crust }\end{array}$ \\
\hline
\end{tabular}

were chosen from typical Dutch lunch items and included a wide range of intensity regarding the orosensory attributes. All food items are commercially available and can be divided into six categories: bread, filling, drinks, desserts, sweets and extra food items (Supplemental Table A1). No novel food items were included. Everything was prepared freshly and according to protocol in the research kitchen in bite-size, but still recognizable, portions of 10 grams. All solid food items were presented on a plate with a fork, the semi-liquid and liquid food items were presented in a cup with a spoon. All food items were served at room temperature, except for the chicken soup, which was served 
at $60^{\circ} \mathrm{C}$. If re-testing was necessary for the orosensory judgment, a second portion was provided to the participant. After each item, participants were instructed to rinse their mouth with water, to avoid cross tasting.

\section{MEASUREMENTS}

\section{ANTHROPOMETRY}

Body weight was measured on a medical scale (Sauter D7470; Ebingen, Germany), after voiding of the bladder when fasted and rounded to the nearest $0.01 \mathrm{~kg}$; height was measured to the nearest $0.1 \mathrm{~cm}$ (stadio meter, model 220; Seca, Hamburg, Germany). BMI was calculated as body weight $(\mathrm{kg})$ divided by the squared height $(\mathrm{m})$. Waist circumference was measured to the nearest $0.1 \mathrm{~cm}$ at the site of the smallest circumference between the rib cage and the iliac crest, whereas the hip circumference was measured to the nearest $0.1 \mathrm{~cm}$ at the level of maximum extension of the buttocks. The waist and hip circumference measurements were obtained with participants in standing position using a tape measure (34).

\section{VISUAL ANALOG SCALES}

Reproducibility, power and validity of visual analogue scales in the assessment of appetite sensations were previously assessed and found to be reliable for appetite research (35). Computerized VAS software was developed by J.M. Born (36). The VAS scales were adjusted to be hundred $\mathrm{mm}$ long on screen and Apple MacBook and Macintosh Powerbook computers were used for all VAS measurements. Subjects were required to complete all VAS questions on each screen, before they were allowed to proceed in the test. The test included questions for appetite profile, for liking and for all orosensory attributes. Overall, the questions were anchored at the far left with "not at all" and at the far right with "extremely". In addition, if a subject thought a specific orosensory attribute was not applicable to a specific food item, they were instructed to rate it as being zero.

VAS were used to assess appetite profile before each test session. The scales were anchored with opposing extremes of feelings of hunger, satiety, thirst, and desire to eat. Participants were trained to click on the appropriate point on each VAS to indicate how they felt at that moment. Liking was characterized using VAS with opposing extremes of liking. Participants were asked to rate liking by answering the following question: "How pleasant is the taste of the food now in your mouth?", while having a mouthful. The $100 \mathrm{~mm}$ VAS was anchored with on the far left "not pleasant at all" and on the far right "extremely pleasant".

The intensity of the orosensory properties of the food items was characterized using VAS with opposing extremes of seven orosensory attributes: sweetness, bitterness, saltiness, sourness, umami, creaminess, and crispiness. Using sweetness as an example, the questions asked and the anchors of the $100 \mathrm{~mm}$ VAS were as follows: "How sweet do you find the food now in your mouth?" with the anchor on the far left "not sweet at all" and on the far right "extremely sweet”. 
In the preliminary test with the independent panel, expected liking was judged using VAS while viewing a randomized presentation of pictures of the same food items.

\section{STRESS TASK}

To induce stress and rest conditions a mathematical task was used $(6,20)$. This mathematical task was a modified and improved version of the computer program previously described and validated by Peters et al. (37) and further validated by Lemmens et al. (38) who confirmed the stress condition by the finding of an increased heart rate, and an increase in anxiety and hostility $(p \leq 0.03)$ using Profile Of Mood State (POMS) (39) and State Trait Anxiety Inventory (STAI) (40) questionnaires. In accordance with the earlier protocols, two versions of the math test were used: an unsolvable stress version combined with irritating music and background noises and a solvable control, rest, version without music and background noises. Either test lasted no longer than 20 minutes. Participants were given the math test after assessing appetite profile and before judging the food items. The order of rest and stress conditions was randomized.

\section{STATISTICS}

Data were analyzed using StatView 5.0 (SAS Institute Inc., Cary, NC, USA). Differences in appetite profile were analyzed using analysis of variance (ANOVA) repeated measures with the six test days being six different measures. Post hoc power analysis using G-Power 3 (Heinrich Heine University, Duesseldorf) for a 2 by 2 repeated measurement design revealed with $n=39$ and $\alpha=0.05$ a power (1- $\beta$ error probability) of 0.86 . To check for order effects the order $x$ liking interaction and the order $x$ orosensory attribute interaction for each orosensory attribute was determined using factorial ANOVA repeated measures. To check for an interaction between liking and orosensory attributes across the 67 food items factorial ANOVA was used with the orosensory attributes as covariates. Group x condition interactions were determined using two-factor ANOVA with repeated measures. Differences in the characterization of liking and orosensory perception between stress and rest within each group of participants were analyzed using ANOVA. Due to unequal cell size, statistics were repeated using non-parametric Kolmogorov Smirnov testing. Differences in the characterization of liking and orosensory perception between normal weight and overweight within each separate condition were analyzed using ANOVA and non-parametric Kolmogorov Smirnov testing. To determine which of the selected orosensory attributes (i.e. sweetness, bitterness, saltiness, sourness, umami, creaminess, crispiness) predicted liking, a multiple linear regression model was used. Simple regression was used to determine if there was a correlation between expected liking and perceived liking. All tests were two-sided and differences were considered significant at $p<0.05$. Values are expressed as mean \pm standard deviation (SD), unless stated otherwise and the adjusted $R^{2}$ value was used. 


\section{RESULTS}

Appetite profiles did not differ between visits. Measurements of appetite profiles were not significantly different between subject groups (i.e. normal weight and overweight or men and women) and were therefore taken together in all further analyses. There were no significant differences in hunger, fullness, satiety, desire to eat and thirst between the six visits (Table 3). Orosensory attributes and liking were recorded in detail (Table 4). The order $x$ liking interaction and the order $x$ orosensory attribute interaction were not statistical significant, which means that order of presentation did not significantly influence liking or any of the orosensory information collected. There was no statistically significant interaction between liking and the orosensory attributes across the 67 food items, implying that there were no halo effects between the liking measurements and the measurements of orosensory attributes. There were no significant differences between males and females in both liking or in orosensory attributes.

\section{OROSENSORY PERCEPTION}

The results of orosensory perception are summarized in table 4. Group x condition interactions were significant for crispiness $\left(F_{(1,2078)}=5.7, p<0.05\right)$, creaminess $\left(F_{(1,2078)}=9.8\right.$, $\mathrm{p}<0.01)$, umami $\left(\mathrm{F}_{(1,2076)}=25.4, \mathrm{p}<0.0001\right)$, sourness $\left(\mathrm{F}_{(1,2078)}=19.6, \mathrm{p}<0.0001\right)$ and saltiness $\left(F_{(1,2078)}=17.0, p<0.0001\right)$, implying that the difference between rest and stress was significantly different between overweight and normal weight participants. The rated perceptual intensity of the orosensory attributes was different between overweight and normal weight participants, it was rated as higher in perceived intensity in normal weight compared to overweight participants: normal weight participants rated sweetness significantly higher in both the rest $\left(\mathrm{F}_{(1,2329)}=10.9, \mathrm{p}<0.001\right)$ and the stress condition

Table 3. Appetite profile over the six visits of all subjects (Mean \pm SD)

\begin{tabular}{llllll} 
& Hunger & Fullness & Satiety & Desire to eat & Thirst \\
\hline Visit 1 & $62.8 \pm 20.0$ & $25.4 \pm 20.8$ & $26.0 \pm 19.6$ & $62.8 \pm 18.5$ & $63.7 \pm 17.3$ \\
Visit 2 & $54.3 \pm 19.0$ & $31.1 \pm 18.7$ & $33.1 \pm 21.9$ & $54.3 \pm 19.9$ & $57.0 \pm 27.8$ \\
Visit 3 & $59.8 \pm 18.4$ & $25.3 \pm 15.7$ & $27.7 \pm 18.7$ & $62.4 \pm 18.4$ & $56.4 \pm 19.6$ \\
Visit 4 & $57.7 \pm 26.6$ & $32.1 \pm 26.0$ & $34.3 \pm 26.6$ & $55.9 \pm 27.2$ & $53.6 \pm 26.0$ \\
Visit 5 & $52.2 \pm 24.7$ & $33.9 \pm 22.7$ & $32.0 \pm 22.0$ & $52.8 \pm 25.2$ & $49.3 \pm 24.9$ \\
Visit 6 & $62.0 \pm 21.8$ & $22.7 \pm 14.4$ & $26.2 \pm 16.7$ & $65.5 \pm 16.7$ & $59.7 \pm 19.7$ \\
\hline P-value & 0.3 & 0.2 & 0.4 & 0.1 & 0.2 \\
\hline
\end{tabular}


Table 4. Average visual analogue scale ratings (mm VAS) of the 67 food items for liking, crispiness, creaminess, umami, sweetness, sourness, bitterness and saltiness, judged by normal weight and overweight in rest and stress. Data is represented as Mean \pm SD.

\begin{tabular}{|c|c|c|c|c|c|c|c|}
\hline & \multicolumn{3}{|c|}{ Normal weight } & \multicolumn{3}{|c|}{ Overweight } & \\
\hline $\begin{array}{l}\text { Food } \\
\text { characteristics }\end{array}$ & Rest & Stress & $\mathrm{p}^{\mathrm{a}}$ & Rest & Stress & $\mathrm{p}^{\mathrm{a}}$ & $\begin{array}{l}\mathrm{p}^{\mathrm{d}} \text { group* } \\
\text { condition }\end{array}$ \\
\hline Liking & $63.2 \pm 25.0^{\mathrm{b}}$ & $59.9 \pm 24.1^{c}$ & $<.01$ & $57.2 \pm 27.7^{b}$ & $54.8 \pm 27.8^{c}$ & $<.05$ & n.s. \\
\hline Crispiness & $24.8 \pm 34.2$ & $23.0 \pm 32.8^{c}$ & n.s. & $26.1 \pm 32.9$ & $26.6 \pm 33.3^{c}$ & n.s. & $<.05$ \\
\hline Creaminess & $31.5 \pm 34.3$ & $26.8 \pm 33.3$ & $<.001$ & $29.5 \pm 33.6$ & $28.5 \pm 34.1$ & n.s. & $<.01$ \\
\hline Umami & $60.2 \pm 27.2^{\mathrm{b}}$ & $54.4 \pm 27.5^{c}$ & $<.0001$ & $56.9 \pm 27.0^{\mathrm{b}}$ & $57.4 \pm 27.0^{c}$ & n.s. & $<.0001$ \\
\hline Sweetness & $45.3 \pm 35.0^{\mathrm{b}}$ & $41.3 \pm 35.0^{c}$ & $<.01$ & $40.3 \pm 33.9^{b}$ & $37.9 \pm 34.9^{c}$ & n.s. & n.s. \\
\hline Sourness & $13.6 \pm 22.7$ & $11.3 \pm 21.0$ & $<.05$ & $11.7 \pm 21.8$ & $13.6 \pm 23.7$ & n.s. & $<.0001$ \\
\hline Bitterness & $7.3 \pm 15.7$ & $6.4 \pm 15.4^{c}$ & n.s. & $8.6 \pm 19.2$ & $8.6 \pm 18.2^{c}$ & n.s. & n.s. \\
\hline Saltiness & $18.5 \pm 27.5$ & $15.1 \pm 26.0^{c}$ & $<.01$ & $18.3 \pm 26.7$ & $18.4 \pm 26.9^{c}$ & n.s. & $<.0001$ \\
\hline
\end{tabular}

${ }^{a}$ p-value: differences between rest and stress within subject group (factorial ANOVA)

${ }^{b}$ differences between normal weight and overweight in rest (factorial ANOVA). Significant at $p<0.005$, ${ }^{c}$ differences between normal weight and overweight in stress (factorial ANOVA). Significant at $p<0.05$ dp-value: group $x$ condition interaction between overweight and normal weight between conditions (two-factor ANOVA with repeated measures)

n.s.=non-significant

$\left(F_{(1,2051)}=5.6, p<0.05\right)$. Additionally, the normal weight group exhibited lower orosensory perception in the stress compared with the rest condition, for creaminess $\left(F_{(1,2556)}=12.6\right.$, $\mathrm{p}<0.001)$, umami $\left(\mathrm{F}_{(1,2556)}=22.4, \mathrm{p}<0.0001\right)$, sweetness $\left(\mathrm{F}_{(1,2556)}=8.6, p<0.01\right)$, sourness $\left(F_{(1,2556)}=3.9, p<0.05\right)$ and saltiness $\left(F_{(1,2556)}=8.4, p<0.01\right)$. In overweight participants, no significant differences were found for the orosensory perception of food in the stress condition when compared with the rest condition.

\section{MULTIPLE REGRESSION ANALYSIS}

In a multiple regression analysis liking was tested as a function of seven orosensory attributes: sweetness, bitterness, saltiness, sourness, umami, creaminess, crispiness. In normal weight participants, liking was positively related with creaminess, umami, sweetness and saltiness, and negatively with bitterness. The same relationships were found in stress as well as in rest (Table 5, $p<0.0001$, respectively $R^{2}=0.14$ and $R^{2}=0.12$ ). 
Table 5. Multiple regression model for normal weight subjects with liking as the dependent variable and crispiness, creaminess, umami, sweetness, sourness, saltiness and bitterness as independent variables

\section{Partial $\beta$ \\ Std. error \\ p-value}

\section{Normal weight rest $(n=20)$}

$R^{2}=0.12, p<0.0001$, intercept $=50.0 \pm 1.8$

$\begin{array}{lccc}\text { crispiness } & -0.003 & 0.02 & 0.87 \\ \text { creaminess } & 0.07 & 0.02 & 0.001 \\ \text { umami } & 0.09 & 0.03 & 0.002 \\ \text { sweetness } & 0.15 & 0.02 & <0.0001 \\ \text { sourness } & -0.06 & 0.03 & 0.05 \\ \text { bitterness } & -0.27 & 0.04 & <0.0001 \\ \text { saltiness } & 0.09 & 0.03 & 0.002\end{array}$

\section{Normal weight rest $(n=19)$}

$R^{2}=0.14, p<0.0001$, intercept $=46.0 \pm 1.6$

\begin{tabular}{lccc} 
crispiness & 0.01 & 0.02 & 0.71 \\
creaminess & 0.12 & 0.02 & $<0.0001$ \\
umami & 0.08 & 0.03 & 0.01 \\
sweetness & 0.16 & 0.02 & $<0.0001$ \\
sourness & -0.04 & 0.03 & 0.22 \\
bitterness & -0.17 & 0.04 & $<0.0001$ \\
saltiness & 0.09 & 0.03 & 0.002 \\
\hline
\end{tabular}

In overweight participants liking was positively related with umami and negatively with bitterness and sourness. The same relationships were found in stress as well as in rest (Table 6, $p<0.0001$, respectively $R^{2}=0.07$ and $R^{2}=0.08$ ).

\section{LIKING}

The difference in liking between groups was unaffected by stress, shown by the absence of significant group $x$ condition interactions for liking (Figure 1). Liking was significantly 
Table 6. Multiple regression model for overweight subjects with liking as the dependent variable and crispiness, creaminess, umami, sweetness, sourness, saltiness and bitterness as independent variables

\section{Partial $\beta$}

\section{Overweight rest $(n=15)$}

$R^{2}=0.08, p<0.0001$, intercept $=49.5 \pm 2.2$

$\begin{array}{lccc}\text { crispiness } & 0.02 & 0.03 & 0.56 \\ \text { creaminess } & -0.004 & 0.03 & 0.88 \\ \text { umami } & 0.20 & 0.04 & <0.0001 \\ \text { sweetness } & 0.01 & 0.03 & 0.78 \\ \text { sourness } & -0.14 & 0.04 & 0.0005 \\ \text { bitterness } & -0.19 & 0.05 & <0.0001 \\ \text { saltiness } & -0.01 & 0.03 & 0.70\end{array}$

\section{Overweight stress $(n=13)$}

$R^{2}=0.07, p<0.0001$, intercept $=48.1 \pm 2.4$

\begin{tabular}{lccc} 
crispiness & -0.003 & 0.03 & 0.92 \\
creaminess & 0.02 & 0.03 & 0.48 \\
umami & 0.18 & 0.04 & $<0.0001$ \\
sweetness & -0.03 & 0.03 & 0.35 \\
sourness & -0.21 & 0.04 & $<0.0001$ \\
bitterness & -0.13 & 0.05 & 0.02 \\
saltiness & 0.04 & 0.04 & 0.26 \\
\hline
\end{tabular}

different between overweight and normal weight participants, always being rated higher by normal weight participants $\left(F_{(1,2078)}=32.3, p<0.0001\right)$, in the stress $\left(F_{(1,2051)}=21.2\right.$, $\mathrm{p}<0.0001)$ as well as in the rest condition $\left(\mathrm{F}_{(1,2329)}=25.9, \mathrm{p}<0.0001\right)$. Furthermore, liking was significantly lower in the stress condition when compared with the rest condition, in overweight $\left(F_{(1,1859)}=4.8, p<0.05\right)$ as well as in normal weight participants $\left(F_{(1,2558)}=9.9\right.$, $\mathrm{p}<0.01)$. Using non-parametric testing the difference in liking between the rest and the stress condition was no longer significant in the overweight subjects $\left(p=0.07, \chi^{2}=6.54\right)$. 


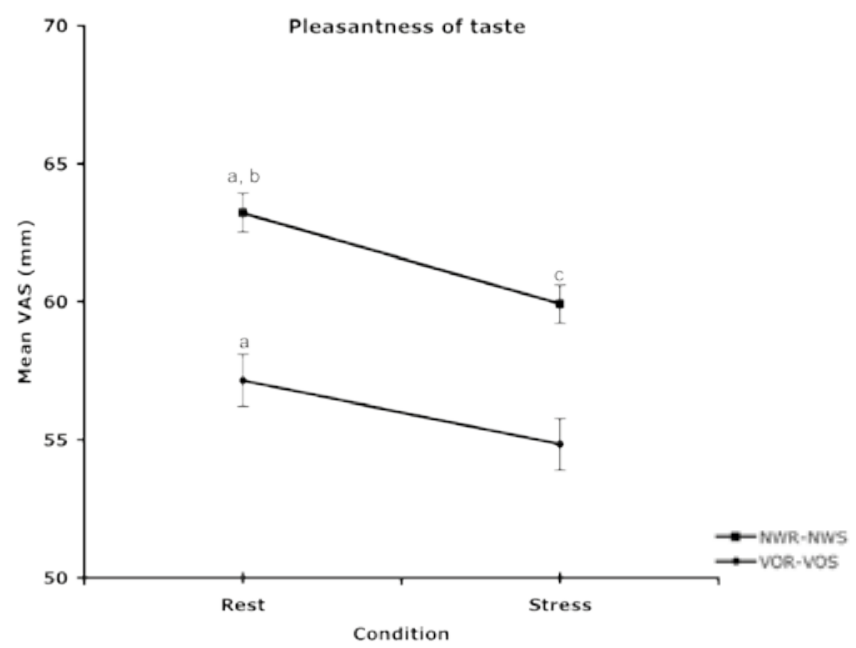

Figure 1. Liking as a function of rest versus stress conditions. Error bars represent SEM. NWR: normal weight participants in rest; NWS: normal weight participants in stress; VOR: visceral overweight participants in rest; VOS: visceral overweight participants in stress. ${ }^{a}$ significant difference between rest and stress within subject group (factorial ANOVA); ${ }^{b}$ significant difference between normal weight and overweight in rest (factorial ANOVA); ${ }^{c}$ significant difference between normal weight and overweight in stress (factorial ANOVA).

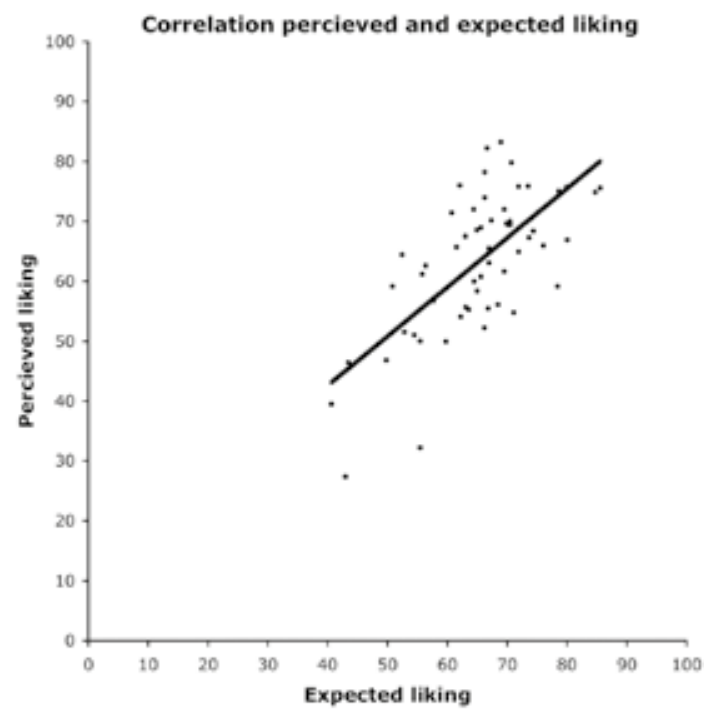

Figure 2. Scatter plot of the mean visual analogue scale (VAS) scores ( $\mathrm{mm}$ ) for perceived liking of the food items during tasting as a function of the expected liking while viewing pictures of the same food items. 


\section{CORRELATION BETWEEN PERCEIVED AND EXPECTED LIKING}

A high correlation was observed between expected liking rated by using pictures, and perceived liking, which was rated during tasting $\left(R^{2}=0.5, p<0.0001\right.$; Figure 2). This high correlation gives further evidence that there were no order or carry-over effects in this trial.

\section{DISCUSSION}

We investigated the effect of stress on liking comparing viscerally overweight participants and normal weight participants. In comparison with the rest condition, stress reduced liking in both groups, independently of visceral adiposity. There are few previous reports on liking in relation to stress. Born et al. have shown that stress can decrease food reward signaling in the brain (20). However, their average predetermined relative liking scores, obtained by using forced choice method, did not differ between the stress and the rest condition (20). However, the use of a forced choice method may have masked slight differences between the stress and the rest condition (20). Support for differences in liking during stress is found in a study of Epstein's group, using 16 restrained and 16 non-restrained women. Between a total of eight taste trials, they performed a variation of the Stroop stressor. Results showed that restrained participants increased their liking ratings over taste trials whereas ratings for non-restrained participants first increased and then decreased to baseline levels by the last trial (41). Our results show a decreased liking in the stress condition when compared with the rest condition in overweight participants as well as in normal weight participants. Therefore, stress seems to influence liking in-dependent of body weight.

Another result of the current study showed that liking appeared to be related to the selected orosensory attributes of food, irrespective of bodyweight or stress. However, the variances explained in the multivariate models were low, suggesting that liking of food is influenced by how the different orosensory attributes of food were perceived. Even though our analyses excluded interactions between attributes from the overall equation, we cannot completely rule out interaction. There may also be other orosensory attributes playing a role, such as taste threshold sensitivity. Although not measured during this trial, other work shows no strong contribution of taste threshold sensitivity to liking or preference (42). For example, 6-n-propylthiouracil (PROP) sensitive individuals maintain preference for bitter products, while there taste threshold for bitter is differed compared to non-PROP sensitive individuals (43).

We also investigated the effect of stress on orosensory attributes (sweetness, bitterness, saltiness, sourness, umami, creaminess, crispiness) in overweight and normal weight participants. In comparison to the rest condition, stress caused a decrease in the rated intensity of several orosensory attributes among normal weight subjects, which was not found in the overweight participants. Previous studies comparing orosensory attributes in normal weight and obese subjects did not take the factor stress into account. However, some studies have shown that sweetness, and sensory cues to high energy density, can 
mitigate effects of stress via the brain's reward system (28). For example, in animals and human infants, the ingestion of sweet and fatty foods, including milk, alleviates crying and other behavioral signs of distress $(44,45)$. This effect depends on sweet taste rather than calories, as non-nutritive sweeteners reduced crying too (46).

In the rest condition, overweight participants showed generally lower liking ratings compared to normal-weight participants. These findings suggest that the general liking of foods is related to body weight. Our findings are in contrast with the studies that show no differences in liking in relationship to weight status (22), but support quite a few studies that show differences in liking for certain food items in obese compared normal weight participants (47-51). However, liking is only one component of food choice and intake behavior and that differences in liking do not completely explain differences in food choice, intake and weight status.

In addition to liking, overweight participants also rated perceived intensity lower compared to normal weight participants for several orosensory attributes; with significant between groups differences for the orosensory attributes crispiness, umami, sweetness, bitterness and saltiness. In order to further analyze these observed difference in orosensory perception, we compared studies on taste thresholds. Earlier studies did not find differences in tasting threshold for various tastes comparing overweight and normal weight participants $(25,26)$. Most studies in which such differences were found included participants after gastric bypass surgeries (25-27). Taken together, it seems less likely that taste threshold differences have caused the differences in orosensory perception in our test. However, to explain differences between normal weight and overweight consumers in terms of their taste sensitivity alone is not appropriate given the complexity of food choice and eating behavior and caution is necessary in drawing conclusions.

A possible explanation for the differences in orosensory perception may be the age difference between our groups. Booth et al. reported that the just noticeable difference in orosensory perception increases with old age, yet liking remained the same (42). However, our subjects were not in the age range where we consider this to play a significant role. Regarding the liking measurements, it is important to highlight that liking measures should not be taken as absolute values and are affected by a wide range of factors. Some articles have shown that liking measures are highly variable and show poor reproducibility across sessions if rather new food products are tested or if satiety for specific nutrients occurs (52-54). Furthermore, no post-hoc measures were taken into account to explain individual differences in VAS usage. However, no outliers in the liking or orosensory ratings were detected. Moreover, the actual differences observed in liking and orosensory perception were small, and although they were statistically significant, the question remains what the actual effects on eating behavior and weight status could be.

To conclude, our results show that orosensory perception and liking of food are reduced in overweight compared to normal weight participants; the latter is especially emphasized during stress. 


\section{ACKNOWLEDGEMENTS}

We thank our participants for their participation in this study. MSWP, MJIM and JMB designed research. JBM developed the computerized $100 \mathrm{~mm}$ VAS. SGTL helped with screening participants. MJIM (supervised by MSWP) conducted research, collected and analyzed the data and wrote the manuscript. JMB, SGTL and TCA reviewed and edited the manuscript.

\section{REFERENCES}

1. Berthoud H-R. Neural control of appetite: cross-talk between homeostatic and non-homeostatic systems. Appetite 2004;43:315-317.

2. Torres SJ, Nowson CA. Relationship between stress, eating behavior, and obesity. Nutrition 2007;23:887-894.

3. Dallman MF. Stress-induced obesity and the emotional nervous system. Trends in Endocrinology \& Metabolism 2010;21:159-165.

4. $\quad$ Adam TC, Epel ES. Stress, eating and the reward system. Physiology \& Behavior 2007;91:449-458.

5. Heatherton TF, Herman CP, Polivy J. Effects of physical threat and ego threat on eating behavior. Journal of Personality and Social Psychology 1991;60:138-143.

6. Rutters F, Nieuwenhuizen AG, Lemmens SGT, Born JM, Westerterp-Plantenga MS. Acute Stressrelated Changes in Eating in the Absence of Hunger. Obesity 2008;17:72-77.

7. Block JP, He Y, Zaslavsky AM, Ding L, Ayanian JZ. Psychosocial stress and change in weight among US adults. American Journal of Epidemiology 2009;170:181-192.

8. Kivimaki M, Head J, Ferrie JE, et al. Work stress, weight gain and weight loss: evidence for bidirectional effects of job strain on body mass index in the Whitehall II study. International Journal of Obesity 2006;30:982-987.

9. Ozier AD, Kendrick OW, Leeper JD, Knol LL, Perko M, Burnham J. Overweight and Obesity Are Associated with Emotion- and Stress-Related Eating as Measured by the Eating and Appraisal Due to Emotions and Stress Questionnaire. Journal of the American Dietetic Association 2008;108:49-56.

10. De Vriendt T, Moreno LA, De Henauw S. Chronic stress and obesity in adolescents: Scientific evidence and methodological issues for epidemiological research. Nutrition, Metabolism and Cardiovascular Diseases 2009;19:511-519.

11. Ulrich-Lai YM, Christiansen AM, Ostrander MM, et al. Pleasurable behaviors reduce stress via brain reward pathways. Proceedings of the National Academy of Sciences 2010;107:20529-20534.

12. Finlayson G, King N, Blundell JE. Liking vs. wanting food: Importance for human appetite control and weight regulation. Neuroscience \& Biobehavioral Reviews 2007;31:987-1002.

13. Epstein LH, Truesdale R, Wojcik A, Paluch RA, Raynor HA. Effects of deprivation on hedonics and reinforcing value of food. Physiology \& Behavior 2003;78:221-227.

14. Berridge KC. 'Liking' and 'wanting' food rewards: Brain substrates and roles in eating disorders. Physiology \& Behavior 2009;97:537-550.

15. Finlayson G, King N, Blundell JE. Is it possible to dissociate 'liking' and 'wanting' for foods in humans? A novel experimental procedure. Physiology \& Behavior 2007;90:36-42.

16. Berridge KC. Food reward: Brain substrates of wanting and liking. Neuroscience \& Biobehavioral Reviews 1996;20:1-25.

17. Mela DJ. Eating for pleasure or just wanting to eat? Reconsidering sensory hedonic responses as a 
driver of obesity. Appetite 2006;47:10-17.

18. Berridge KC. Motivation concepts in behavioral neuroscience. Physiology \& Behavior 2004;81:179209.

19. Epstein LH, Wright SM, Paluch RA, et al. Food hedonics and reinforcement as determinants of laboratory food intake in smokers. Physiology \& Behavior 2004;81:511-517.

20. Born JM, Lemmens SGT, Rutters F, et al. Acute stress and food-related reward activation in the brain during food choice during eating in the absence of hunger. International Journal of Obesity 2010;34:172-181.

21. Cox DN, Perry L, Moore PB, Vallis L, Mela DJ. Sensory and hedonic associations with macronutrient and energy intakes of lean and obese consumers. International Journal of Obesity Related Metabolic Disorders 1999;23:403-410.

22. Cox DN, van Galen M, Hedderley D, Perry L, Moore PB, Mela DJ. Sensory and hedonic judgments of common foods by lean consumers and consumers with obesity. Obesity Research 1998;6:438-447.

23. Lemmens SG, Schoffelen PFM, Wouters L, et al. Eating what you like induces a stronger decrease of 'wanting' to eat. Physiology \& Behavior 2009;98:318-325.

24. Bartoshuk LM, Duffy VB, Hayes JE, Moskowitz HR, Snyder DJ. Psychophysics of sweet and fat perception in obesity: problems, solutions and new perspectives. Philosophical Transactions of the Royal Society B: Biological Sciences 2006;361:1137-1148.

25. De Graaf C. sensory responses, food intake and obesity. In: Mela DJ, ed. Food, diet and obesity. Cambridge, England: Woodland Publishing Limited, 2005:137-159.

26. Nasser J. Taste, food intake and obesity. Obesity Reviews 2001;2:213-218.

27. Scruggs D, Buffington C, Cowan G. Taste Acuity of the Morbidly Obese before and after Gastric Bypass Surgery. Obesity Surgery 1994;4:24-28.

28. Edward LG. Emotional influences on food choice: Sensory, physiological and psychological pathways Physiology \& Behavior 2006;89:53-61.

29. WHO. Obesity: preventing and managing the global epidemic. Report of a WHO consultation. World Health Organ Tech Rep Ser. 2000;894:1-253.

30. Björntorp P. Do stress reactions cause abdominal obesity and comorbidities? Obesity Reviews 2001;2:73-86.

31. Björntorp P, Rosmond R. Obesity and cortisol. Nutrition 2000;16:924-936.

32. Stunkard AJ, Messick S. The three-factor eating questionnaire to measure dietary restraint, disinhibition and hunger. Journal of Psychosomatic Research 1985;29:71-83.

33. Westerterp-Plantenga MS. Eating behavior in humans, characterized by cumulative food intake curves--a review. Neuroscience \& Biobehavioral Reviews 2000;24:239-248.

34. Westerterp KR, Wouters L, Van Marken Lichtenbelt WD. The Maastricht protocol for the measurement of body composition and energy expenditure with labeled water. Obesity Research 1995;3 49-57.

35. Flint A, Raben A, Blundell J, Astrup A. Reproducibility, power and validity of visual analogue scales in assessment of appetite sensations in single test meal studies. International Journal of Obesity Related Metabolic Disorders 2000;24:38-48.

36. Born JM, Lemmens SG, Martens MJI, Formisano E, Goebel R, Westerterp-Plantenga MS. Differences between liking and wanting signals in the human brain and relations with cognitive dietary restraint and body mass index. American Journal of Clinical Nutrition 2011;94:392-403.

37. Peters ML, Godaert GLR, Ballieux RE, et al. Cardiovascular and endocrine responses to experimental stress: Effects of mental effort and controllability. Psychoneuroendocrinology 1998;23:1-17.

38. Lemmens SG, Rutters F, Born JM, Westerterp-Plantenga MS. Stress augments food 'wanting' and energy intake in visceral overweight subjects in the absence of hunger. Physiology \& Behavior 2011;103:157-163.

39. Albrecht RR, Ewing SJ. Standardizing the administration of the Profile of Mood States (POMS): 
development of alternative word lists. Journal of Personality Assessment 1989;53:31-39.

40. Gershon T, David F, Gilad W. A statistical reevaluation of the stai anxiety questionnaire. Journal of Clinical Psychology 1985;41:239-244.

41. Mitchell SL, Epstein LH. Changes in taste and satiety in dietary-restrained women following stress. Physiology \& Behavior 1996;60:495-499.

42. Booth DA, Conner MT, Gibson EL. Measurement of food perception, food preference, and nutrient selection. Annals of the New York Academy of Sciences 1989;561:226-242.

43. Tepper BJ, White EA, Koelliker Y, Lanzara C, D’Adamo P, Gasparini P. Genetic Variation in Taste Sensitivity to 6-n-Propylthiouracil and Its Relationship to Taste Perception and Food Selection. Annals of the New York Academy of Sciences 2009;1170:126-139.

44. Blass EM, Shide DJ, Weller A. Stress-reducing effects of ingesting milk, sugars, and fats. A developmental perspective. Annals of the New York Academy of Sciences 1989;575:292-305.

45. Upadhyay a, Aggarwal R, Narayan S, Joshi M, Paul VK, Deorari AK. Analgesic effect of expressed breast milk in procedural pain in term neonates: a randomized, placebo-controlled, double-blind trial. Acta Paediatrica 2004;93:518-522.

46. Barr RG, Pantel MS, Young SN, Wright JH, Hendricks LA, Gravel R. The response of crying newborns to sucrose: is it a "sweetness" effect? Physiology \& Behavior 1999;66:409-417.

47. Drewnowski A, Brunzell JD, Sande K, Iverius PH, Greenwood MRC. Sweet tooth reconsidered: Taste responsiveness in human obesity. Physiology \& Behavior 1985;35:617-622.

48. Drewnowski A, Kurth C, Holden-Wiltse J, Saari J. Food preferences in human obesity: Carbohydrates versus fats. Appetite 1992;18:207-221.

49. Macdiarmid JI, Vail A, Cade JE, Blundell JE. The sugar-fat relationship revisited: differences in consumption between men and women of varying BMI. International Journal of Obesity 1998;22:10531061.

50. Mela DJ, Sacchetti DA. Sensory preferences for fats: relationships with diet and body composition. American Journal of Clinical Nutrition 1991;53:908-915.

51. Rissanen A, Hakala P, Lissner L, Mattlar CE, Koskenvuo M, T. R. Acquired preference especially for dietary fat and obesity: a study of weight-discordant monozygotic twin pairs. International Journal of Obesity 2002;26:973-977.

52. Köster EP. The psychology of food choice: some often encountered fallacies. Food Quality and Preference 2003;14:359-373.

53. Köster EP, Couronne T, Léon F, Lévy C, Marcelino AS. Repeatability in hedonic sensory measurement: a conceptual exploration. Food Quality and Preference 2003;14:165-176.

54. Lévy CM, Köster EP. The relevance of initial hedonic judgements in the prediction of subtle food choices. Food Quality and Preference 1999;10:185-200. 


\section{APPENDIX}

Supplemental Table 1. Description of the 67 food items divided in six categories.

\begin{tabular}{|c|c|c|c|c|c|}
\hline Bread & Filling & Drinks & Dessert & Sweets & Extra \\
\hline $\begin{array}{l}\text { Baguette } \\
\text { (white) }\end{array}$ & Apricot jam & Apple juice & Apple & $\begin{array}{l}\text { Doritos } \\
\text { (nacho } \\
\text { cheese) }\end{array}$ & $\begin{array}{l}\text { Chicken } \\
\text { soup }\left(60^{\circ} \mathrm{C}\right)\end{array}$ \\
\hline Brown bread & Brie cheese & Buttermilk & $\begin{array}{l}\text { Apricot } \\
\text { cottage } \\
\text { cheese }\end{array}$ & $\begin{array}{l}\text { Lay's natural } \\
\text { chips }\end{array}$ & $\begin{array}{l}\text { Iceberg } \\
\text { salad }\end{array}$ \\
\hline $\begin{array}{l}\text { Brown hard } \\
\text { roll }\end{array}$ & $\begin{array}{l}\text { Chocolate } \\
\text { paste }\end{array}$ & $\begin{array}{l}\text { Carbonated } \\
\text { water }\end{array}$ & Banana & $\begin{array}{l}\text { Lay's paprika } \\
\text { chips }\end{array}$ & $\begin{array}{l}\text { Cracottes } \\
\text { toast }\end{array}$ \\
\hline $\begin{array}{l}\text { Brown soft } \\
\text { bread }\end{array}$ & $\begin{array}{l}\text { Chocolate } \\
\text { sprinkles }\end{array}$ & $\begin{array}{l}\text { Chocolate } \\
\text { milk (full fat) }\end{array}$ & Butter cookie & $\begin{array}{l}\text { Liquorish } \\
\text { (sweet) }\end{array}$ & $\begin{array}{l}\text { Cooking } \\
\text { cream }\end{array}$ \\
\hline $\begin{array}{l}\text { Cracker } \\
\text { (natural) }\end{array}$ & Egg salad & Coca cola & Vanilla cake & $\begin{array}{l}\text { Milk } \\
\text { chocolate }\end{array}$ & $\begin{array}{l}\text { Cheese } \\
\text { cookies }\end{array}$ \\
\hline Croissant & $\begin{array}{l}\text { Forest fruit } \\
\text { jam }\end{array}$ & Fanta & $\begin{array}{l}\text { Chocolate } \\
\text { custard }\end{array}$ & $\begin{array}{l}\text { Napoleon } \\
\text { sour bon } \\
\text { bons }\end{array}$ & $\begin{array}{l}\text { Crunch } \\
\text { muesli apple }\end{array}$ \\
\hline $\begin{array}{l}\text { Currant } \\
\text { bread }\end{array}$ & $\begin{array}{l}\text { Fruit } \\
\text { sprinkles }\end{array}$ & Fristi & $\begin{array}{l}\text { Chocolate } \\
\text { mousse }\end{array}$ & $\begin{array}{l}\text { Peanuts } \\
\text { (salted) }\end{array}$ & $\begin{array}{l}\text { Kinder } \\
\text { bueno } \\
\text { cookie }\end{array}$ \\
\hline $\begin{array}{l}\text { Pumper- } \\
\text { nickel }\end{array}$ & $\begin{array}{l}\text { Gouda } \\
\text { cheese }\end{array}$ & $\begin{array}{l}\text { Milk } \\
\text { (skimmed) }\end{array}$ & $\begin{array}{l}\text { Forest fruit } \\
\text { yoghurt }\end{array}$ & $\begin{array}{l}\text { TUC } \\
\text { (original) } \\
\text { biscuits }\end{array}$ & $\begin{array}{l}\text { Dark grape } \\
\text { juice }\end{array}$ \\
\hline White bread & Ham & Orange juice & Liege waffle & Twix & \\
\hline $\begin{array}{l}\text { White hard } \\
\text { roll }\end{array}$ & $\begin{array}{l}\text { Peanut } \\
\text { butter }\end{array}$ & Plain water & $\begin{array}{l}\text { Marzipan } \\
\text { cake }\end{array}$ & $\begin{array}{l}\text { White } \\
\text { chocolate }\end{array}$ & \\
\hline $\begin{array}{l}\text { White soft } \\
\text { roll }\end{array}$ & $\begin{array}{l}\text { Salami } \\
\text { (plain) }\end{array}$ & Schweppes & $\begin{array}{l}\text { Orange } \\
\text { (peeled) }\end{array}$ & Wine gums & \\
\hline $\begin{array}{l}\text { Whole wheat } \\
\text { roll }\end{array}$ & $\begin{array}{l}\text { Sandwich } \\
\text { spread }\end{array}$ & $\begin{array}{l}\text { White wine } \\
\text { (alcohol free) }\end{array}$ & $\begin{array}{l}\text { Vanilla } \\
\text { custard }\end{array}$ & & \\
\hline
\end{tabular}




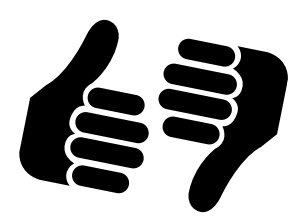




\section{CHAPTER 7}

\section{FLEXIBILTTY OF FOOD-REWARD RELATED BRAIN SIGNALING IN OVERWEIGHT AND NORMAL WEIGHT SUBJECTS}

Martens MJ, Born JM, Lemmens SG, Karhunen L, Heinecke A, Goebel R, Adam TC, Westerterp-Plantenga MS.

Submitted 


\section{ABSTRACT}

Background: flexibility of food-reward related brain signaling (FRS) between food and non-food-stimuli may differ between overweight and normal weight subjects and depend on a fasted or satiated state.

Objective: assessing this flexibility in response to visual food vs. non-food cues. Design: 20 normal weight (age $=22.4 \pm 0.4 \mathrm{y}$, Body Mass index $(\mathrm{BMI})=22.7 \pm 0.2 \mathrm{~kg} / \mathrm{m}^{2}$ ) and 20 overweight participants (age $=24.0 \pm 0.7 \mathrm{y}, \mathrm{BMl}=28.1 \pm 0.3 \mathrm{~kg} / \mathrm{m}^{2}$ ) completed 2 functional magnetic resonance imaging scans. Subjects arrived fasted and consumed breakfast comprising $20 \%$ of subject-specific energy requirements between two successive scans. A block paradigm and a food>non-food contrast was used to determine FRS.

Results: an overall stimulus $\mathrm{x}$ condition $\mathrm{x}$ subject group effect was observed in the anterior cingulate cortex (ACC) $\left(p<0.006, F_{(1,38)}=9.12\right)$ and right putamen $\left(p<0.006, F_{(1,38)}=9.27\right)$. In all participants, FRS decreased from fasted to satiated state in the cingulate $\left(\mathrm{p}<0.005, \mathrm{t}_{(39)=} 3.15\right)$ and right prefrontal cortex $(\mathrm{PFC})\left(\mathrm{p}<0.006, \mathrm{t}_{(39)}=3.00\right)$. In fasted state they showed FRS in the PFC $\left(p<0.004, t_{(39)}=3.17\right)$, left $\left(p<0.009, t_{(39)}=2.95\right)$, right insula $\left(p<0.005, t_{(39)}=3.12\right)$, cingulate cortex $\left(p<0.004, t_{(39)}=3.21\right)$ and thalamus $\left(p<0.006, t_{(39)}=2.96\right)$. In satiated state, FRS was limited to the left $\left(p<0.005, t_{(39)}=3.21\right)$, right insula $\left(p<0.006, t_{(39)}=3.04\right)$ and cingulate cortex $\left(p<0.005, t_{(39)}=3.15\right)$. Regarding subject group, in the fasted state FRS in the AAC was more pronounced in overweight vs. normal weight subjects $\left(p<0.005, F_{(1,38)}=9.71\right)$, while in satiated state, FRS was less pronounced in overweight vs. normal weight subjects in the ACC $\left(p<0.006, F_{(1,38)}=9.18\right)$ and PFC ( $\left.p<0.006, F_{(1,38)}=8.86\right)$, suggesting lower inhibitory control in the overweight. Conclusion: FRS was higher in the overweight in the satiated state, yet when sufficiently satiated they show decreased inhibitory control, facilitating overeating. 


\section{INTRODUCTION}

Understanding the integrative role of the central nervous system in energy and reward homeostasis has become increasingly important as the prevalence of obesity and obesityrelated diseases is rising worldwide $(1,2)$. Previous observations suggest an overlap between the neurocircuitries regulating reward perception and energy homeostasis (3, 4) with homeostatic and reward circuitries acting in concert to regulate eating behavior. Disruption of the interaction between these circuitries might promote overeating and contribute to obesity (3).

Previous functional magnetic resonance imaging (fMRI) studies show that food cues (images, smells and tastes) activate brain regions involved in the processing of reward and control (5-7), including i.e. the nucleus accumbens, the striatum, the ventral tegmental area as well as the anterior cingulate, and prefrontal cortices (5-7). In line with the proposition that obesity is associated with a disruption of the reward circuitry in response to food, previous fMRI studies suggest that overweight/ obese participants show greater brain signaling in response to food cues and anticipated reward compared to normal weight participants (8-12), pre- as well as post-prandially $(8,10,11,13,14)$. Even after diet-induced weight loss, formerly obese humans still exhibit an increased responsiveness to food-cues in reward related brain regions (15-18).

In general, the response to food stimuli was found to be decreased post- versus preprandially $(3,19)$. However, only a few studies investigating food-reward related brain signaling investigated both, a pre- and post-prandial state $(1,19-21)$. The majority of studies has been conducted in the fasted state because of the higher motivation to eat and increased incentive salience of food (10-12, 22-25). However, in the fasted state the processes involved in food reward are intertwined with the homeostatic regulation of food intake and thus difficult to decipher (26). Imaging studies conducted in the post-prandial state argue that the excess energy intake in obesity is at least partly due to eating in the absence of hunger (non-homeostatic eating) $(13,27)$. Therefore, we assessed differences between overweight and normal weight subjects regarding their food-reward related brain signaling in response to food and non-food-stimuli in a fasted as well as a satiated state. The design furthermore controlled for subject specific energy requirement and visual complexity. A similar subject specific design was previously used in a positron emission tomography study by Tataranni et al. (28).

We hypothesized that overweight will show a higher food-reward related brain signaling in the fasted state compared to normal weight subjects. This difference was hypothesized to remain, despite a decrease in salience from the fasted to the satiated condition. 


\section{METHODS AND PROCEDURES}

The study was approved and registered under MEC09-3-085 by the Medical Ethical Committee of Maastricht University, Maastricht, Netherlands, and at the Central Committee on Research Involving Human Subjects, The Hague, Netherlands, under NL30898.068.09. The study was registered in the Dutch clinical trial register under number NTR2174.

\section{SUBJECTS}

In total, 45 subjects were screened. Informed, written consent was obtained from all subjects. Inclusion criteria were healthy male and female subjects, body mass index (BMI) between 20 and $35 \mathrm{~kg} / \mathrm{m}^{2}$, and right-handedness. Exclusion criteria were recent dieting, smoking, a personal or familial history of psychiatric disorder, having metallic fragments in the body, or use of intrauterine contraceptives. Due to the inclusion criteria, forty subjects were included; subject characteristics are summarized in Table 1. The research procedures were in accordance with the Helsinki Declaration. All subjects were informed on the purpose, procedures and potential risks of the study prior to signing the informed consent.

Table 1. Mean $( \pm$ SEM) subject characteristics

\begin{tabular}{lll} 
Subject characteristics & Normal weight & Overweight \\
\hline Male $(\mathrm{n})$ & 10 & 10 \\
Female $(\mathrm{n})$ & 10 & 10 \\
Age (years) & $22.4 \pm 0.5$ & $23.7 \pm 1.0$ \\
BMl $\left(\mathrm{kg} / \mathrm{m}^{2}\right)$ & $22.7 \pm 0.3^{\mathrm{a}}$ & $28.1 \pm 0.5$ \\
Waist-hip ratio & $0.76 \pm 0.02$ & $0.79 \pm 0.01$ \\
TFEQ F1 & $4.7 \pm 0.7$ & $6.5 \pm 0.6$ \\
TFEQ F2 & $4.2 \pm 0.4$ & $4.8 \pm 0.5$ \\
TFEQ F3 & $5.1 \pm 0.6$ & $4.7 \pm 0.8$ \\
DER (MJ) & $12.2 \pm 0.3$ & $13.0 \pm 0.5$ \\
\hline
\end{tabular}

\footnotetext{
a Significantly different between normal weight and overweight $(p<0.0001)$. TFEQ F1-3: Three-factor eating questionnaire factor 1 till 3; DER: daily energy requirement calculated according to the equations of Harris and Benedict and adjusted for the appropriate physical activity level assed by the Baecke questionnaire, expressed in Mega Joules (MJ).
} 


\section{EXPERIMENTAL SET-UP}

To create a fasted and a satiated condition, subjects came to the university after an overnight fast of $10 \mathrm{~h}$. Subjects were instructed not to drink any alcoholic beverages the day before the test and not to eat or drink anything, except for water, after 10 PM the evening before testing. Subjects verbally confirmed their adherence to these instructions. The test day included 4 visual analog scale (VAS) questionnaires for assessing appetite profile and $2 \mathrm{fMRI}$ scans, after which tastiness of the food and non-food pictures were assessed using VAS questionnaires (Figure 1A). Breakfast, which was given between the first and second fMRI scan, created the subsequent satiated condition. Breakfast consisted of typical Dutch breakfast items, comprising a typical healthy breakfast with $18 \%$ protein, $47 \%$ carbohydrate and $35 \%$ fat. The breakfast provided $20 \%$ of subjectspecific calculated daily energy requirements (DER). DER was calculated individually for each of the subjects by multiplying basal metabolic rate (BMR) by the appropriate physical activity factor derived from the Baecke screening questionnaire (mean \pm SEM for all subjects: $1.7 \pm 0.01)(29)$. The BMR was calculated according to the equation of HarrisBenedict (mean \pm SEM for all subjects: $7.4 \pm 0.16 \mathrm{MJ} /$ day) (30). Breakfast was offered immediately after the first scan and had to be consumed in full within 20 minutes, before the second scan.

\section{VISUAL ANALOG SCALE QUESTIONNAIRES}

To determine the effect of the breakfast on the appetite profile, VAS for the factors, hunger, fullness, satiety, desire to eat and thirst were used. VAS were administered four times, before the first scan and immediately after the first scan before breakfast, 20 minutes after the start of breakfast and immediately after the second scan (Figure 1A). The mean of the first two questionnaires was used as 'fasted' measurement and the mean of the last two questionnaires was used as the 'satiated' measurement. To determine whether subjects were able to discriminate between the food and non-food pictures, VAS assessing tastiness were used. These VAS were administered after the completion of both fMRI scans. Food and non-food pictures were shown in a randomized order with the VAS questionnaires beneath each picture. The VAS questionnaires consisted of $100 \mathrm{~mm}$ lines, anchored with "not at all" at the far left "extremely" at the far right. Questions asked were: "How hungry are you?" "How full do you feel?" "How satiated do you feel?" "How large is your desire to eat?" "How thirsty are you?" and "How tasty do you find the picture shown above?". Subjects were instructed to make a single vertical mark at the appropriate point between the two anchors on each scale to indicate their subjective feelings.

\section{FMRI SETTINGS AND PARADIGM}

Subjects were scanned in a Siemens Magnetom Allegra magnetic resonance imaging (MRI) system (3 Tesla, Siemens AG, Erlangen, Germany), with the standard one- 
A

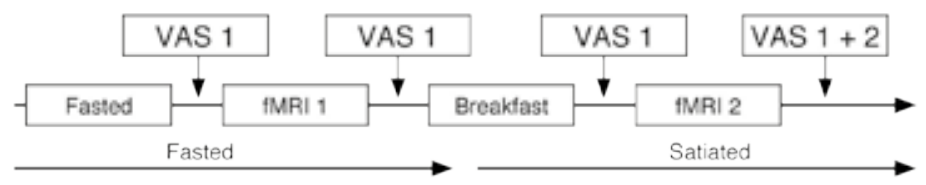

Examples food/non-food stimuli

B

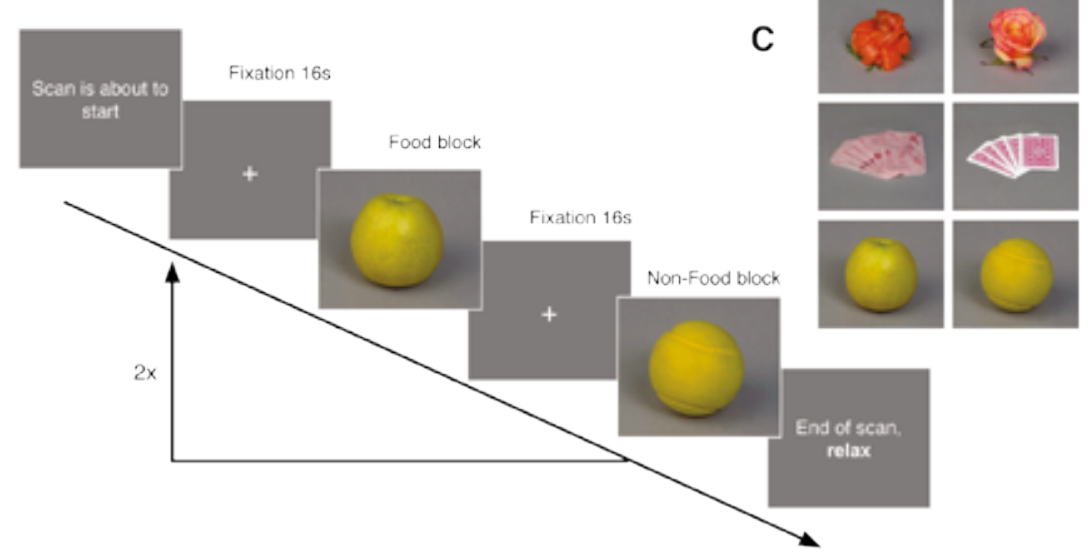

Figure 1. Experimental design: The paradigm consisted of 2 sequential cycles of 6 blocks, 3 different blocks of each stimulus type, each containing 8 pictures, shown for 2 seconds. Blocks were represented in a random order and pictures within the blocks were represented in a permutated order. Different paradigms were used in the fasted and satiated state of which the order was counterbalanced between the subjects. fMRI: functional magnetic resonance imaging, VAS 1: visual analog scales assessing appetite profile, VAS 2: visual analog scales assessing tastiness.

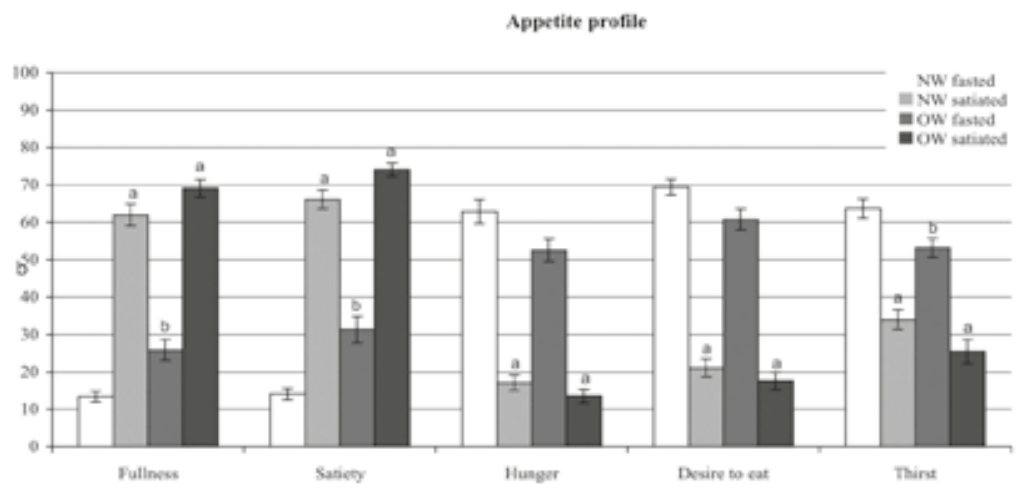

Figure 2. Appetite profile assessed using visual analogue scales (mean \pm SEM). $n$ per group $=20$. VAS questionnaires data were analyzed using two-factor analysis of variance including Bonferroni corrections. VAS questionnaires for appetite were analyzed for the difference pre to post meal, taking baseline-scores as a covariant into account. Tests were two-sided and differences were considered significant at $p<0.05$. The change in VAS scores from the fasted to the satiated state was not significantly different between the subject groups for any of the appetite factors. ${ }^{a}$ Difference between fasted and satiated state, $p<0.0001$; ${ }^{b}$ difference between NW and OW, p<0.05. n per group = 20. "NW": normal weight subjects, "OW": overweight subjects. 


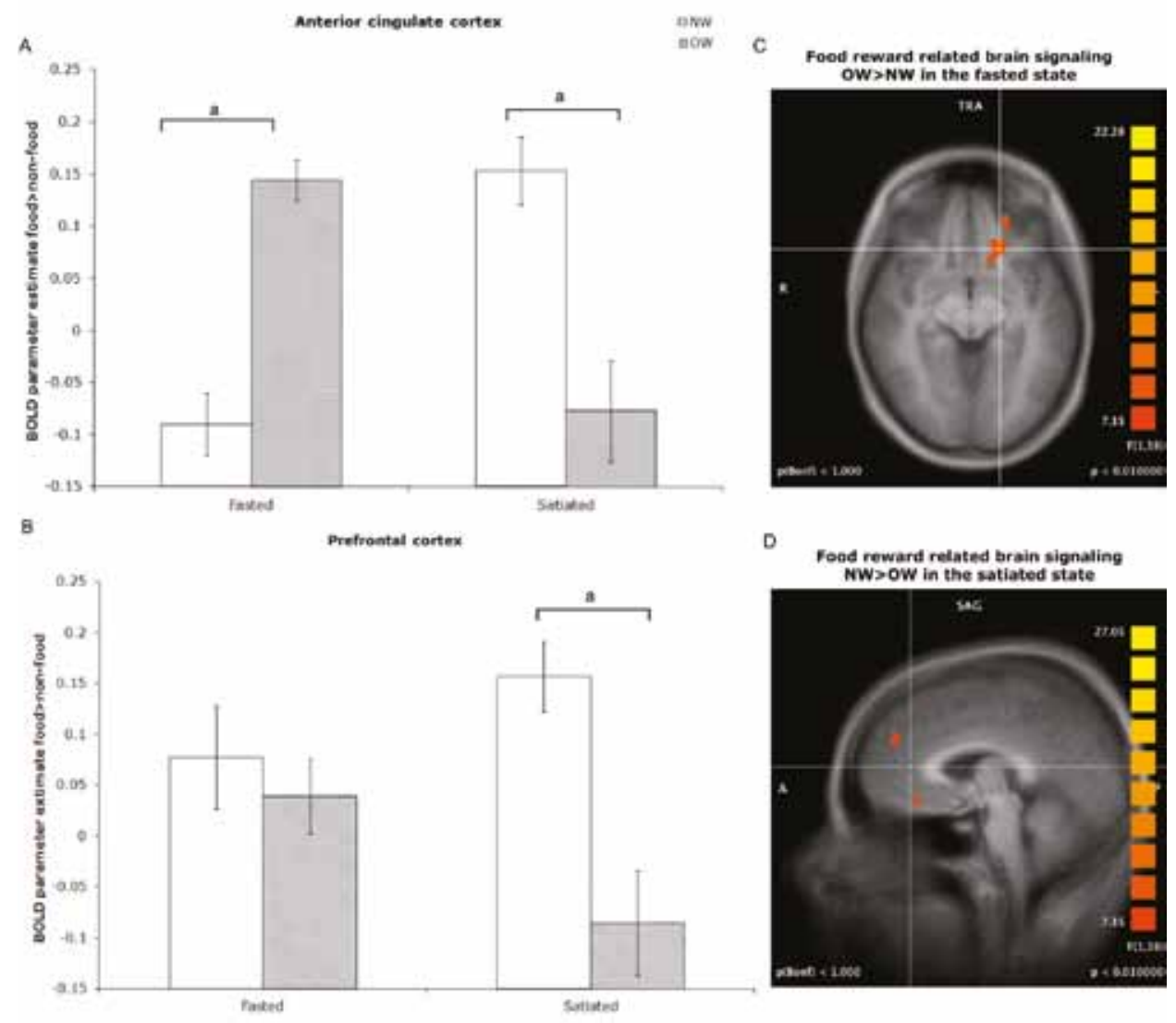

Figure 3. Differences in specific food-reward related brain signaling between NW and OW in the fasted and

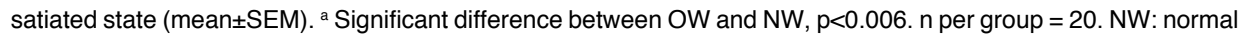
weight subjects, OW: overweight subjects

channel head coil. The subject position was confirmed with T1-weighted scout images. During the functional run, subjects were presented with blocks of food and non-food pictures. Both food and non-food pictures blocks were comprised of both natural and artificial objects (Figure 1C). Food and non-food stimuli where previously validated (31); nonfood stimuli were carefully matched with the food stimuli (31). The photograph of each object was presented on a grey background and the non-food items were matched for color, luminance and visual complexity with the food items (31). All pictures were designed and photographed at the University of Kuopio (31). The paradigm consisted of two sequential cycles of six blocks, three blocks of each stimulus type (food and the non-food items), each block containing eight different pictures (Figure 1B). The stimuli were presented in a counter-balanced manner. The inter-stimulus interval (ISI) was 16 
seconds. To minimize activation related to eye movements during the ISI, the subjects were instructed to visually fixate a central cross on the screen. Each image was shown for two seconds. The computer that controlled the stimulus display was triggered by the scanning sequence. Paradigms composed of different pictures were used in the fasted and satiated state; the order of these different paradigms was counterbalanced between the subjects.

fMRI images were acquired throughout the session by using a $\mathrm{T2}^{*}$-weighted protocol to obtain a blood oxygen level dependent $\mathrm{T}^{*}$ signal $\left(\mathrm{TR}=2 \mathrm{~s}, \mathrm{TE}=26 \mathrm{~ms}\right.$, flip angle $=90^{\circ}$, matrix=96 $\times 96$, field of view=269, voxel size $3 \times 3 \times 2.9 \mathrm{~mm}$, and gap=0.1 mm).

\section{FMRI DATA PREPROCESSING}

All fMRI data were analysed with BrainVoyager QX version 2.3 software (Brain Innovation BV, Maastricht, Netherlands). The first two volumes of each run were discarded for analysis because of T1 saturation effects. Preprocess of the functional data included a slice scan time correction with cubic spline interpolation, three-dimensional motion correction with trilinear interpolated motion estimation (for alignment) and subsequent windowed sinc interpolation (for final re-sampeling), and temporal high-pass filtering for removal of lowfrequency noise with a window of 4 cycles. In the data analysis following preprocessing, the motion correction parameters were included as confound predictors in the general linear model (GLM) using the Brainvoyager Analysis-Predictor tool (BVA-Predictor Tool, J.M. Born, Maastricht (21)). Functional data were aligned to each subject's own 1-mm isovoxel high-resolution T1-weighted anatomical scan, and per run a coregistered volumetime-course was created. The auto alignment was performed by using a 6-parameter affine alignment and was corrected manually under visual inspection, if necessary. Finally, all images were transformed into the Talairach coordinate system (32) by using the standard procedure in the BrainVoyager QX version 2.3 software (Brain Innovation BV) that resulted in a resolution of $3 \times 3 \times 3-\mathrm{mm}$ voxels, which resulted in functional voxels of $27 \mathrm{~mm}^{3}$. Finally, in order to increase the signal-to-noise ratio, the volume-time-courses were spatially smoothed with a $4 \mathrm{~mm}$ full-width-at-half-maximum isotropic Gaussian kernel. For the creation of the GLM and for running the cluster-level threshold estimator tool, as discussed below, a mask was created. The 1-mm isovoxel high-resolution T1weighted anatomical scan of each subject was used to segregate brain from head tissue (grey and white matter) in an automated way, followed by transformation into the Talairach coordinate system. The ventricles were removed from the resulting anatomical scans and the group-average was used to create a mask file.

All statistical analyses were superimposed on a group-average anatomical brain image.

\section{DATA ANALYSES}

Data were analyzed using BrainVoyager QX version 2.3, Microsoft Excel and Statview version 5.0. 
VAS questionnaires data were analyzed using two-factor analysis of variance (ANOVA) including Bonferroni corrections. VAS questionnaires for appetite were analyzed for the difference between pre- and post-meal, taking baseline-scores as a covariant into account. Tests were two-sided and differences were considered significant at $p<0.05$.

To analyze the brain activation, separate predictors for food and non-food were created to be applied in GLM analyses and to be used in the first-level analyses and subsequent second-level analyses. The onset and duration of each trial were defined as the onset and duration of the image presentation (16 s), and the trials were convolved with the standard canonical two-gamma hemodynamic-response function. Additionally, motion correction parameters were added as confound predictors. Based on this modeling approach, the baseline estimation rests on remaining fixation times during each ISI. To investigate the conditions separately and to perform group contrasts of comparisons of fasted and satiated conditions, dummy coding was applied with the BVA-Predictor Tool software. An overall analysis of variances for the factor sex was performed, no effect of sex was observed in any reward related brain area.

Regarding analyses for the complete subject group, whole brain responses were analyzed in a 2 (stimulus: food, non-food) $\times 2$ (condition: fasted, satiated) $\times 2$ (group: normal weight, overweight) random-effects analysis of variance. Furthermore, interaction group contrasts were used to compare differences in activations from the fasted to the satiated condition for the complete subject group in whole brain images.

To compare the subject groups, analyses of variances were conducted for the fasted and the satiated condition in whole brain images using the separate beta-maps for each subject of the relevant contrasts and adding the BMI-category as the between subject factor.

Correlation analyses were conducted in the fasted and the satiated state by testing for a correlation between the relevant contrasts and the covariate BMI.

The resulting whole-brain statistical $F, t$ and $r$ maps were used to identify the resulting significant brain activation at a voxel threshold of $p=0.01$. Thresholded maps were then submitted to a whole-brain correction criterion based on the estimate of the map's spatial smoothness and on an iterative procedure (Monte Carlo simulation) for estimating clusterlevel false-positive rates. After 1,000 iterations, the minimum cluster size threshold that yielded a cluster-level false-positive rate (alpha) of $5 \%$ was applied to the each separate statistical maps $(33,34)$. The Talairach Client (http://www.talairach.org) was consulted to obtain an anatomical label of each single voxel of each significant cluster (35). Excel was used to make an inventory on the quantity of each anatomical label of all the voxels within a cluster, in order to make a correct judgment on the anatomical localization of each significant cluster.

When testing our hypotheses we focused on brain areas involved in the processing of reward and control, introduced in the introduction (i.e.: the nucleus accumbens, the striatum, the ventral tegmental area as well as the anterior cingulate, and prefrontal cortices). 
Table 2. Summary of the fMRI analysis and results

\begin{tabular}{|c|c|c|c|}
\hline Statistical test & $\begin{array}{l}\text { Cluster } \\
\text { threshold }\end{array}$ & Anatomical label resulting clusters & Estimated BA \\
\hline $\begin{array}{l}\text { Stimuli } x \text { condition } x \\
\text { subject group }\end{array}$ & 10 & $\begin{array}{l}\text { Anterior cingulate (bilateral) } \\
\text { Putamen R }\end{array}$ & $24,25,32$ \\
\hline Stimuli $x$ condition & 18 & $\begin{array}{l}\text { Cingulate gyrus (bilateral) } \\
\text { Middle frontal gyrus (PFC) R }\end{array}$ & $\begin{array}{l}32 \\
8\end{array}$ \\
\hline \multirow[t]{4}{*}{ Fasted: $\mathrm{F}>\mathrm{NF}$} & 31 & $\begin{array}{l}\text { Superior/middle/medial frontal gyrus } \\
\text { (PFC) (bilateral) } \\
\text { Insula L }\end{array}$ & $\begin{array}{c}8,9 \\
10,46 \\
13\end{array}$ \\
\hline & & Insula R & 13 \\
\hline & & Cingulate gyrus (bilateral) & 31 \\
\hline & & Thalamus (bilateral) & \\
\hline $\begin{array}{l}\text { Fasted: stimuli } x \\
\text { subject group }\end{array}$ & 10 & Anterior cingulate $(A A C) L$ & 32 \\
\hline $\begin{array}{l}\text { Fasted: correlation } \\
\text { F>NF with BMI }\end{array}$ & 8 & Anterior cingulated (AAC) $\mathrm{L}$ & 32 \\
\hline \multirow[t]{3}{*}{ Satiated: $\mathrm{F}>\mathrm{NF}$} & 17 & Insula L & 13 \\
\hline & & Insula R & 13 \\
\hline & & Anterior cingulate (AAC) (bilateral) & 24,31 \\
\hline \multirow{2}{*}{$\begin{array}{l}\text { Satiated: stimuli x } \\
\text { subject group }\end{array}$} & 11 & Anterior cingulated (AAC) (bilateral) & 32 \\
\hline & & Superior frontal gyrus (PFC) (bilateral) & 8,9 \\
\hline $\begin{array}{l}\text { Satiated: correlation } \\
\text { F>NF with BMI }\end{array}$ & 8 & Superior frontal gyrus (PFC) (bilateral) & 6,9 \\
\hline
\end{tabular}

The Talairach Client (http://www.talairach.org) was consulted to obtain an anatomical label of each single voxel of each significant cluster (35). Excel was used to make an inventory on the quantity of each anatomical label of all the voxels within a cluster, in order to make a correct judgment on the anatomical localization of each significant cluster, here the peak voxel coordinates are given as a reference. Cluster threshold was based on the 


\begin{tabular}{|c|c|c|c|c|c|}
\hline $\begin{array}{l}\text { Number of } \\
\text { voxels }\end{array}$ & Statistical value & P-value & $\begin{array}{l}\text { Peak voy } \\
\text { Talaraich }\end{array}$ & linate & \\
\hline & & & $x$ & $y$ & z \\
\hline 748 & $F_{(1,38)}=9.12$ & 0.0054 & 2 & 10 & -9 \\
\hline 422 & $F_{(1,38)}=9.27$ & 0.0052 & 29 & -8 & 9 \\
\hline 673 & $t_{(39)}=3.15$ & 0.0043 & -1 & 13 & 42 \\
\hline 584 & $t_{(39)}=3.00$ & 0.0054 & 29 & 43 & 45 \\
\hline 29069 & $t_{(39)}=3.17$ & 0.0043 & 2 & 13 & 45 \\
\hline 1086 & $t_{(39)}=2.95$ & 0.0059 & -13 & 7 & -9 \\
\hline 1558 & $t_{(39)}=3.12$ & 0.0044 & 35 & 7 & -6 \\
\hline 11371 & $t_{(39)}=3.21$ & 0.0041 & -1 & -44 & 33 \\
\hline 940 & $t_{(39)}=2.96$ & 0.0058 & 2 & -17 & 6 \\
\hline 1291 & $F_{(1,38)}=9.71$ & 0.0047 & -13 & 19 & -12 \\
\hline 457 & $r_{(38)}=0.47$ & 0.0038 & -13 & 16 & -12 \\
\hline 1032 & $t_{(39)}=3.21$ & 0.0040 & 41 & 7 & -6 \\
\hline \multirow[t]{2}{*}{795} & $t_{(39)}=3.04$ & 0.0051 & -40 & 4 & -6 \\
\hline & $t_{(39)}=3.15$ & 0.0042 & -1 & 31 & 21 \\
\hline 420 & $F_{(1,38)}=9.18$ & 0.0053 & -7 & 37 & -9 \\
\hline 1146 & $F_{(1,38)}=8.86$ & 0.0058 & -16 & 52 & 33 \\
\hline 958 & $r_{(38)}=-0.45$ & 0.0042 & -13 & 25 & 57 \\
\hline
\end{tabular}

estimate of the map's spatial smoothness and on an iterative procedure (Monte Carlo simulation) for estimating cluster-level false-positive rates. After 1,000 iterations, the minimum cluster size threshold that yielded a clusterlevel false-positive rate (alpha) of $5 \%$ was applied to the each separate statistical maps $(33,34)$. $\mathrm{n}$ per group = 20. Abbreviations: AAC, anterior cingulate cortex; BA, Brodmann area; F>NF, food - non-food contrast; $L$, left hemisphere; PFC, prefrontal cortex; R, right hemisphere. 


\section{RESULTS}

The fasted state before the first scan was confirmed by low VAS scores for satiety and fullness, and high scores for hunger, thirst and desire to eat (Figure 2). Eating the subjectspecific breakfast lead to significantly decreased hunger, thirst and desire to eat, and to increased satiety and fullness for the remainder of the session (Figure 2, $p<0.0001$ ). The change in VAS scores from the fasted to the satiated state was not significantly different between the subject groups for any of the appetite factors.

Subjects were able to discriminate between food and non-food pictures as they judged the food pictures to be significantly tastier compared to the non-food pictures $(p<0.0001)$. FMRI results are summarized in Table 2. Significant differences in activated areas indicate a consistently higher activation in response to food compared to non-food cues; activation in response to non-food cues was never higher compared to food cues. An overall stimuli (food, non-food) $x$ condition (fasted, satiated) $x$ subject group (normal weight, overweight) effect was observed in the anterior cingulate cortex $(A A C)(p<0.006$, $\left.F_{(1,38)}=9.12\right)$ and the right putamen $\left(p<0.006, F_{(1,38)}=9.27\right)$, implying a larger change in specific food-reward related brain signaling from the fasted to the satiated condition in the overweight compared to the normal weight, as will be further detailed below. Comparing the fasted with the satiated state, participants showed a decrease in food-reward related brain signaling from the fasted to the satiated state in the cingulate $\left(p<0.005, t_{(39)}=3.15\right)$ and the right prefrontal cortex (PFC) $\left(\mathrm{p}<0.006, \mathrm{t}_{(39)}=3.00\right)$.

In the fasted state the whole group of participants showed a specific food-reward related brain signaling in response to the food $>$ non-food contrast in the PFC $(p<0.004$, $\left.\mathrm{t}_{(39)}=3.17\right)$, left $\left(\mathrm{p}<0.009, \mathrm{t}_{(39)}=2.95\right)$ and right insula $\left(\mathrm{p}<0.005, \mathrm{t}_{(39)}=3.12\right)$, cingulate cortex $\left(p<0.004, t_{(39)}=3.21\right)$ and thalamus $\left(p<0.006, t_{(39)}=2.96\right)$. Only in the ACC this signaling was more pronounced in the overweight vs. the normal weight subjects $(p<0.005$, $F_{(1,38)}=9.71$ ) (Figure 3A). Furthermore, the food $>$ non-food contrast activation in the ACC was positively associated with $\mathrm{BMI}\left(\mathrm{p}<0.004, \mathrm{r}_{(38)}=0.47 \pm 0.002\right)$.

In the satiated state the complete subject group's specific food-reward related brain signaling in reaction to the food $>$ non-food contrast was limited to the left $(p<0.005$, $\left.t_{(39)}=3.21\right)$ and right insula $\left(p<0.006, t_{(39)}=3.04\right)$ and ACC $\left(p<0.005, t_{(39)}=3.15\right)$. When satiated, signaling in the ACC was less pronounced in the overweight vs. the normal weight subjects $\left(p<0.006, F_{(1,38)}=9.18\right.$ ) (Figure 3A). At the same time, in the satiated state a less pronounced food-reward related brain signaling in the overweight vs. normal weight subjects was observed in the PFC $\left(p<0.006, F_{(1,38)}=8.86\right)$ (Figure 3B), suggesting a lower inhibitory control. In the satiated condition, the food>non-food contrast was negatively associated with BMI in the left PFC $\left(p<0.005, r_{(38)}=-0.45 \pm 0.002\right)$. 


\section{DISCUSSION}

The current study assessed differences between overweight and normal weight subjects in food-reward related brain signaling between food and non-food-stimuli comparing a fasted and a satiated state, while controlling for subject specific energy requirement. We hypothesized that overweight vs. normal weight subjects show a more pronounced food-reward related brain signaling in the fasted state, which may remain elevated compared to the normal weight, despite a decreased salience from the fasted to the satiated condition.

Our results show that overweight vs. normal weight subjects showed more pronounced food-reward anticipating related brain signaling in the fasted state in the ACC. This is in line with previous research $(1,36,37)$. Führer et al. previously observed a significant interaction in activation pattern between the states of hunger and satiety and stimulation with food and non-food images in the left ACC, the superior occipital sulcus and in the vicinity of the right amygdala (1).

The second part of our hypothesis, comparing the fasted and the satiated state, was only partly confirmed; we observed a decrease in food-reward related brain signaling from the fasted to the satiated state in the cingulate and the right PFC, which was also observed in previous research (3). However, the results did not confirm our hypothesis regarding the difference between normal weight and overweight subjects in the satiated state. In fact, the exact opposite was found: when sufficiently satiated, food-reward related brain signaling was less pronounced in the overweight compared to the normal weight subjects in the ACC and the PFC. This suggests that the higher focus on food in the overweight, which has been reported in the literature $(3,11,23)$, may fade in a sufficiently satiated state achieved by providing a meal according to subject-specific energy requirements. Born et al. previously identified the cingulated cortex as a brain area specific for 'wanting' signaling (19). We observed that a post-prandial decreased food-reward related signaling in the cingulate cortex in the overweight vs. normal weight can be attributed to the provision of a meal meeting subject-specific energy requirements. In addition to "wanting", the incentive salience concept by Berridge et al. introduces the component of "liking" (25, 38-41). We did not find any differences between normal weight and overweight subjects in brain signaling in the insula, the area associated with 'liking' (19). We can thus speculate that liking for food does not change between a fasted and satiated state comparing overweight and weight subjects. This is in line with several studies reporting that individuals rate liking at a constant level across several food items, irrespective of weight status or satiety state $(20,42-46)$.

However, our results show that post-prandial brain signaling in the PFC was lower in the overweight compared to the normal weight, which we speculate may imply less inhibitory control in the overweight when satiated. The prefrontal cortex forms an important part of the circuitry in which associations between visual cues and the actions or choices they 
specify are formed and it plays a central role in the inhibition of inappropriate behaviors (47-49). A previous PET study by Tataranni et al. in lean subjects, which used a subject specific design similar to ours, already showed that satiation was associated with an increased activity in the PFC (28). Other PET studies in lean and obese subjects further indicated that the PFC may play an important role in the central regulation of eating behavior by sending inhibitory inputs $(28,36,47-52)$. These studies showed that satiation was associated with an increased activity in the PFC. However, when comparing obese with lean people studies show conflicting results $(28,48-51)$. Gautier et al. reported a larger increase in PFC activity from the fasted to the satiated state in the obese vs. lean men and women $(50,51)$, while Le et al. showed the exact opposite (49). The most recent study in line with our results shows an association between obesity and a satiation-related reduction in PFC activity (53). In an earlier study, Le et al. reported the same increase in PFC activity caused by satiety in post-obese women compared to lean women. In obese women this increase was significantly lower compared to both lean and post-obese women (48). The lack of differences in PFC signaling between lean and post-obese research participants may be due to functional differences in the PFC as a consequence of obesity and are reversible, thus flexible. Since research showed that the decreased inhibitory control, observed as a decreased PFC signaling in the obese, could be reversible, neurofeedback methodology to increase activity in the prefrontal cortex may be a target for prevention in the future. Among the studies using fMRI, the group of Stice et al. among others showed that in a hungry state BMI is negatively associated with activation in the PFC when subjects are required to inhibit responses to appetizing foods $(13,23)$. A similar inverse relationship between BMI and PFC activation was found in the current study in the satiated state.

We did not observe an effect of sex in any of the reward related brain areas, although previous neuroimaging studies have reported significant gender differences in brain activation during the physiological conditions of hunger and satiety in response to flavor $(54,55)$, food pictures $(37,56)$ and in response to pure tastes $(57)$. Strong points of our study are the simultaneous investigation of obese and lean participants in a fasted and satiated state. Moreover, the use of well matched food and non-food cues and providing meals meeting identical subject-specific energy requirements. Limitations of the present study are that subjects did not perform a task during scanning. Therefore, we are not absolutely sure that attention to the stimuli was paid throughout the entire experiment. Furthermore, the repetition of the measurement on the same day is a limitation. In future studies, adding a task during the inter-stimulus interval and counterbalancing the conditions on different test days would eliminate these limitations.

In conclusion, food reward related signaling was higher in the overweight in the satiated state. When sufficiently satiated, food reward related signaling is lower in the overweight compared to the normal-weight, but inhibitory control is decreased, facilitating overeating, which may result in eating in the absence of hunger. 


\section{ACKNOWLEDGEMENTS}

We thank our subjects for their participation in this study. Furthermore, we thank $A$. Heinecke for extensive support with BrainVoyager QX version 2.3 software (Brain Innovation BV). The authors' responsibilities were as follows: MJIM: conceived and conducted the experiment, including the $\mathrm{fMRI}$, analyzed data, and wrote the manuscript; JMB: advised on the setup of the paradigm, assisted the experiment $\mathrm{FMRI}$, and the fMRI preprocessing, reviewed the manuscript; SGTL: assisted the experiment fMRI, reviewed the manuscript; LK: provided the food and non-food pictures for the paradigm, advised on the setup of the paradigm; $A H$ : assisted the fMRI preprocessing and data analysis; RG: advised on the setup of the $\mathrm{fMRI}$ paradigm, supervised $\mathrm{fMRI}$ data analysis, and reviewed the manuscript; TCA: advised on the data analyses and reviewed the manuscript and MSW-P: conceived and supervised the experiment, supervised data analysis, and reviewed the manuscript. Top Institute Food and Nutrition did not influence the study design, implementation, analysis, or interpretation of data. None of the authors declared a conflict of interest.

\section{REFERENCES}

1. Fuhrer D, Zysset S, Stumvoll M. Brain Activity in Hunger and Satiety: An Exploratory Visually Stimulated fMRI Study. Obesity. 2008;16:945-50.

2. Schwartz MW, Woods SC, Porte D, Seeley RJ, Baskin DG. Central nervous system control of food intake. Nature. 2000;404:661-71.

3. Volkow ND, Wang G-J, Baler RD. Reward, dopamine and the control of food intake: implications for obesity. Trends in Cognitive Sciences. 2011;15:37-46.

4. Lattemann DF. Endocrine links between food reward and caloric homeostasis. Appetite. 2008;51:4525.

5. Berthoud H, Lenard N, Shin A. Food reward, hyperphagia, and obesity. Am J Physiol Regul Integr Comp Physiol 2011;300:R1266-77.

6. O'Doherty JP. Reward representations and reward-related learning in the human brain: insights from neuroimaging. Current Opinion in Neurobiology. 2004;14:769-76.

7. Del Parigi A, Gautier J-F, Chen K, Salbe AD, Ravussin E, Reiman E, Tataranni PA. Neuroimaging and Obesity. Annals of the New York Academy of Sciences. 2002;967:389-97.

8. Stice E, Yokum S, Burger K, Epstein L, DM. S. Youth at risk for obesity show greater activation of striatal and somatosensory regions to food. J Neurosci. 2011;31:4360-6.

9. Gearhardt A, Yokum S, Orr P, Stice E, Corbin W, Brownell K. Neural correlates of food addiction. Arch Gen Psychiatry. 2011;68:808-16.

10. Rothemund Y, Preuschhof C, Bohner G, Bauknecht H-C, Klingebiel R, Flor H, Klapp BF. Differential activation of the dorsal striatum by high-calorie visual food stimuli in obese individuals. Neurolmage. 2007;37:410-21.

11. Stoeckel LE, Weller RE, Cook lii EW, Twieg DB, Knowlton RC, Cox JE. Widespread reward-system activation in obese women in response to pictures of high-calorie foods. Neurolmage. 2008;41:63647. 
12. Stice E, Spoor S, Bohon C, Veldhuizen M, DM S. Relation of reward from food intake and anticipated food intake to obesity: a functional magnetic resonance imaging study. J Abnorm Psychol. 2008;117.:924-35.

13. Frankort A, Roefs A, Siep N, Roebroeck A, Havermans R, Jansen A. Reward activity in satiated overweight women is decreased during unbiased viewing but increased when imagining taste: an event-related fMRI study. Int J Obes. 2011;36:627-37.

14. Martin LE, Holsen LM, Chambers RJ, Bruce AS, Brooks WM, Zarcone JR, Butler MG, Savage CR. Neural Mechanisms Associated With Food Motivation in Obese and Healthy Weight Adults. Obesity. 2009;18:254-60.

15. Sweet LH, Hassenstab JJ, McCaffery JM, Raynor HA, Bond DS, Demos KE, Haley AP, Cohen RA, Del Parigi A, Wing RR. Brain response to food stimulation in obese, normal weight, and successful weight loss maintainers. Obesity. 2011.

16. DelParigi A, Chen K, Salbe A, Hill J, Wing R, Reiman E, Tataranni P. Persistence of abnormal neural responses to a meal in postobese individuals. Int J Obes Relat Metab Disord. 2004;28:370-7.

17. DelParigi A, Chen K, Salbe A, Hill J, Wing R, Reiman E, Tataranni P. Successful dieters have increased neural activity in cortical areas involved in the control of behavior. Int J Obes. 2007;31:4408.

18. McCaffery J, Haley A, Sweet L, Phelan S, Raynor H, Del Parigi A, Cohen R, Wing R. Differential functional magnetic resonance imaging response to food pictures in successful weigh-loss maintainers relative to normal-weight and obese controls. Am J Clin Nutr. 2009;90:928-34.

19. Born J, Lemmens S, Martens M, Formisano E, Goebel R, MS W-P. Differences between liking and wanting signals in the human brain and relations with cognitive dietary restraint and body mass index. Am J Clin Nutr. 2011;94:392-403.

20. Born JM, Lemmens SGT, Rutters F, Nieuwenhuizen AG, Formisano E, Goebel R, WesterterpPlantenga MS. Acute stress and food-related reward activation in the brain during food choice during eating in the absence of hunger. International Journal of Obesity. 2010;34:172-81.

21. Born JM, Martens MJI, Rutters F, Lemmens SGT, Goebel R, Westerterp-Plantenga MS. High HPAaxis activation disrupts the link between liking and wanting with liking and wanting related brain signaling. Physiology \& Behavior. 2012;105:321-4.

22. Wallner-Liebmann S, Koschutnig K, Reishofer G, Sorantin E, Blaschitz B, Kruschitz R, Unterrainer HF, Gasser R, Freytag F, et al. Insulin and Hippocampus Activation in Response to Images of HighCalorie Food in Normal Weight and Obese Adolescents. Obesity. 2011;18:1552-7.

23. Batterink L, Yokum S, Stice E. Body mass correlates inversely with inhibitory control in response to food among adolescent girls: An fMRI study. Neurolmage. 2010;52:1696-703.

24. Siep N, Roefs A, Roebroeck A, Havermans R, Bonte ML, Jansen A. Hunger is the best spice: An fMRI study of the effects of attention, hunger and calorie content on food reward processing in the amygdala and orbitofrontal cortex. Behavioural Brain Research. 2009;198:149-58.

25. Berridge KC. Motivation concepts in behavioral neuroscience. Physiology \& Behavior. 2004;81:179209.

26. Rolls ET. Sensory processing in the brain related to the control of food intake. Proceedings of the Nutrition Society. 2007;66:96-112.

27. Zheng $\mathrm{H}$, Lenard NR, Shin AC, Berthoud HR. Appetite control and energy balance regulation in the modern world: reward-driven brain overrides repletion signals. Int J Obes. 2009;33:S8-S13.

28. Tataranni P, Gautier J, Chen K, Uecker A, Bandy D, Salbe A, Pratley R, Lawson M, Reiman E, Ravussin E. Neuroanatomical correlates of hunger and satiation in humans using positron emission tomography. Proc Natl Acad Sci U S A. 1999;96:4569-74.

29. Philippaerts RM, Westerterp KR, Lefevre J. Doubly Labeled Water Validation of three Physical Activity Questionnaires. Int J Sports Med. 1999;20:284-9. 
30. Harris JA, Benedict FG. A Biometric Study of Human Basal Metabolism. Proc Natl Acad Sci. 1918;4:370-3.

31. Kaurijoki S, Kuikka JT, Niskanen E, Carlson S, Pietiläinen KH, Pesonen U, Kaprio JM, Rissanen A, Tiihonen J, Karhunen L. Association of serotonin transporter promoter regulatory region polymorphism and cerebral activity to visual presentation of food. Clinical Physiology and Functional Imaging. 2008;28:270-6.

32. Talairach J, Tournoux P. Co-Planar Stereotaxic Atlas of the Human Brain: 3-Dimensional Proportional System - an Approach to Cerebral Imaging. New York: Thieme Medical Publishers; 1988.

33. Goebel R, Esposito F, Formisano E. Analysis of functional image analysis contest (FIAC) data with brainvoyager QX: From single-subject to cortically aligned group general linear model analysis and self-organizing group independent component analysis. Human Brain Mapping. 2006;27:392-401.

34. Forman S, Cohen J, Fitzgerald M, Eddy W, Mintun M, DC N. Improved assessment of significant activation in functional magnetic resonance imaging (fMRI): use of a cluster-size threshold. Magnetic Resonance in Medicine. 1995;33:636-47.

35. Lancaster JL, Woldorff MG, Parsons LM, Liotti M, Freitas CS, Rainey L, Kochunov PV, Nickerson D, Mikiten SA, Fox PT. Automated Talairach Atlas labels for functional brain mapping. Human Brain Mapping. 2000;10:120-31.

36. Volkow ND, Wang G-J, Telang F, Fowler JS, Goldstein RZ, Alia-Klein N, Logan J, Wong C, Thanos PK, et al. Inverse Association Between BMI and Prefrontal Metabolic Activity in Healthy Adults. Obesity. 2008;17:60-5.

37. Frank S, Laharnar N, Kullmann S, Veit R, Canova C, Hegner YL, Fritsche A, PreissI H. Processing of food pictures: Influence of hunger, gender and calorie content. Brain Research. 2010;1350:159-66.

38. Berridge KC. Food reward: Brain substrates of wanting and liking. Neuroscience \& Biobehavioral Reviews. 1996;20:1-25.

39. Berridge KC. 'Liking' and 'wanting' food rewards: Brain substrates and roles in eating disorders. Physiology \& Behavior. 2009;97:537-50.

40. Berthoud H-R. Neural control of appetite: cross-talk between homeostatic and non-homeostatic systems. Appetite. 2004;43:315-7.

41. Finlayson G, King N, Blundell JE. Is it possible to dissociate 'liking' and 'wanting' for foods in humans? A novel experimental procedure. Physiology \& Behavior. 2007;90:36-42.

42. Cox DN, Perry L, Moore PB, Vallis L, Mela DJ. Sensory and hedonic associations with macronutrient and energy intakes of lean and obese consumers. International Journal of Obesity Related Metabolic Disorders. 1999;23:403-10.

43. Cox DN, van Galen M, Hedderley D, Perry L, Moore PB, Mela DJ. Sensory and hedonic judgments of common foods by lean consumers and consumers with obesity. Obesity Research. 1998;6:438-47.

44. Epstein LH, Truesdale R, Wojcik A, Paluch RA, Raynor HA. Effects of deprivation on hedonics and reinforcing value of food. Physiology \& Behavior. 2003;78:221-7.

45. Lemmens SG, Rutters F, Born JM, Westerterp-Plantenga MS. Stress augments food 'wanting' and energy intake in visceral overweight subjects in the absence of hunger. Physiology \& Behavior. 2011;103:157-63.

46. Mela DJ. Eating for pleasure or just wanting to eat? Reconsidering sensory hedonic responses as a driver of obesity. Appetite. 2006;47:10-7.

47. Yokum S, $\mathrm{Ng} \mathrm{J}$, Stice E. Attentional Bias to Food Images Associated With Elevated Weight and Future Weight Gain: An fMRI Study. Obesity. 2011;19:1775-83.

48. Le D, Pannacciulli N, Chen K, Salbe A, Del Parigi A, Hill J, Wing R, Reiman E, Krakoff J. Less activation in the left dorsolateral prefrontal cortex in the reanalysis of the response to a meal in obese than in lean women and its association with successful weight loss. Am J Clin Nutr 2007;86:573-9.

49. Le D, Pannacciulli N, Chen K, Del Parigi A, Salbe A, Reiman E, J K. Less activation of the left 
dorsolateral prefrontal cortex in response to a meal: a feature of obesity. Am J Clin Nutr. 2006;84:72531.

50. Gautier J, Chen K, Salbe A, Bandy D, Pratley R, Heiman M, Ravussin E, Reiman E, PA T. Differential brain responses to satiation in obese and lean men. Diabetes. 2000;49:838-46.

51. Gautier J, Del Parigi A, Chen K, Salbe A, Bandy D, Pratley R, Ravussin E, Reiman E, Tataranni P. Effect of satiation on brain activity in obese and lean women. Obes Res. 2001;9:676-84.

52. Wang G, Volkow N, Telang F, Jayne M, Ma Y, Pradhan K, Zhu W, Wong C, Thanos P, et al. Evidence of gender differences in the ability to inhibit brain activation elicited by food stimulation. Proc Natl Acad Sci U S A. 2009;106:1249-54.

53. Le DSNT, Chen K, Pannacciulli N, Gluck M, Reiman EM, Krakoff J. Reanalysis of the Obesity-Related Attenuation in the Left Dorsolateral Prefrontal Cortex Response to a Satiating Meal Using Gyral Regions-of-Interest. Journal of the American College of Nutrition. 2009 December 1, 2009;28:667-73.

54. Del Parigi A, Chen K, Gautier J, Salbe A, Pratley R, Ravussin E, Reiman E, Tataranni P. Sex differences in the human brain's response to hunger and satiation. Am J Clin Nutr 2002;75:1017-22.

55. Smeets P, de Graaf C, Stafleu A, van Osch M, Nievelstein R, van der Grond J. Effect of satiety on brain activation during chocolate tasting in men and women. Am J Clin Nutr. 2006;83:1297-305.

56. Cornier M-A, Salzberg AK, Endly DC, Bessesen DH, Tregellas JR. Sex-based differences in the behavioral and neuronal responses to food. Physiology \&amp; Behavior. 2010;99:538-43.

57. Haase L, Green E, Murphy C. Males and females show differential brain activation to taste when hungry and sated in gustatory and reward areas. Appetite. 2010;57:421-34. 


\section{CHAPTER 8 \\ GENERAL DISCUSSION}

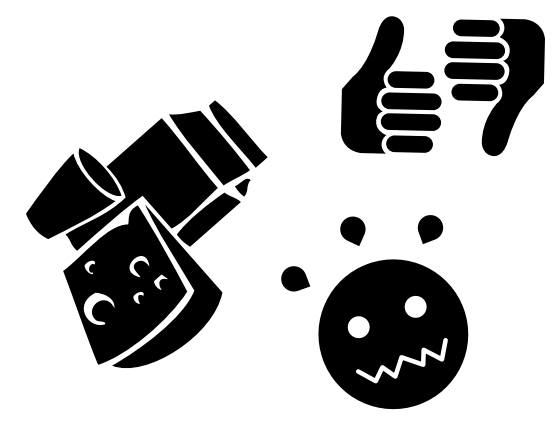


The research presented in this thesis focused on the identification of risks for dysregulated appetite. Texture, mode of consumption, stress, food reward and decreased inhibition were related to differences in appetite profile, physiological parameters, liking and orosensory perception of food and weight-status. A selection of risks for dysregulated appetite was made; other risks such as sleep deprivation, distraction during the meal, unbalanced macronutrient-intakes etc. are beyond the scope of this thesis. The identified risks for dysregulated appetite may influence meal termination, leading to overeating and eating in the absence of hunger, thereby increasing the risk for overweight and obesity. Potential mechanisms by which each of these risks can influence meal termination and lead to overeating are discussed below. From risk identification, possible strategies to avoid overeating and eating in the absence of hunger are derived. Finally, the overall conclusions and recommendations for future research are provided.

\section{TEXTURE AND MODE OF CONSUMPTION}

Previous literature delivers inconclusive results regarding the effect of texture on satiation and satiety. Most studies, excluding those investigating soup, show that energy-yielding liquids elicit less satiation and cause less satiety compared to their solid counterparts (1-8). Thus, the lower satiating value of energy containing liquids may cause overeating through a delayed meal termination as well as a weaker compensatory dietary response throughout the day.

However, our research showed that this effect of texture on appetite profile appears to be macronutrient specific, with a larger effect of protein. Solid protein caused more satiation and more satiety compared to liquefied protein, indicating that liquefied protein could cause a delayed meal termination. This observation is supported by previous studies that show a higher postprandial hunger and desire to eat and a weaker compensatory dietary response after a liquid high-protein meal compared to a more viscous or solid high-protein meal (9-11). Some of these studies substantiated this observation by lower plasma total ghrelin, glucose and insulin concentrations, but not by differences in leptin, CCK or GLP-1 concentration $(9,11)$. Regarding the hormonal responses, Haber et al. found similar increases in plasma-glucose and insulin concentrations, independent of the liquid or solid state, for high-carbohydrate meals that were comparable to those served in our study (4). In addition, we showed a significant relationship between desire to eat and ghrelin concentrations and between fullness and insulin concentrations $(\approx 35 \%)$ in our carbohydrate conditions. Also, previous studies indicate a role of these peptides in the effect of food texture on appetite profile $(4,9,11)$.

Taken together, the risk for dysregulated appetite by the consumption of energy containing liquids has been identified and substantiated for protein. Although desire to eat and ghrelin concentrations changed synchronously with fullness and insulin ratings in the carbohydrate condition, the effects for dysregulated appetite by the consumption of liquid carbohydrate and fat remain to be investigated. 
In addition to the effect of texture on appetite profiles, the difference in mode of consumption appears to play a role. The notion that eating a liquid meal, or liquefied in texture can have a relatively high satiating value was already underlined by studies showing that soups have a higher satiety value than beverages; despite their fluid form $(1,12-16)$. In our study, an effect of texture on desire to eat and fullness was observed only when mode of consumption differed, but not when only the texture was different. Furthermore, the majority of the subjects wanted to consume more of the same meal when the liquefied meal was drunk from a glass, in order to alleviate hunger. Fullness was rated lowest and thirst and desire to eat were rated highest when the complete meal had to be drunk. The lower fullness indicates that drinking a meal could cause a delayed meal termination. Drinking a liquid meal was not perceived as thirst quenching and thirst was quenched most by water served separately with the meal. We concluded that food consumption alleviates hunger mainly through eating while thirst is mainly quenched by drinking water separately from the meal. Drinking a meal is a risk for dysregulated appetite because the lower fullness implicates a delayed meal termination. These results indicate that the distinctions between perception of hunger and thirst and eating and drinking are blurred when modes of consumption do not correspond. Therefore, the highest risk for dysregulated appetite appears to lie in drinking a high-calorie liquid meal.

The above-described risks for dysregulated appetite may be applied usefully as follows. For the application of protein-diets for body-weight management, eating a solid protein appears to be more satiating than drinking a liquid protein. However, given the wellknown compliance issues regarding high protein-diets, drinking liquid proteins may still prove useful.

Similarly, the lower satiating value of drinking a meal could be used profitably in illnesses such as cancer cachexia and anorexia nervosa or for sport drinks, where primarily energy is required without any added satiating value. In the case of anorexia nervosa evidence supporting this view is found in studies showing a more successful weight gain and decreased risk to develop a phobia of gaining weight in patients treated with a liquid formula diet compared to those treated with regular meals, positive reinforcement or activity restriction $(17,18)$.

\section{STRESS}

Stress has been shown to be a risk factor for dysregulated appetite, since it is associated with eating in the absence of hunger $(19,20)$ through effects on the reward system and the HPA axis.

Assessing the role of body weight and stress on liking and orosensory perception of food showed that both were reduced in overweight people and that liking is reduced during stress. Previously, we showed that decreased activation in brain areas associated with 
food reward during stress was associated with increased energy intake in the absence of hunger (21). Furthermore, higher wanting for snacks in the absence of hunger during stress results in higher energy intake in viscerally overweight subjects (22). Decreased liking combined with a decreased reward signaling in the brain (21) and an increased wanting in the absence of hunger (22) places overweight subjects in an especially vulnerable position for a delayed meal termination and eating in the absence of hunger during stress. Those results emphasize the role of stress as a risk factor for dysregulated appetite.

It remains to be shown whether it is possible to discontinue the vicious cycle of stress leading to increased HPA-axis functioning and eating comfort foods, which in turn leads to further increases in HPA-output and in emotional stress due to increased weight status. To shed light on this question, we wanted to further elucidate the effect of single macronutrients on meal-induced cortisol secretion. We observed that particularly the consumption of carbohydrates prohibited a decrease in cortisol concentrations after the normally observed morning peak. Protein as well as fat caused a significant decrease in cortisol concentrations when compared to carbohydrate, but showed no difference from the control condition of water. Previous research was unsuccessful in finding a macronutrient composition that is able to positively affect the cortisol response (23). Based on our results we therefore conclude that carbohydrate intake should be avoided during stress. However, practically this seems like a difficult task since research shows an increased consumption of carbohydrate-rich so-called "comfort foods", particularly high in sugar, but also fat during stress $(20,24-30)$. One possible solution to avoid eating in the absence of hunger during stress could be eating what you like during a meal while being hungry, despite an overall decreased liking of food items during stress (31).

\section{FOOD REWARD AND INHIBITION}

It has been shown that the experience of food-reward is different for overweight individuals compared to normal-weight individuals. While everybody anticipates a certain degree of food-reward before the meal, this appears to be significantly stronger in the overweight, as indicated by the following observations.

Overweight humans display a hyper-responsivity of brain areas involved in reward related signaling in response to food cues (sight, smell and taste) as well as in response to the anticipated receipt of palatable foods (32-37). When food is actually consumed, overweight humans appear to show reduced reward circuitry activation, i.e. in the dorsal striatum $(34,36,38)$. These findings were underlined by the finding of reduced D2 receptor availability in overweight individuals vs. healthy controls $(32,34,36,39-41)$. Furthermore, differences in brain signaling related to meal termination were shown. For deciding to terminate a meal, inhibitory control signaling in the brain is necessary. It has 
been observed that obese individuals show altered activation in brain areas involved in this inhibitory control (42-46). Obese individuals were shown to have lower regional brain volumes of white and gray matter in these brain areas implicated in inhibitory control, such as the prefrontal cortex (PFC) $(47,48)$. Furthermore, these lower regional brain volumes appeared to be related to future weight gain $(47,48)$.

The functional magnetic resonance imaging (fMRI) study presented in this thesis added further insights to these observations by assessing differences between overweight and normal weight subjects in food-reward related brain signaling comparing a fasted and a satiated state in response to visual food and non-food cues. First, we observed stronger brain signaling before the meal, related to anticipated food-reward. This was more pronounced in overweight compared to lean participants. Furthermore, our study showed that the hyper-responsivity of reward-related brain areas in response to food cues faded away in overweight subjects when they were sufficiently satiated. The latter was reached by controlling for subject specific energy requirements, in other words, by providing them with individually sufficient food to feel satiated.

With respect to meal termination, we observed less post-prandial brain signaling in the PFC in the overweight compared to the normal weight subjects as well as an inverse relationship between PFC signaling and BMI in the satiated state. These results imply less inhibitory control in the overweight when satiated. This could easily lead to a delayed decision to terminate the meal and thus eating in the absence of hunger. Stice et al., also found a negative correlation between PFC activation and BMI when subjects were required to actively inhibit responses to appetizing foods (42), concluding that obese or overweight individuals show less inhibitory control related to food reward. In our study, we emphasize that this decreased inhibitory control is especially relevant in the satiated state. Altered PFC signaling in obesity is also confirmed by positron emission tomography studies. Despite contradicting results, these studies generally conclude that satiation elicits different PFC responses in obese and lean individuals leading to less inhibitory control. Gautier et al. find a higher increase in regional cerebral blood flow in the PFC from the fasted to the satiated state in obese compared to lean individuals, while Le DS et al. find a higher decrease in response to a fixed meal as well as a meal controlled for subject specific energy requirement $(43-46,49)$. However, two more recent studies are in line with our results showing an association between obesity and a satiation-related reduction in PFC activity $(45,49)$. Those studies use a more stringent and robust multiple-level, random-effects statistical approach or a hypothesis-driven region-of-interest-based approach in stead of a fixed-effect analysis $(45,49)$.

Taken together, regarding dysregulated appetite, overweight humans appear particularly vulnerable to overeating due to increased sensitivity to food cues in a hungry state, and because of decreased inhibitory control in a satiated state.

Dietary restraint may affect this kind of dysregulated appetite. In a previous study a relation between dietary restraint and reward signaling in the nucleus accumbens 
was shown (50). Born et al. found that dietary restrained subjects may emphasize the anticipated rewarding value of food before the meal in a hungry state, while they show decreased reward-related signaling in the satiated state, supporting termination of the meal (50). This mirrors the observation in our study that reward sensitivity disappears when fully satiated. Learned anticipated food-reward and disappearance of foodreward when satiated may be anchored in the reward-related brain signaling areas. Restrained eating has been defined according to the three factor eating questionnaire (TFEQ), consisting of cognitive dietary restraint, disinhibition and feelings of hunger (5153). When subjects act strongly in a cognitive dietary restrained way, this needs to be supported by a low risk for disinhibition, and for hunger. When disinhibition overrules cognitive restraint, this causes overeating or eating in the absence of hunger (54-57). Therefore, a high behavioral disinhibition may relate to low brain signaling for inhibitory control, as observed in the PFC in our study. A previous study by Le et al. indicates that the lower inhibitory control signaling observed in obesity could be reversible (46). They showed that post-obese women had the same increase in PFC activity caused by satiety as do lean women, while in obese women this increase was confirmed to be significantly lower compared to both lean and post-obese women (46). Therefore, cognitive training, perhaps via a neurofeedback methodology, may be a way to decrease behavioral disinhibition or increase inhibitory control signaling in the PFC, which may reduce overeating and thereby could introduce a new weight loss strategy.

\section{CONCLUSIONS}

The research described in this thesis identified texture, mode of consumption, stress and high sensitivity to food reward when hungry, as well as low inhibitory control when satiated as risk factors for dysregulated appetite.

Regarding the texture effect on appetite, our research shows that this effect is specifically related to protein, with solid protein causing more satiation and leading to more satiety compared to liquefied protein. This indicates that liquefied protein could cause a delayed meal termination. With regard to mode of consumption, we conclude that food consumption alleviates hunger mainly by eating while thirst is mainly quenched by drinking water separately from the meal. The lower fullness indicates that drinking a meal could cause a delayed meal termination.

Furthermore, we showed that stress causes a decreased orosensory perception and a decreased liking of food; also liking of food is influenced by weight status. Therefore, the decreased liking during stress is especially emphasized in overweight subjects. Moreover, our research showed that particularly carbohydrate may affect HPA activity under conditions of stress. Previous research implies that overweight subjects are especially vulnerable for a delayed meal termination and eating in the absence of hunger during stress. 
The fMRI research presented in this thesis shows that overweight humans are particularly vulnerable to overeating because of an increased sensitivity to food cues in a hungry state and a decreased inhibitory control in a satiated stated, which delays meal termination. The decreased inhibitory control in the satiated state is observed as a lower signaling in the PFC, which can be interpreted as a neurofunctional correlate of poor inhibitory control, a trait that is associated with overeating and weight gain. We speculate that the reversibility of this altered signaling in the PFC cortex observed in obesity could in the future be used in the treatment of obesity through cognitive training combined with a neurofeedback methodology.

Taken together, texture, mode of consumption and stress are risk factors of dysregulated appetite by causing a delayed meal termination. The decreased inhibitory control signaling in the satiated state in the overweight supports a delayed meal termination.

These conclusions show peripheral as well as central risks of dysregulated appetite. Behavioral and physiological factors may affect both; the homeostatic or non-homeostatic (reward-related) brain mechanisms via the gut-brain axis. A change in gut peptides may change the anticipated food-reward signaling or possibly the inhibitory control signaling in the brain. Therefore, the gut-brain axis is an important target for future research.

\section{FUTURE PERSPECTIVES}

Unraveling the pathways that contribute to individual differences in risks of dysregulated appetite and subsequent weight gain is warranted for the successful treatment and prevention of obesity. As summarized in this thesis, $\mathrm{fMRI}$ studies are delivering insights into weight-status related difference in food-reward signaling and inhibitory control signaling in the brain, which may contribute to individual differences in eating behavior. However, food intake is not only determined by the brain, but also by peripheral factors such as the gut-peptides. The interaction between peripheral hormones and neural circuits is referred to as the gut-brain axis. Future research into the interaction of gut and brain in the regulation of food intake is necessary. Combining our fMRI set-up with a stepwise design of different surgical as well as behavioral weight loss strategies may contribute to finding the optimal balance between gut and brain activity for weight loss and weight maintenance. Dieting has been proven very difficult to adhere to because energy restriction-induced biological adaptations evoke strong feelings of hunger and craving for food $(58,59)$. Surgical interventions have proven more successful regarding long-term weight loss and metabolic improvements. Post surgical benefits include changes in gastrointestinal hormone release and changes in brain activity, however the interactions between both remain unclear.

An interesting addition to the current research could be the role of endocannabinoids in palatable food intake. Increased endocanabinoid levels together with increased ghrelin levels are implicated in non-homeostatic eating and could therefore form a connection 
between the gut and the brain that is especially active during eating in the absence of hunger (60).

On a technical level, these fMRI studies would benefit from novel high field fMRI with field strengths of 7 Tesla and above. These will offer the opportunity to study networks involved in homeostatic and non-homeostatic appetite regulation with a higher resolution and therefore in much more detail (61). The higher detail will enable us to study subregions of for example the nucleus accumbens or the hypothalamus, which for certain small regions is not possible with 3 Tesla systems.

Future research using other MRI techniques and methods of analyses, such as diffusion tensor imaging (DTI) will reveal more details about the connectivity and the communication between different brain areas.

Combining previous research on inhibitory control signaling with new techniques and a higher field strength could enable us to use the reversibility of altered PFC signaling observed in obesity for the treatment of obesity through cognitive training. There is already growing evidence for neurofeedback as a valuable treatment module in neuropsychiatric disorders such as attention-deficit hyperactivity disorder, epilepsy, autism and anxiety, although results are often preliminary (62). More research is needed before neurofeedback methodology may be used as a treatment of obesity, as it is shown that behavioral disinhibition is easier learned than inhibition (63).

Overall, identifying altered activity in the gut-brain axis after obesity treatment surgery, together with cognitive neurofeedback training may be a promising strategy for obesity treatment and needs to be further explored. This strategy would not only address weight loss as a target, but also hedonic satisfaction, leading to a higher efficiency and efficacy in the treatment of obesity. 


\section{REFERENCES}

1. Almiron-Roig E, Chen $\mathrm{Y}$, Drewnowski A. Liquid calories and the failure of satiety: how good is the evidence? Obesity Reviews 2003;4:201-212.

2. Cassady B, Considine R, RD M. Beverage consumption, appetite, and energy intake: what did you expect? Am J Clin Nutr. 2012;95:587-593.

3. DiMeglio DP, Mattes RD. Liquid versus solid carbohydrate: effects on food intake and body weight. Int J Obes Relat Metab Disord 2000;24:794-800.

4. Haber GB, Heaton KW, Murphy D, Burroughs LF. Depletion and disruption of dietary fibre: effects on satiety, plasma-glucose, and serum-insulin The Lancet 1977;310:679-682.

5. Mattes RD, Rothacker D. Beverage viscosity is inversely related to postprandial hunger in humans. Physiology \& Behavior 2001;74:551-557.

6. Mourao DM, Bressan J, Campbell WW, Mattes RD. Effects of food form on appetite and energy intake in lean and obese young adults. Int J Obes 2007;31:1688-1695.

7. Zijlstra N, Mars M, de Wijk RA, Westerterp-Plantenga MS, de Graaf C. The effect of viscosity on ad libitum food intake. Int J Obes 2007;32:676-683.

8. Zijlstra N, Mars M, de Wijk RA, Westerterp-Plantenga MS, Holst JJ, de Graaf C. Effect of viscosity on appetite and gastro-intestinal hormones. Physiol Behav. 2009;97:68-75.

9. Leidy HJ, Apolzan J, Mattes R, Campbell W. Food form and portion size affect postprandial appetite sensations and hormonal responses in healthy, nonobese, older adults. Obesity 2010;18:293-299.

10. Rothacker DQ, Watemberg S. Short-term hunger intensity changes following ingestion of a meal replacement bar for weight control. International Journal of Food Sciences and Nutrition 2004;55:223226.

11. Tieken SM, Leidy HJ, Stull AJ, Mattes RD, Schuster RA, Campbell WW. Effects of Solid versus Liquid Meal-replacement Products of Similar Energy Content on Hunger, Satiety, and Appetite-regulating Hormones in Older Adults. Horm Metab Res. 2007;39:389-394.

12. Himaya A, Louis-Sylvestre J. The Effect of Soup on Satiation. Appetite 1998;30:199-210.

13. Kissileff HR. Effects of physical state (liquid-solid) of foods on food intake: procedural and substantive contributions. Am J Clin Nutr 1985;42:956-965.

14. Mattes R. Soup and satiety. Physiol Behav. 2005;83:739-747.

15. Rolls BJ, Bell EA, Thorwart ML. Water incorporated into a food but not served with a food decreases energy intake in lean women. Am J Clin Nutr 1999;70:448-455.

16. Tournier A, Louis-Sylvestre J. Effect of the physical state of a food on subsequent intake in human subjects. Appetite 1991;16:17-24.

17. Okamoto A, Yamashita T, Nagoshi Y, et al. A behavior therapy program combined with liquid nutrition designed for anorexia nervosa. Psychiatry and Clinical Neurosciences 2002;56:515-520.

18. Arii I, Yamashita T, Kinoshita M, Shimizu H, Nakamura M, Nakajima T. Treatment for inpatients with anorexia nervosa: comparison of liquid formula with regular meals for improvement from emaciation. Psychiatry Clin Neurosci. 1996;50:55-59.

19. Lemmens S, Martens E, Kester A, MS W-P. Changes in gut hormone and glucose concentrations in relation to hunger and fullness. Am J Clin Nutr. 2011;94:717-725.

20. Rutters F, Nieuwenhuizen AG, Lemmens SGT, Born JM, Westerterp-Plantenga MS. Acute Stressrelated Changes in Eating in the Absence of Hunger. Obesity 2008;17:72-77.

21. Born JM, Lemmens SGT, Rutters F, et al. Acute stress and food-related reward activation in the brain during food choice during eating in the absence of hunger. International Journal of Obesity 2010;34:172-181.

22. Lemmens SG, Rutters F, Born JM, Westerterp-Plantenga MS. Stress augments food 'wanting' and 
energy intake in visceral overweight subjects in the absence of hunger. Physiology \& Behavior 2011;103:157-163.

23. Lemmens S, Born J, Martens E, Martens M, Westerterp-Plantenga M. Influence of consumption of a high-protein vs. high-carbohydrate meal on the physiological cortisol and psychological mood response in men and women. PLoS One. 2011;6:e16826.

24. Elfhag K, Erlanson-Albertsson C. Sweet and fat taste preference in obesity have different associations with personality and eating behavior. Physiol Behav. 2006;88:61-66.

25. Epel E, Lapidus R, McEwen B, Brownell K. Stress may add bite to appetite in women: a laboratory study of stress-induced cortisol and eating behavior. Psychoneuroendocrinology 2001;26:37-49.

26. Garg N, Wansink B, Inman J. The Influence of Incidental Affect on Consumers' Food Intake. Journal of Marketing 2007;71:194-206.

27. Kuo L, Czarnecka M, Kitlinska J, Tilan J, Kvetnanský R, Zukowska Z. Chronic stress, combined with a high-fat/high-sugar diet, shifts sympathetic signaling toward neuropeptide $Y$ and leads to obesity and the metabolic syndrome. Ann N Y Acad Sci. 2008;1148:232-237.

28. Oliver G, Wardle J, Gibson E. Stress and food choice: a laboratory study. Psychosom Med. 2000;62:853-865.

29. Salbe AD, DelParigi A, Pratley RE, Drewnowski A, Tataranni PA. Taste preferences and body weight changes in an obesity-prone population. Am J Clin Nutr 2004;79:372-378.

30. Zellner DA, Loaiza S, Gonzalez Z, et al. Food selection changes under stress. Physiol Behav. 2006;87:789-793.

31. Lemmens SG, Schoffelen PFM, Wouters L, et al. Eating what you like induces a stronger decrease of 'wanting' to eat. Physiol Behav. 2009;98:318-325.

32. Gearhardt A, Yokum S, Orr P, Stice E, Corbin W, Brownell K. Neural correlates of food addiction. Arch Gen Psychiatry 2011;68:808-816.

33. Rothemund Y, Preuschhof C, Bohner G, et al. Differential activation of the dorsal striatum by highcalorie visual food stimuli in obese individuals. Neurolmage 2007;37:410-421.

34. Stice E, Spoor S, Bohon C, Veldhuizen M, DM S. Relation of reward from food intake and anticipated food intake to obesity: a functional magnetic resonance imaging study. J Abnorm Psychol. 2008;117:924-935.

35. Stice E, Yokum S, Bohon C, Marti N, Smolen A. Reward circuitry responsivity to food predicts future increases in body mass: Moderating effects of DRD2 and DRD4. Neurolmage 2010;50:1618-1625.

36. Stice E, Yokum S, Burger K, Epstein L, DM. S. Youth at risk for obesity show greater activation of striatal and somatosensory regions to food. J Neurosci. 2011;31:4360-4366.

37. Stoeckel LE, Weller RE, Cook lii EW, Twieg DB, Knowlton RC, Cox JE. Widespread reward-system activation in obese women in response to pictures of high-calorie foods. Neurolmage 2008;41:636647.

38. Stice E, Spoor S, Bohon C, Small D. Relation between obesity and blunted striatal response to food is moderated by TaqIA A1 allele. Science 2008;322:449-452.

39. Volkow N, Wang G, Fowler J, Telang F. Overlapping neuronal circuits in addiction and obesity: evidence of systems pathology. Philos Trans R Soc Lond B Biol Sci. 2008;363:3191-200.

40. Volkow N, Wang G-J, RD B. Reward, dopamine and the control of food intake: implications for obesity. Trends in Cognitive Sciences 2011 2011;15:37-46.

41. Volkow ND, Wang G-J, Maynard L, et al. Brain dopamine is associated with eating behaviors in humans. International Journal of Eating Disorders 2003;33:136-142.

42. Batterink L, Yokum S, Stice E. Body mass correlates inversely with inhibitory control in response to food among adolescent girls: An fMRI study. Neurolmage 2010;52:1696-1703.

43. Gautier J, Chen K, Salbe A, et al. Differential brain responses to satiation in obese and lean men. Diabetes. 2000;49:838-846. 
44. Gautier J, Del Parigi A, Chen K, et al. Effect of satiation on brain activity in obese and lean women. Obes Res. 2001;9:676-684.

45. Le D, Pannacciulli N, Chen K, et al. Less activation of the left dorsolateral prefrontal cortex in response to a meal: a feature of obesity. Am J Clin Nutr. 2006;84:725-731.

46. Le D, Pannacciulli N, Chen K, et al. Less activation in the left dorsolateral prefrontal cortex in the reanalysis of the response to a meal in obese than in lean women and its association with successful weight loss. Am J Clin Nutr. 2007;86:573-579.

47. Pannacciulli M, Del Parigi A, Chen K, Le D, Reiman E, Tataranni P. Brain abnormalities in human obesity: a voxel-based morphometric study. Neurolmage 2006;31:1419-1425.

48. Yokum S, $\mathrm{Ng} \mathrm{J}$, Stice E. Relation of regional gray and white matter volumes to current BMI and future increases in BMI: a prospective MRI study. Int J Obes 2012:5.

49. Le DSNT, Chen K, Pannacciulli N, Gluck M, Reiman EM, Krakoff J. Reanalysis of the Obesity-Related Attenuation in the Left Dorsolateral Prefrontal Cortex Response to a Satiating Meal Using Gyral Regions-of-Interest. Journal of the American College of Nutrition 2009;28:667-673.

50. Born J, Lemmens S, Martens M, Formisano E, Goebel R, MS W-P. Differences between liking and wanting signals in the human brain and relations with cognitive dietary restraint and body mass index. Am J Clin Nutr. 2011;94:392-403.

51. Berthoud H-R. Neural control of appetite: cross-talk between homeostatic and non-homeostatic systems. Appetite 2004;43:315-317.

52. James W. WHO recognition of the global obesity epidemic. Int J Obes 2008;32:S120-6.

53. Selassie M, Sinha A. The epidemiology and aetiology of obesity: a global challenge. Best Pract Res Clin Anaesthesiol. 2011;25:1-9.

54. de Castro JM, Lilenfeld LRR. Influence of heredity on dietary restraint, disinhibition, and perceived hunger in humans. Nutrition 2005;21:446-455.

55. Dykes J, Brunner E, Martikainen P, Wardle J. Socioeconomic gradient in body size and obesity among womenthe role of dietary restraint, disinhibition and hunger in the Whitehall II study. Int J Obes Relat Metab Disord 2003;28:262-268.

56. Hays N, Bathalon G, McCrory M, Roubenoff R, Lipman R, Roberts S. Eating behavior correlates of adult weight gain and obesity in healthy women aged 55-65 y. Am J Clin Nutr 2002;75:476-483.

57. Lindroos A, Lissner L, Mathiassen M, et al. Dietary intake in relation to restrained eating, disinhibition, and hunger in obese and nonobese Swedish women. Obes Res 1997;5:175-182.

58. Berthoud H-R, Zheng H, Shin AC. Food reward in the obese and after weight loss induced by calorie restriction and bariatric surgery. Annals of the New York Academy of Sciences 2012:no-no.

59. Rosenbaum M, Sy M, Pavlovich K, Leibel R, Hirsch J. Leptin reverses weight loss-induced changes in regional neural activity responses to visual food stimuli. J Clin Invest. 2008;118:2583-2591.

60. Monteleone P, Piscitelli F, Scognamiglio P, et al. Hedonic eating is associated with increased peripheral levels of ghrelin and the endocannabinoid 2-arachidonoyl-glycerol in healthy humans: a pilot study. J Clin Endocrinol Metab. 2012;97:E917-24.

61. De Martino F, Esposito F, van de Moortele P-F, et al. Whole brain high-resolution functional imaging at ultra high magnetic fields: An application to the analysis of resting state networks. Neurolmage 2011;57:1031-1044.

62. Heinrich H, Gevensleben H, StrehI U. Annotation: Neurofeedback - train your brain to train behaviour. Journal of Child Psychology and Psychiatry 2007;48:3-16.

63. Guerrieri R, Nederkoorn C, Jansen A. Disinhibition is easier learned than inhibition. The effects of (dis) inhibition training on food intake. Appetite 2012;59:96-99. 
104 
SUMMARY 
The etiology of obesity or overweight can be assigned to a disturbance in energy balance. The cause of this disturbance is diverse and complex and has been attributed to numerous factors, including physiological, environmental, behavioral, neuro-endocrine and genetic factors. This thesis deals with the role of risks of dysregulated appetite in the current obesity and overweight epidemic, especially focusing on the role of texture, stress, food reward and inhibition in meal termination.

Regarding texture, previous literature is inconclusive with regard to the satiating value of solid and liquid meals. With regard to this texture effect, the research in this thesis focused on single macronutrient meals (Chapter 2 and 3). Results indicate that the effect of texture on appetite profile is macronutrient specific, with solid protein causing more satiation and leading to more satiety compared to liquefied protein. With regard to carbohydrate, results show that liquefied and solid carbohydrate meals do not differ in satiating capacity. A significant relationship between desire to eat and ghrelin concentrations and between fullness and insulin concentrations was shown in the carbohydrate conditions.

In addition, difference in mode of consumption appears to play a role in the effect of texture on appetite. The same texture can be delivered to the oral cavity by drinking or eating, depending on the delivery by a particular utensil. In previous studies, it is impossible to disentangle the effects of food texture and those of mode of consumption of foods on differences in satiating value between liquids and solids. Thus, the studies in this thesis assessed the effects of structure, mode of consumption of food, and additional drinking of water on fullness and thirst (Chapter 4). Results show that mode of consumption plays a role in alleviating hunger and thirst. Hunger was best relieved by consuming calories through eating and not through drinking, while thirst was best quenched by drinking water separate from the meal.

Previous literature indicates a vicious cycle in which stress leads to eating in the absence of hunger, with a preference for foods high in fat and sugar, which in turn increases HPAaxis activity. In this context, the research described in this thesis investigated the effects of single macronutrients on plasma cortisol concentrations and the effect of stress on liking and on the orosensory perception of food (Chapter 5 and 6). Results show that protein as well as fat caused a significant decrease in cortisol concentrations when compared to carbohydrate, but showed no difference from the control condition of water, while the consumption of carbohydrates prohibited a decrease in cortisol concentrations after the normally observed morning peak. Furthermore, stress causes a decreased orosensory perception and a decreased liking of food; also liking of food is influenced by weight status. Therefore, the decreased liking during stress is especially emphasized in overweight subjects.

Disruption of the interaction between energy and reward regulation might promote overeating and contribute to obesity. Previous studies indicate a disruption of this interaction in overweight or obese individuals. Overweight humans display a hyper- 
responsivity of brain areas involved in reward related signaling in response to food cues and to the anticipated receipt of palatable foods. Overweight humans appear to show reduced reward circuitry activation when food is actually consumed. Furthermore, obese individuals show altered activation in brain areas involved in inhibitory control. The flexibility of food-reward related brain signaling was investigated in normal weight and overweight subjects, using functional magnetic resonance imaging (fMRI) (Chapter 7). Results show a stronger brain signaling before the meal, which is more pronounced in overweight compared to lean participants. This hyper-responsivity of reward-related brain areas in response to food cues is related to not reaching energy balance; overweight subjects no longer display hyper-responsivity when sufficiently satiated or simply by having been given enough to eat, regarding their energy-balance level. Sufficient satiation is achieved by controlling for subject specific energy requirements. Furthermore, results show less post-prandial brain signaling in the prefrontal cortex (PFC) in the overweight compared to the normal weight subjects as well as an inverse relationship between PFC signaling and BMI in the satiated state, implying less inhibitory control in the overweight when satiated.

In conclusion, from studies described in this thesis it appears that the texture effect on appetite is specifically related to protein, with solid protein causing more satiation and leading to more satiety compared to liquefied protein. Moreover, mode of consumption plays a role in alleviating hunger and thirst. Food consumption alleviates hunger mainly by eating while thirst is mainly quenched by drinking water separately from the meal.

Stress causes a decreased liking of food, which is especially emphasized in overweight subjects. No single macronutrient was found to favorably influence the cortisol response. However, particularly carbohydrate may affect HPA activity unfavorably, by relatively increasing it under conditions of stress.

The $\mathrm{fMRI}$ research presented in this thesis shows that overweight humans are particularly vulnerable to overeating because of an increased sensitivity to food cues in a hungry state and a decreased inhibitory control, in a satiated stated.

Taken together, texture, mode of consumption and stress are risk factors of dysregulated appetite by causing a delayed meal termination. The decreased inhibitory control signaling in the satiated state in the overweight supports a delayed meal termination. In the future, the flexibility of altered PFC signaling observed in obesity could be used for the treatment of obesity through cognitive training combined with a neurofeedback methodology. Furthermore, future research into the interaction of gut and brain in the regulation of food intake is necessary. 
100 
SAMENVATTING 
Het ontstaan van overgewicht en zwaarlijvigheid is te wijten aan een verstoring van de energiebalans. De oorzaak van een verstoorde energiebalans is divers en complex en wordt toegeschreven aan verschillende factoren; fysiologische factoren, omgevingsfactoren, neuro-endocriene factoren, genetische aanleg en gedrag. Dit proefschrift behandelt de rol van risico's op ontregelde eetlust in de huidige epidemie van overgewicht en zwaarlijvigheid, met een specifieke focus op de rol van textuur, stress, belonende waarde van voeding en inhibitie bij maaltijd beëindiging.

Tot nu toe gepubliceerde literatuur met betrekking tot textuur is verdeeld over de verzadigende waarde van vaste en vloeibare maaltijden. Het onderzoek in dit proefschrift betreffende dit textuur effect legt zich hoofdzakelijk toe op maaltijden bestaande uit één macronutriënt (Hoofdstukken 2 en 3). De resultaten van dit onderzoek tonen aan dat het effect van textuur op eetlust macronutriënt specifiek is; een vaste eiwitmaaltijd zorgt voor meer verzadiging dan een vergelijkbare vloeibare eiwitmaaltijd. De koolhydraatmaaltijden vertoonden geen verschil in verzadigende waarde maar gaven een significante relatie te zien tussen de wens om te eten en ghreline concentraties en tussen een vol gevoel en insuline concentratie na de maaltijd.

Bovendien speelt de manier van consumptie een rol in het effect van textuur op eetlust. Eenzelfde textuur kan naar de mondholte gebracht worden door deze te drinken of te eten, afhankelijk van gebruik van een glas of bestek. In vorige studies die verschillen in de verzadigende waarde van vaste en vloeibare structuren onderzochten is het onmogelijk om de effecten van textuur en van de manier van consumptie van elkaar te onderscheiden. Daarom richt het onderzoek in dit proefschrift zich op de effecten van structuur, manier van consumptie en op het aanvullend drinken van water op een vol gevoel en op dorst (Hoofdstuk 4). De huidige resultaten laten zien dat de manier van consumeren een rol speelt in het verminderen van honger en dorst. Honger werd meer gestild wanneer het voedsel werd geconsumeerd door het te eten en minder door het te drinken, terwijl dorst meer werd gelest door water apart bij de maaltijd te drinken, dan door water in het voedsel te verwerken.

Voorafgaand onderzoek wijst op een vicieuze cirkel waarbij stress leidt tot eten zonder dat iemand honger heeft, met een verhoogde voorkeur voor vet en suiker, die opnieuw zorgt voor een verhoogde activiteit van de hypothalamus-hypofyse-bijnier-as (HPA-as). Met deze vicieuze cirkel als achtergrond, werden de effecten van elk macronutriënt apart op de concentratie van cortisol in het plasma onderzocht; bovendien werd het effect van stress op de waardering voor voedsel en op de oro-sensorische waarneming ervan onderzocht (Hoofdstukken 5 en 6). Dit onderzoek toont aan dat, in vergelijking tot koolhydraat, proteïne en vet zorgden voor een significante daling van de cortisol concentraties. Deze daling was niet verschillend van de daling die werd waargenomen in de controle conditie water. Koolhydraat verhinderde de daling van de cortisol concentraties die normaal waargenomen wordt na de piek in de ochtend. Voorts werd geconstateerd dat stress zorgt voor een verminderde waardering voor voedsel en een 
verminderde oro-sensorische waarneming ervan. De waardering voor het voedsel werd ook beïnvloed door de gewichtsstatus; hierdoor wordt de geringere waardering tijdens stressvolle omstandigheden vooral geaccentueerd bij overgewichtige proefpersonen.

De verstoring van het samenspel tussen de regulatie van energie-inname en van de belonende waarde van voedsel kan ertoe leiden dat mensen teveel gaan eten, hetgeen bijdraagt aan de ontwikkeling van obesitas. Mensen met overgewicht vertonen een overgevoeligheid van de gebieden in de hersenen die betrokken zijn bij het signaleren van de belonende waarde van voeding. Dit gebeurt zowel bij blootstelling aan prikkels gerelateerd aan voedsel als bij de anticipatie van het ontvangen van smakelijk voedsel. Aan de andere kant lijken deze mensen juist een verminderde activiteit te vertonen in deze beloninggerelateerde hersengebieden, wanneer ze het voedsel werkelijk consumeren. Daarenboven laten mensen met obesitas een gewijzigde activiteit in de hersengebieden die betrokken zijn bij de controle over inhibitie van voedselinname zien. Het onderzoek beschreven in dit proefschrift maakte gebruik van functionele magnetische resonantie beeldvorming (fMRI) om de flexibiliteit in de hersensignalering van de belonende waarde van voeding in kaart te brengen bij normaal- en overgewichtige proefpersonen (Hoofdstuk 7). De resultaten geven een hogere hersensignalering voor de maaltijd in hersengebieden gerelateerd aan de belonende waarde van voeding te zien; deze was meer uitgesproken bij overgewichtige proefpersonen in vergelijking tot normaalgewichtige proefpersonen. De overgewichtige proefpersonen verloren deze overgevoeligheid voor prikkels gerelateerd aan voeding wanneer ze voldoende te eten kregen, gebaseerd op persoonsspecifieke energiebehoeftes. Dit wijst erop dat de, in andere studies waargenomen overgevoeligheid van de hersengebieden betrokken bij de signalering van de belonende waarde van voeding bij overgewichtige mensen gerelateerd is aan het niveau van de energie balans. Met andere woorden, men moet wel genoeg te eten krijgen om ook de bijbehorende belonende waarde te ervaren. $\mathrm{Na}$ de maaltijd, wanneer de overgewichtige proefpersonen in energiebalans waren gevoed, vertonen ze echter een verminderde hersensignalering in de prefrontale cortex (PFC), zodanig dat hoe sterker het overgewicht, hoe zwakker deze hersensignalering. Deze resultaten wijzen op een verminderde controle over de inhibitie van voedselinname bij de overgewichtigen wanneer ze verzadigd zijn.

Uit de resultaten van de studies beschreven in dit proefschrift wordt geconcludeerd dat het effect van textuur op eetlust vooral van toepassing is bij maaltijden hoog in proteïnen; vaste proteïne maaltijden zorgen voor een hogere verzadiging dan proteïne maaltijden in vloeibare toestand. Verder blijkt de manier van consumptie een rol te spelen bij het verminderen van honger en dorst. Honger wordt vooral gestild door het eten van voedsel, terwijl dorst vooral gelest wordt door water apart bij de maaltijd te drinken.

De daling die stress veroorzaakt in de waardering voor voedsel komt vooral naar voren bij overgewichtige proefpersonen. Geen enkel macronutriënt is op zichzelf in staat om 
de cortisol reactie gunstig te beïnvloeden, maar vooral koolhydraat kan de activiteit van de HPA-as ongunstig beïnvloeden tijdens stressvolle omstandigheden.

De fMRI studie in dit proefschrift toont aan dat vooral overgewichtige mensen teveel kunnen gaan eten door een grotere gevoeligheid voor prikkels gerelateerd aan voedsel in een gevaste toestand, terwijl het risico op overeten in een gevoede toestand vooral gezocht moet worden in een verminderde controle over de inhibitie van voedselinname. Alles overziend, zijn textuur, manier van consumeren en stress risico factoren voor ontregelde eetlust door het veroorzaken van een vertraagde beëindiging van de maaltijd. De verminderde signalering in de PFC wanneer er voldoende gegeten is, is gerelateerd aan verminderde controle over beëindiging van voedselinname, wat de bevindingen van vertraagde beëindiging van de maaltijd ondersteund.

Mogelijk kan de flexibiliteit van de veranderde signalering in de PFC die waargenomen wordt bij obesitas in de toekomst gebruikt worden als een doelwit voor de behandeling van obesitas door middel van het gebruik van cognitieve training in combinatie met een neuronale terugkoppelingsmethode. Daarenboven is toekomstig onderzoek naar de rol van de interactie tussen het brein en het maagdarmstelsel in de regulatie van voedselinname noodzakelijk. 
DANKWOORD 
Alleen had ik het nooit gered. Dus om te beginnen: simpelweg BEDANKT aan iedereen die zijn steentje heeft bijgedragen aan het tot stand komen van dit proefschrift.

Allereerst wil ik mijn promotores bedanken. Margriet, u staat aan de basis van de groei die ik heb doorgemaakt. Bij deze wil ik u bedanken om me de kans te geven om bij $\mathrm{u}$ te promoveren alsook voor de uitstekende begeleiding. Geen moeite was u teveel, waar ook ter wereld, ik kreeg altijd onmiddellijk respons. Ik heb erg genoten van de vele congressen en uitjes. Rainer, vielen herzlichen Dank für Ihre Hilfe beim Entwurf der fMRI Studien. Ihre Ratschläge waren immer sehr hilfreich und unsere Gespräche sehr angenehm! Ich freue mich auf unsere zukünftige Zusammenarbeit. Tanja, bedankt voor de hulp bij de laatste loodjes. Ik voel me altijd zeer welkom bij jou en kijk erg uit naar onze toekomstig samenwerking, ik weet zeker dat ik veel van je zal leren.

Next, I would like to thank all the members of the reviewing committee, Prof. dr. ir. R.P. Mensink, Dr. N. Bouvy, Prof. dr. E. Formisano, Prof. dr. A.A.M Masclee, and Prof. dr. T. Moran, for their interest in my work and the evaluation of my thesis.

Astrid en Femke, jullie waren van de start twee grote voorbeelden voor mij. Bedankt dat jullie mij willen bijstaan als Paranimfen. Astrid, als eerste kamergenootje stond jij me met raad en daad bij. Ik had aan jou altijd een luisterend oor, zowel op professioneel als op persoonlijk gebied. Je advies heeft me heel vaak geholpen, bedankt hiervoor! Femke, jouw enorme enthousiasme en onuitputtelijke energie op de werkvloer werkten inspirerend. Mijn eerste artikel kwam er dankzij jouw hulp met het proefopzet, de analyses en zelfs het schrijven. Daarnaast zorgde je voor welgekomen pauzes en de nodige hydratatie 'tea, anyone?'. Het was een plezier om met je samen te werken en ik heb veel van je geleerd, bedankt hiervoor!

Minstens evenveel hulp kreeg ik van mijn volgende twee kamergenoten; Sofie en Jurriaan. Jullie moet ik beiden bedankten voor jullie eindeloze geduld. We hebben vele B1001 meetings doorstaan samen, maar ook veel plezier gemaakt als kamergenoten waarvoor ik jullie wil bedanken. Sofie, iedereen kon jou alles vragen, en dat deden ze ook! Wat jij allemaal voor mij hebt gedaan is teveel om op te noemen, bedankt voor alles. Jurriaan, zonder jou was ik misschien nog steeds mijn eerste fMRI analyses aan het draaien. Bedankt voor alle kennis die je me bijbracht.

Naast alle (oud)collega's van Humane Biologie, wil ik mijn (oud)clustergenoten bedanken voor de aangename werksfeer en de leuke tijden, zowel op de UM als op de vele congressen: Alberto, Ananda, Anneke, Arie, Eveline, Freeha, Guilio, Guy, Hanne, Marcel, Margriet, Pilou, Rick, Sanne, Siti, Stefan, Stijn.

Een speciaal woordje van dank voor Loek, Paul, Jos, Wendy, Martine, Claudia, Desiree 
en llona voor de goede ondersteuning, analyses en welgekomen hulp bij het oplossen van allerhande vragen en problemen.

Armin, vielen herzlichen Dank für Ihre Hilfe beim Brainvoyager.

Ex-leden van het B1001 TIFN projectteam, werkzaam in Wageningen, Nicolien, Pleunie, Natasja, Monica, Annette, en Kees, samen hebben we veel meetings doorstaan. Bedankt voor de gezelligheid.

Vrienden en familie, bedankt voor jullie oprechte interesse in mijn werk en voor de nodige ontspannende feestjes, etentjes en reizen.

Maarten, jouw hulp bij de opmaak en het ontwerp van de cover was van onschatbare waarde. Het was ongelooflijk makkelijk samenwerken met jou. Bedankt dat ik op je kon rekenen!

Beste Depaneurs(euses), bedankt voor het deskundig opvangen van Bert tijdens mijn vele afwezigheden en voor het voorzien van de nodige ontspannende reizen naar de sneeuw. Ik hoop dat jullie hier de komende jaren zeker mee door gaan!

Nele en Nic, op jullie kunnen we altijd rekenen voor hulp, voor een luisterend oor of voor een stevig feestje. Bedankt dat jullie me willen helpen met het feest!

Christa en Rob, als ik zelf een zus en schoonbroer had mogen kiezen zouden jullie het zijn. Op jullie kunnen we altijd rekenen. Bedankt voor al de etentjes en gezellige avonden, dat er nog héél veel mogen volgen!

Alida, André, Wendy, Jo, Katrien en Jan-Bert bedankt voor alles, mede door jullie werd Diepenbeek mijn tweede thuis.

Mama en papa, jullie hebben mij altijd alle kansen gegeven en nu nog. Zonder jullie zou ik dit nooit bereikt hebben. Mama, ettelijke uren ben je wakker gebleven als ik tot 's nachts studeerde, altijd had ik een luisterend oor en geen afstand was te ver om me te komen halen. Bedankt voor alles wat jullie voor mij gedaan hebben en nog steeds doen, bedankt voor alle steun!

Bert, allerliefste schat, onze relatie begon samen met mijn AlO periode, wat het er niet altijd makkelijker op maakte. Maar ik heb in jou mijn steun en toeverlaat gevonden. Bedankt voor je liefde, begrip en vertrouwen de afgelopen jaren. Ik kijk uit naar de volgende uitdagingen, nu samen; huisje, tuintje, boompje. Ik kijk uit naar onze toekomst samen. 
100 
LIST OF PUBLICATIONS 


\section{FULL PAPERS FIRST AUTHOR}

Martens MJ, Rutters F, Lemmens SG, Born JM, Westerterp-Plantenga MS. Effects of single macronutrients on serum cortisol concentrations in normal weight men. Physiol Behav. 2010;101(5):563-7.

Martens MJ, Lemmens SG, Born JM, Westerterp-Plantenga MS. A solid high-protein meal evokes stronger hunger suppression than a liquefied high-protein meal. Obesity. $2011 ; 19(3): 522-7$.

Martens MJ, Westerterp-Plantenga MS. Mode of consumption plays a role in alleviating hunger and thirst. Obesity. 2012;20(3):517-24.

Martens MJ, Born JM, Lemmens SG, Westerterp-Plantenga MS. Liking and the orosensory perception of food in a stress versus rest condition in overweight and normal weight participants. Food Qual Prefer. 2012;26(2):252-258

Martens MJ, Lemmens SG, Born JM, Westerterp-Plantenga MS. Satiating capacity and post-prandial interactions between appetite parameters and blood values with solid and liquefied carbohydrate meals. PLoS-One. 2012;7(7): Epub 2012 Jul 26.

Martens MJ, Born JM, Lemmens SG, Karhunen L, Heinecke A, Goebel R, Adam TC, Westerterp-Plantenga MS. Flexibility of food-reward related brain signaling in overweight and normal weight subjects. Submitted for publication.

\section{FULL PAPERS CO-AUTHOR}

Geerts J, Martens M, Vandevenne JE, Gelin G, Grieten M, Weyns F, Stinissen P, Palmers $\mathrm{Y}$, Wuyts J. Functional magnetic resonance imaging for preoperative localisation of eloquent brain areas relative to brain tumours: clinical implementation in a regional hospital. JBR-BTR. 2007;90(4):258-63.

Lemmens SG, Schoffelen PF, Wouters L, Born JM, Martens MJ, Rutters F, WesterterpPlantenga MS. Eating what you like induces a stronger decrease of 'wanting' to eat. Physiol Behav. 2009;98(3):318-25.

Born JM, Lemmens SG, Martens MJ, Formisano E, Goebel R, Westerterp-Plantenga MS. Differences between liking and wanting signals in the human brain and relations with cognitive dietary restraint and body mass index. Am J Clin Nutr. 2011;94(2):392-403. 
Lemmens SG, Martens EA, Born JM, Martens MJ, Westerterp-Plantenga MS. Staggered meal consumption facilitates appetite control without affecting postprandial energy intake. J Nutr. 2011;141(3):482-8.

Lemmens SG, Born JM, Martens EA, Martens MJ, Westerterp-Plantenga MS. Influence of consumption of a high-protein vs. high-carbohydrate meal on the physiological cortisol and psychological mood response in men and women. PLoS One. 2011;6(2):e16826.

Born JM, Martens MJ, Rutters F, Lemmens SG, Goebel R, Westerterp-Plantenga MS. High HPA-axis activation disrupts the link between liking and wanting with liking and wanting related brain signaling. Physiol Behav. 2012;105(2):321-324.

Born JM, Martens MJ, Lemmens SG, Goebel R, Westerterp-Plantenga MS. Protein v. carbohydrate intake differentially affects liking- and wanting-related brain signalling. $\mathrm{Br} \mathrm{J}$ Nutr. 2012 May 29:1-6.

Lemmens SG, Martens EA, Born JM, Martens MJ, Westerterp-Plantenga MS. Lack of effect of high-protein vs. high-carbohydrate meal intake on stress-related mood and eating behavior. Nutr J. 2012;10(1):136.

Rutters F, La Fleur S, Lemmens SG, Born JM, Martens MJ, Adam TC. The HypothalamicPituitary-Adrenal Axis, Obesity, and Chronic Stress Exposure: Foods and HPA Axis. Curr Obes Rep. DOI 10.1007/s13679-012-0024-9. [Epub ahead of print].

Born JM, Martens MJ, Lemmens SG, Goebel R, Westerterp-Plantenga MS. A Nonlinear relationship between fooc choice related brain signaling in the absence of hunger and BMI. Submitted for publication.

\section{PRESENTATIONS AND ABSTRACTS}

Martens MJ, Nieuwenhuizen AG, Rutters F, Westerterp-Plantenga MS. The effect of macronutrient intake on cortisol concentrations in normal weight men. European Congress on Obesity; 6-9 May 2009; Amsterdam, the Nederlands. Obesity Facts 2009;2(suppl 2):137. Poster presentation

Martens MJ, Lemmens SG, Born JM, Westerterp-Plantenga MS. Is the liking aspect of rewarding value of food affected by stress? $10^{\text {th }}$ Benjamin Franklin Lafayette Seminar: 22-26 June 2009; Frejus, France. Invited speaker 
Martens MJ, Nieuwenhuizen AG, Lemmens SG, Born JM, Westerterp-Plantenga MS. Stress does not affect determinants of hedonic value of acceptable foods. 17th Congress of the Society for the Studies of Ingestive Behavior; 29 July - 1 August 2009; Portland, USA. Appetite 2009;52(3):847. Poster presentation

Martens MJ, Lemmens SG, Born JM, Westerterp-Plantenga MS. Is the liking aspect of rewarding value of food affected by stress? NWO Werkgemeenschap Voeding; 8-9 October 2009; Deurne, the Nederlands. Oral presentation

Martens MJ, Lemmens SG, Born JM, Westerterp-Plantenga MS. Changes in liking of foods during stress as a function of body weight. International Congress on Obesity; 11-15 July 2010; Stockholm, Sweden. Obesity Reviews 2010;11(Suppl. 1):313. Poster presentation

Martens MJ, Westerterp-Plantenga MS. Nutrient ingestion by eating and drinking and the effects of mode of conveyance, texture and additional water to drink. NWO Werkgemeenschap Voeding; 14-15 October 2010; Deurne, the Nederlands. Oral presentation

Martens MJ, Westerterp-Plantenga MS. Nutrient ingestion by eating and drinking and the effects of mode of conveyance, texture and additional water to drink. European Congress on Obesity; 25-28 May 2001; Istanbul, Turkey. Obesity Reviews 2011;12(Suppl. 1):161. Poster presentation

Martens MJ, Westerterp-Plantenga MS. Mode of consumption plays a role in alleviating hunger and thirst. 11th Benjamin Franklin Lafayette Seminar: 20-24 June 2009; Frejus, France. Invited speaker

Martens MJ, Westerterp-Plantenga MS. Liking as part of rewarding value of dairy protein in relation to weight status and stress. Nizo Dairy Conference: 21-23 September 2011; Arnhem, the Nederlands. Poster and oral presentation

Martens MJ, Born JM, Lemmens SG, Westerterp-Plantenga MS. Avoidance of reward deficiency. $11^{\text {th }}$ European Nutrition Conference: 25-29 October 2011; Madrid, Spain. Oral presentation

Martens MJ, Westerterp-Plantenga MS. Liking as part of rewarding value of dairy protein in relation to weight status and stress. Annual Nutrim symposium; 2 November 2011; Maastricht, The Netherlands. Poster presentation 
Martens MJ, Born JM, Lemmens SG, Westerterp-Plantenga MS. Avoidance of reward deficiency. European Congress on Obesity; 9-12 May 2012; Lyon, France. Poster presentation

Martens MJ, Born JM, Lemmens SG, Karhunen L, Heinecke A, Goebel R, Adam TC, Westerterp-Plantenga MS. Flexibility of food-reward related brain signalling in overweight and normal weight subjects. $18^{\text {th }}$ Congress of the Society for the Studies of Ingestive Behavior; 10-14 July 2012; Zurich, Switzerland. Poster presentation 
12 
ABOUT THE AUTHOR 
Mieke Martens was born in Herk-de-Stad, Belgium on the $18^{\text {th }}$ of February 1985 . The first three years of secondary school she completed at the "Humaniora Virga-Jesse" in Hasselt after which she relocated to the "Ursula Instituut" in Herk-de-Stad where she finished secondary school in 2002. September 2003 Mieke started her study Biomedical Sciences at the University Hasselt in Belgium, where she graduated with high distinction in 2007 as Master in Clinical Molecular Life Sciences, with the thesis "Functional MRimaging of the brain, clinical application with brain tumors and reproducibility of motor cortex activation" March 2008 Mieke started her PhD research as part of a project of Top Institute Food and Nutrition (TIFN) at the department of Human Biology, Maastricht University. The research performed during this project, under supervision of Prof. dr. M.S. Westerterp-Plantenga, is described in this thesis entitled "Risks for dysregulated appetite - texture, stress, food reward and inhibition" and was approved in August 2012. During her PhD project, Mieke presented several abstracts at international conferences. She was awarded with the $4^{\text {th }}$ young scientist award for best oral communication and poster presentation at the NIZO Dairy Conference in 2011 and with the award for best communication at the $11^{\text {th }}$ European Nutrition Conference, October 2011 in Madrid, Spain.

Currently, Mieke is working as a post-doctoral researcher at the department of Human Biology, Maastricht University, to continue her functional magnetic resonance imaging research in a new project entitled "Effect of different weight-loss methods on gut-brain interactions and their implications for weight maintenance and prevention of metabolic disease". 
ABOUT THE AUTHOR 
180 


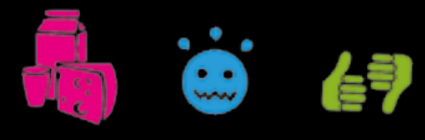

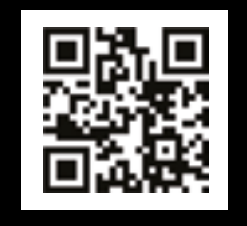

WW.MARTENSMJ.BE 